Análise paramétrica e validação experimental de um cabeçote de extrusão baseado em rosca, para uma para impressão 3-D.

Orientadora: Profa. Dra. Zilda de Castro Silveira

São Carlos

2015 



\author{
UNIVERSIDADE DE SÃO PAULO - USP \\ ESCOLA DE ENGENHARIA DE SÃO CARLOS - EESC
}

MATHEUS STOSHY DE FREITAS

\title{
Análise paramétrica e validação experimental de um cabeçote de extrusão baseado em rosca, para impressão 3-D.
}

Dissertação apresentada a Escola de Engenharia de São Carlos, Universidade de São Paulo, como requisito parcial para obtenção do título de Mestre em Engenharia Mecânica.

Área de concentração: Projeto Mecânico.

Orientadora: Prof ${ }^{a}$. Dra ${ }^{a}$ Zilda de Castro Silveira

São Carlos

2015 


\begin{abstract}
AUTORIZO A REPRODUÇÃO TOTAL OU PARCIAL DESTE TRABALHO, POR QUALQUER MEIO CONVENCIONAL OU ELETRÔNICO, PARA FINS DE ESTUDO E PESQUISA, DESDE QUE CITADA A FONTE.
\end{abstract}

\footnotetext{
Freitas, Matheus Stoshy

F437a Análise paramétrica e validação experimental de um cabeçote de extrusão baseado em rosca, para impressão 3-D / Matheus Stoshy Freitas; orientador Zilda de Castro Silveira. São Carlos, 2015.

Dissertação (Mestrado) - Programa de Pós-Graduação em Engenharia Mecânica e Área de Concentração em Projeto Mecânico -- Escola de Engenharia de São Carlos da Universidade de São Paulo, 2015.

1. manufatura aditiva. 2. extrusão com pó. 3 . processamento de polímeros. 4. intercambiabilidade. 5. análise térmica. 6. planejamento experimental. 7. FDM. I. Título.
} 

Concidato: Engorhoiro MATHEUS STOSHY DE FREITAS.

Tiłulo da dissertaço: "Anólise paramétrica e validoçào experimental de um caboçote de extrusäo cm rosca, oarc imoressäo 3-D".

Data da de'era: 14/01/2015

\section{Comissõo Julgadora:}

Prola. Dra. Zilda de Castro Silveira (Orientadora)

Escola do Engenharia de sāo CorlosifFsci

Profa. Dro. Márcla Cristina Brancifortì

Escola de Engenharia de Sáo Corros/EFsC)

Frof. Dr. Gregory Bregion Daniel

IUniversidade Esladual de Campiros/UNICAMP!

Coordenodor do Frograma de Pós-Graduaçäo em Engenhora Mocanica: Pro'. Associcoo Marcelo Areias Trindade

Prescene dxy Comissōo de Pós-Giodudxọo: Prof. Associado Paulo César Lima Segantine

\section{Resultado:}
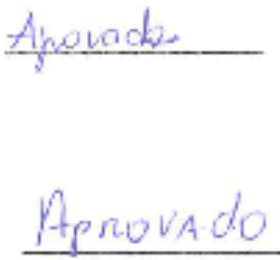

PPRONATDO 



\section{Dedicatória}

Dedico este trabalho à minha família, aos meus amigos, colegas de trabalho e orientadores e colaboradores. 



\section{Agradecimentos}

À todos aqueles que, de alguma maneira nesse caminho que tenho percorrido, me ensinaram algo.

Agradeço a professora e amiga Dra. Zilda de Castro Silveira, pela confiança, suporte, crédito nas minhas capacidades, e tanto esforço e dedicação no auxílio à busca do conhecimento.

Agradeço à Dr. Pedro Noritomi, pela amizade, apoio e grande ajuda.

Agradeço ao Dr. Jorge Vicente Lopes da Silva pela amizade, apoio e confiança.

Agradeço aos colegas: Daniel Takanori, Paulo Inforçatti Neto, Frederico David de Sena Pereira, José Luis Dávila e Gustavo dos Santos Ribeiro pela amizade, ajuda e o prazer de se trabalhar em equipe.

Agradeço a todos os amigos da DT3D (Divisão de Tecnologias Tridimensionais, CTI - Renato Archer) MCTI - Ministério da Ciência e Tecnologia e Inovação e ao CNPq, pela bolsa e suporte de infraestrutura.

Agradeço à Petrobrás, pela bolsa de pesquisa em projeto. 



\section{RESUMO}

Freitas, M. S. (2015) Análise paramétrica e validação experimental de um cabeçote de extrusão baseado em rosca, para impressão 3-D. Dissertação de mestrado. Departamento de Engenharia Mecânica, Escola de Engenharia de São Carlos, Universidade de São Paulo. 113 p.

O objetivo desse trabalho consiste na validação experimental e implementação de melhorias de projeto, de um cabeçote de extrusão com rosca de seção variável usada em uma impressora 3-D experimental. O primeiro estudo realizado envolveu a análise térmica por elementos finitos do sistema rosca-cilindro, com o intuito de se verificar a implantação de um sistema de refrigeração com suportes aletados ao longo do barril que têm como função a dissipação de calor gerado no processo de extrusão, por convecção forçada. O perfil de temperaturas ao longo do barril também é um resultado importante e uma validação experimental foi realizada com medições realizadas em termopar. Foram realizados testes de extrusão utilizando o polímero Nylon 12 PA e o polímero biodegradável PCL (Polycaprolactona), que permitiram a avaliação da estrutura do material extrudado, através da visualização de imagens de MEV (Microscopia Eletrônica de Varredura) e avaliação da forma dos filamentos. Scaffolds foram fabricados utilizando o sistema em estudo e submetidos à mesma avaliação com imagens de MEV. Por meio de um DOE (Design of Experiments) foram conduzidas medições de diâmetros dos filamentos extrudados, que revelaram 0 fenômeno de inchamento de extrudado, para o menor diâmetro de bico. Com o maior diâmetro do bico de deposição foram gerados scaffolds, com porosidade controlada $e$ também foi demonstrada a capacidade de extrusão e deposição de materiais compósitos (polimérico/cerâmico). O cabeçote demonstrou, portanto, sua capacidade em aplicações de pesquisa, que envolvam geração de filamentos e protótipos poliméricos e cerâmicos. Esses materiais encontram aplicações desde a engenharia tecidual até aplicações industriais, com ou sem controle de porosidade. Um estudo preliminar sobre a melhoria do projeto mecânico do cabeçote incluiu a redução do seu peso, por meio da troca do sistema de redução, com a escolha de um redutor cicloidal ou harmônico e retirada de material da estrutura, o que deve reduzir o peso do sistema em aproximadamente $38 \%$.

Palavras-chave: manufatura aditiva; extrusão com pó; processamento de polímeros; intercambiabilidade; análise térmica; planejamento de experimentos. 



\begin{abstract}
Freitas, M. S. (2015) Parametric analysis and experimental validation of an extrusion head based on screw applied to 3-D printer. Master Thesis Dissertation. Department of Mechanical Engineering, Sao Carlos School of Engineering, University of Sao Paulo. 113 p.

This work presents the experimental validation and design improvements of an extrusion head with variable section applied of an experimental 3-D printer. The first study was the thermal analysis by finite elements of the barrel-screw system. The aim is to verify the cooling capacity resulted from the implantation of a cooling system with finned supports along the extrusion barrel. This cooling system should dissipate the heat generated in extrusion process by forced convection. The temperature profile along the barrel is also an important result and an experimental validation was performed with measuring obtained by a thermo-coupling. Extrusion trials were performed processing Nylon 12 PA and a biodegradable polymer PCL (Polycaprolactone). In these trials, the structure of extruded material, in filament shape, was evaluated using SEM (Scanning Electron Microscopy) images. Scaffolds generation were performed and these were evaluated with the same method using SEM. A DOE (Design of Experiments) method, in which measurements of filaments diameters were conducted, have revealed the extrusion swelling in both nozzles tips used $(0.4$ and $0.8 \mathrm{~mm})$, but with more strong effects for the smaller one.Scaffolds with controlled porosity were generated using the large nozzle tip and the extrusion capacity could be demonstrated, not only with polymers, but also with composites of the type polymer/ceramic. Therefore, it can be indicated that the extrusion head in study can be applied in research fields in which the generation of filaments, polymer and polymer/ceramic prototypes, were necessary as tissue engineering or industrial applications, with or without porosity control. A preliminary study included the weight reduction by changing the reduction system and removing material from the head's structure. This study could indicate that these improvements could reduce the total weight of the extrusion head in $38 \%$.
\end{abstract}

Key-words: additive manufacturing; powder extrusion; polymer processing; interchangeable; thermal analysis; design of experiments. 



\section{Lista de Figuras}

Figura 2.1 - Estimativa de crescimento para o mercado de MA (Fonte: Lux Research Inc., Acesso: 12/11/2013) apud Pallarolas (2013). ......................... 7 Figura 2.2: Limites dimensionais atuais (escala meso) e futuro dimensional das tecnologias PR. Escala macro: um avião autônomo de 28 metros de envergadura com partes construídas em PR e, posteriormente, coladas (Integração da Lockheed Martin). Escala micro: um sistema mecânico com engrenagens menores que $1 \mathrm{~mm}$ de diâmetro. Escalanano: uma peça na forma de boi com as dimensões de um glóbulo vermelho. Oliveira (2008) ................. 8 Figura 2.3 - Esquema do processo de estereolitografia ............................... 9 Figura 2.4 - Modo de funcionamento de uma técnica de MA, Multijet. ............. 10 Figura 2.6- Representação esquemática do processo de impressão 3D Cortesia: Centro de Tecnologia da Informação Renato Archer. ........................ 12 Figura 2.7: Reconstrução de rosto de Santo Antônio em processo de MA em gesso com tecnologia de impressão por aglutinante. Fonte: Centro de Tecnologia da Informação Renato Archer, DT3D........................................ 12 Figura 2.8 - Desenho esquemático da patente de um cabeçote alimentado por material na forma de pellets proposto por Cheng(2010 ............................... 35 Figura 2.9: Aplicação funcional de tecnologia SLS para polímeros com fabricação de coletor de admissão em Nylon, para projeto Fórmula SAE USP São Carlos. 14

Figura 2.10: Mancal de rolamento em aço inox sendo fabricado em máquina de MA de metais por laser, Concept Laser® (Fonte: CTI, 2014) ......................... 15 Figura 2.11: Esquema de funcionamento do processo de sinterização por feixe de elétrons. Fonte: http://www.mechanicalengineeringblog.com/ (2014) ......... 16 Figura 2.12 - Processo de MA, LENS ........................................................ 16 Figura 2.13- Esquema simplificados do processo FDM. Fonte: CIMENJECT . 18 Figura 2.14 - Parafusos de extrusão rosca dupla, Drobny (2007)................. 20 Figura 2.15 - Parafuso de extrusão rosca simples, Drobny(2007)................... 20 Figura 2.16 - Esquema de extrusora industrial convencional com barril ventilado Drobny (2007) 21

Figura 2.17: Parâmetros geométricos para mini-extrusora. 22

Figura 3.2 - Máquina desktop de impressão 3D Fab@CTI. 31

Figura 3.3 - Cabeçotes para impressão 3D em máquina desktop utilizados na Fab@CTI 32

Figura 3.4 - (a) Desenho de patente do cabeçote de injeção por seringa e (b) Desenho esquemático da patente - High-Precision Modelling Filament ........... 33 Figura 3.5 - Desenho esquemático da patente de um cabeçote alimentado por material na forma de pellets proposto por Cheng (2010) ............................... 35 Figura 3.8 - Esquema de extrusora industrial convencional com barril ventilado (Handbook of thermoplastic elasrtomers) 21

Figura 4.1: Projeto do cabeçote de extrusão com destaque na parte vermelha desenvolvida neste trabalho. 36

Figura 4.2 Sistema de coordenadas no barril de extrusão. (White and Potente, 2003). 39

Figura 4.3 - Fluxograma simplificado para cálculo de resistência mecânica no parafuso de extrusão. 42

Figura 4.4 - Fluxograma simplificado para cálculo de resistência mecânica no parafuso de extrusão. 42 
Figura 4.5 - Diagrama de cálculo de para rosca de extrusão 44

Figura 4.6 - Fluxograma para o cálculo do torque do motor, considerando a poliamida.....................................51

Figura 4.7 - Esquema dos modos de transferência de calor no projeto do

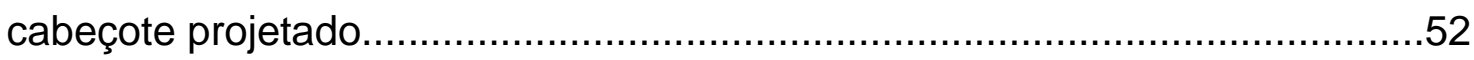

Figura 4.8 - Modelo CAD do barril de extrusão com os suportes aletados.... 56 Figura 4.9 - Tipos de elementos contidos em biblioteca de programas de FEM (Adaptado: Azevedo, 2014) .58

Figura 4.10 - Etapas realizadas para a análise térmica utilizando o programa

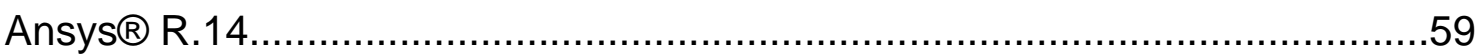

Figura 5.1 - Suporte aletado construído em tecnologia DMLS. ...................... 60 Figura 5.2 -Teste de aquecimento realizado com o cabeçote de extrusão. ....6 60 Figura 6.1 - a) Simulação 1 b) Simulação 2 c) Simulação 3 d) Simulação $4 \ldots .61$ Figura 6.2: Temperaturas ao longo do tempo nas simulações numéricas ........63 63 Figura 7.2 - CAD do cabeçote de extrusão................................................ 67 Figura 7.3: Primeira validação do cabeçote com Nylon 12 PA® (Poliamida 12) 68

Figura 7.4 - Filamentos extrudados de Nylon 12 PA 69

Figura 7.5 - Cabeçote de extrusão em estudo prototipando um modelo 3D, em Nylon ${ }^{\circledR} 12$ 69

Figura 7.6 - Foto micrografias de filamentos de Nylon 12 PA......................... 70

Figura 7.7 - Fotomicrografias de material PCL (policaprolactona).................. 71

Figura 7.8: Cabeçote de extrusão por rosca realizando a deposição de um scaffold de PCL 72

Figura 8.1 Espectro FTIR do pó de PCL CAPA® 6505 e dos scaffolds de PCL S9 e S18, fabricados com a maior temperatura e velocidades. ...................... 74

Figura 9.1 (a) Microscopia da secção transversal do scaffold 200x e (b) microscopia mostrando a arquitetura $0 \% 90^{\circ}$ para o scaffold $90 \mathrm{x} . \ldots \ldots \ldots \ldots \ldots \ldots . . . . . .75$ Figura 9.2 - Inchamento do Extrudado. Fonte: Bretas e D'Ávila (2005) ........... 76 Figura 9.3 Microscopias estéreo: a) Scaffold S1 (bico $0.80 \mathrm{~mm}$ ), b) Scaffold S18 (bico $0.45 \mathrm{~mm}$ )..........................77

Figura 9.4. Microscopia do scaffold S1 mostrando a microporosidade da superfície. 77

Figura 10.1 - Gráficos dos diâmetros dos filamentos extrudados obtidos no DOE 78

Figura 10.2: Matriz de correlação entre a resposta, média do diâmetro dos filamentos, e variáveis de entrada.79

Figura 10.3: Matriz de correlação entre a resposta, desvio padrão médio, e variáveis de entrada.....................80

Figura 10.6: Diâmetro dos bicos x Temperatura x Diâmetro médio dos filamentos 88

Figura 11.1 - Scaffolds feitos em PCL/TCP-Beta ....................................... 90

Figura 11.2: Micrografias de scaffolds de PCL/TCP-beta .............................. 92

Figura 11.3 - Deposição de scaffolds com oxiapatita ................................... 93

Figura 11.4 - Deposição de corpo poroso com Nylon 12 PA® e alumina........ 94

Figura 12.1: Funcionamento de redutor harmônico. Harmonic Drive (2013).... 96

Figura 12.2: Funcionamento de redutor harmônico. Harmonic Drive (2013).... 96 
Figura 12.3: Especificações de redutor harmônico. Harmonic Drive (2013) .... 97 Figura 12.4: Esquema de montagem de um redutor cicloidal ......................... 98 Figura 13.1(a): Coroa de Liga de Ti6Al4V (b) Coroa de Liga de alumínio EOS AlSi10Mg 98

Figura 13.2: Redução do peso das placas laterais, superiores e frontal do redutor. 99

Figura 13.3: Cabeçote com peso reduzido 100

Figura 13.4: Cabeçote original. ..100 



\section{Lista de Tabelas}

Tabela 2.1: Aplicações de MA em setores de atividades. ............................. 7

Tabela 2.2: Processos de sinterização em MA ........................................ 17

Tabela 4.1 - Resumo dos cálculos do parafuso...................................... 44

Tabela 4.2 - Parâmetros de projeto, valores adotados e calculados ............... 45

Tabela 4.3 - Níveis de cada parâmetro dos experimentos. ...........................4 47

Tabela 4.4 - Respostas dos dados combinando-se os parâmetros ................. 48

Tabela 4.5 - Propriedades dos materiais nas simulações .............................. 57

Tabela 4.6 - Dados da simulação........................................................ 57

Tabela 4.7: Condições de contorno para as simulações numéricas ................ 58

Tabela 6.1: Temperaturas no regime permanente e tempos até atingir o regime

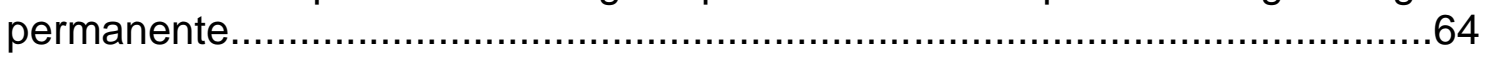

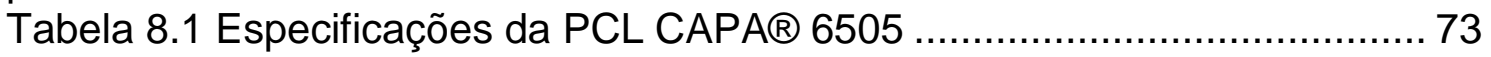

Tabela 8.2. Bandas características da PCL e bandas obtidas para o material puro e os scaffolds S9 e S18.............................................................74

Tabela 10.1: Tabela de DOE para a fabricação de scaffolds de PCL. ............. 78 



\section{Lista de Abreviaturas e Siglas}

ABS - Acrilonitrila butadieno estireno

ASTM - AmericanSociety for Testing and Materials

CAD - Computer Aided Design (Projeto Assistido por Computador)

CTI - Centro de Tecnologia da Informação Renato Archer

DLP - Digital Light Processor (Processamento Digital de Luz)

DMLS - Direct Metal Laser Sintering (Sinterização Direta de Metal á Laser)

DOE - Design of Experiments (Planejamento de Experimentos)

EBM - Electron Beam Melting (Derretimento por feixe de elétrons)

FDM - Filament Deposition Modeling (Modelamento por Deposição de

filamento)

FTIR - Fourier Transform Infrared Spectroscopy (Espectroscopia Infravermelho por Transformada de Fourier)

LENS - Laser Engineering Net-Shape

MA - Manufatura Aditiva

MEV - Microscopia Eletrônica de Varredura

P\&D - Pesquisa e desenvolvimento

PCL - Poli-caprolactona

$P R$ - Prototipagem rápida

RPM - Rotações por minuto

SEM - Scanning Electron Microscope

SLS - Selective Laser Sintering (Sinterização Seletiva à Laser)

TCP-Beta - Tricalcium Phosphate Beta (Trifosfato de cálcio Beta)

3-D - Tridimensional 



\section{Lista de símbolos}

KT -_Matriz de condutividade de

material

$\mathrm{T}$ - Vetor de nós de temperaturas

pontuais

$Q$ - Vetor de cargas térmicas

$q_{v}$ - taxa de variação interna de calor

$\rho$-densidade

$\mathrm{t}$ - tempo

c - capacidade calorífica

$U$ - velocidade linear

W - comprimento de tambor

$\mathrm{H}$ - folga uniforme

$\mathrm{kg} / \mathrm{m}^{3}$

$\Delta \mathrm{p}$ - variação de pressão

Segundos

$\mathrm{J} / \mathrm{K}$

$\mathrm{m} / \mathrm{s}$

$\mathrm{m}$

$\mathrm{m}$

$\eta$ - viscosidade

$\mathrm{Pa} / \mathrm{m}$

Pa.s

of - densidade do fluído

$\mathrm{kg} / \mathrm{m}^{3}$

$\Phi$ - ângulo de hélice

Graus

rpm

D - diâmetro da rosca de extrusão

$\mathrm{m}$

Vriec- Taxa de volume necessário de

$m^{3} / s$

material saindo do bico de extrusão

$\mathrm{W}$ - largura do filete

$\mathrm{m}$

$R$ - raio da rosca de extrusão

$\mathrm{m}$

$L$ - comprimento do parafuso

$\mathrm{m}$

$\sigma$ - tensão de (tração/compressão)

$\mathrm{Pa}$

$\tau_{a}$ - tensão de cisalhamento

$\mathrm{Pa}$

Tp- Torque na rosca de extrusão

N.m

E - Módulo de Young

G - aceleração da gravidade

Xc- Taxa de compressão

$\mathrm{n}$ - índice de lei das potências

m- índice de consistência

k- coeficiente de condução

h-coeficiente de convecção

$T_{s}$ - temperatura da superfície

$T_{\infty}$ - temperatura do fluído

$E_{b}$ - Energia emissiva máxima

$\sigma_{s b}$ - constante de Stefan-Boltzmann

$B_{e}$ - inchamento do extrudado

$\mathrm{Pa}$

$\mathrm{m} / \mathrm{s}^{2}$

$D_{e}$ - diâmetro do extrudado

$\mathrm{W} /(\mathrm{m} . \mathrm{K})$

$\mathrm{W} /(\mathrm{m} . \mathrm{K})$

$\stackrel{\circ}{C}$

$\stackrel{\circ}{\mathrm{C}}$

$\mathrm{J}$

$W /\left(m^{2} \cdot K^{4}\right)$

$D_{c}$ - diâmetro do capilar

$\mathrm{m}$

$\mathrm{m}$ 



\section{Sumário}

1 - INTRODUÇÃO

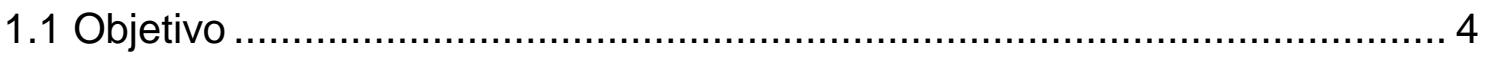

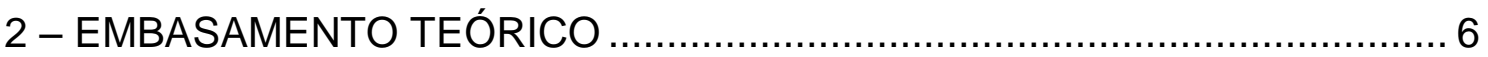

2.1 - Considerações sobre Manufatura Aditiva ………................................. 6

2.2 - Técnicas de manufatura aditiva .................................................... 8

2.2.1 - Processos de Fotopolimerização................................................ 9

2.2.2 - Processo de impressão por aglutinante....................................... 11

2.2.3 - Processo de sinterização/fusão de pó ........................................... 13

2.2.4 - Processos baseados em fusão ................................................... 18

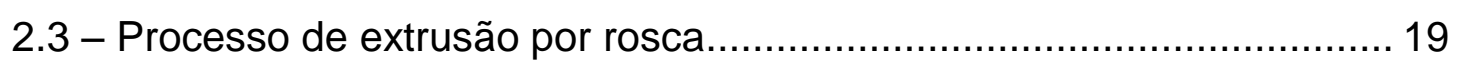

2.3.1 - Considerações sobre o perfil de roscas de extrusão ……………..... 21

2.4 - Conceitos sobre planejamento de experimentos ................................ 24

2.5 - Considerações sobre o método de elementos finitos aplicado a problemas de transferência de calor ....................................................... 27

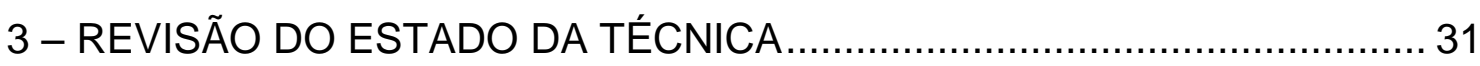

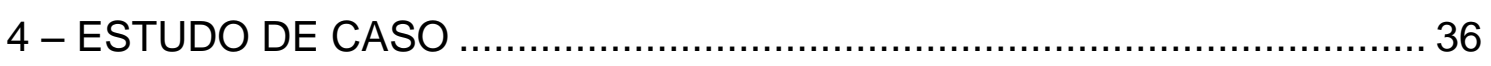

4.1 - Dimensionamento do par cilindro-rosca de extrusão .............................. 38

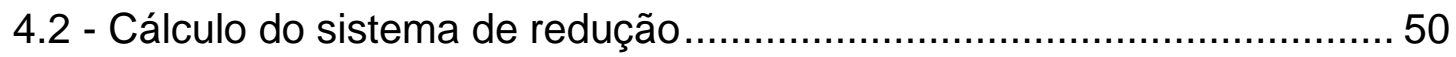

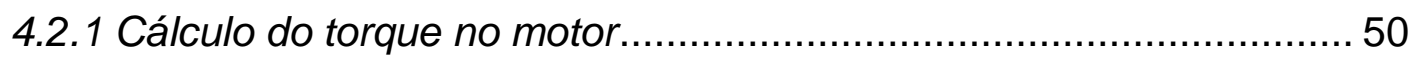

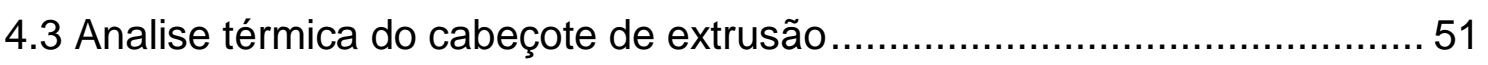

4.4 Validação experimental da analise térmica e discussões dos resultados . 60

5. VALIDAÇÃO EXPERIMENTAL DO CABEÇOTE DE EXTRUSÃO............... 67

5.1 Análise de degradação dos polímeros …………………………......... 72

5.2 Análise morfológica utilizando Microscopia Eletrônica de Varredura ......... 75

5.3 Planejamento de experimentos para verificação de características

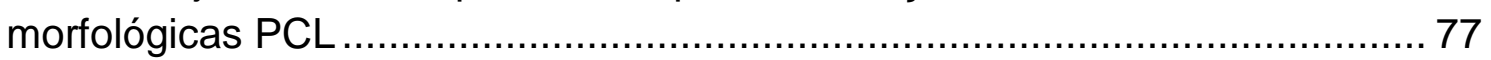

5.4 Testes preliminares com materiais compósitos .......................................... 89

5.4.1 Validação com PCL/ TCP-Beta (Parâmetros) …………………......... 90

5.4.2. Validação com PCL/La20OAP(Parâmetros) …................................ 92

5.4.3. Validação Nylon 12 PA e Alumina (Parâmetros) .................................. 93

6.1. Proposta de redução de peso cabeçote de extrusão por rosca ............... 98 
7. CONCLUSÕES E TRABALHOS FUTUROS

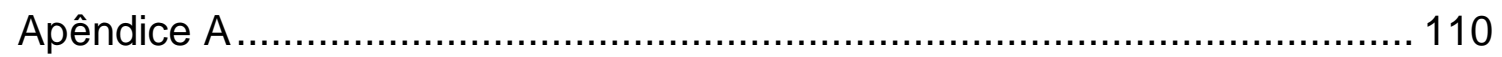




\section{1 - INTRODUÇÃO}

A utilização da manufatura aditiva para geração de peças, nos mais variados segmentos produtivos e de serviços, teve um aumento significativo nos últimos cinco anos. Entretanto, segundo o Manyika (2012): McKinsey Global Institute, menos do que $30 \%$ dessas peças foram classificadas como protótipos funcionais, modelos de apresentação e moldes. Nesse percentual, as principais indústrias usuárias desta tecnologia foram: aeroespacial, automotiva e processamento de plásticos, embora haja aplicações crescentes da manufatura aditiva para geração de componentes personalizados tais como: próteses, joias e áreas da saúde.

A manufatura aditiva possui características fundamentais, para se transformar em um futuro próximo, não somente em um meio de produção complementar às técnicas de remoção de material e de conformação mecânica na indústria, mas também em atender diretamente demandas específicas nas áreas da saúde, como a engenharia tecidual, engenharia biomédica e tecnologia assistiva; e também na geração de famílias de bens de consumo. As características citadas anteriormente estão associadas à flexibilidade em se reduzir: o tempo de desenvolvimento do projeto do produto, o desperdício de matéria-prima, além de também reduzir ou até mesmo eliminar custos com ferramental, permitindo a geração de formas e estruturas de alta complexidade.

Todas essas características convergem para uma simplificação da logística da manufatura. Entretanto, o atual estado de desenvolvimento das tecnologias da manufatura aditiva produz peças e produtos com menor precisão e, em volume de produção muito inferior, quando comparados com os processos tradicionais de remoção de material e de deformação mecânica. A manutenção do equipamento, qualificação da mão de obra e compra de matéria-prima, associada a um maior volume de produção configuram outras restrições do amplo uso da manufatura aditiva no mercado e na pesquisa, principalmente no Brasil. 
O rápido desenvolvimento de melhores e de novos materiais de engenharia e das próprias técnicas de manufatura aditiva nos países industrializados oferece uma perspectiva real, para melhoria dos processos de deposição de material. O protótipo rápido se tornará cada vez mais funcional, próximo das especificações de projeto e de fabricação, com características físico-químicas e propriedades mecânicas progressivamente superiores. Esse avanço tem possibilitado o desenvolvimento de novos segmentos de aplicação, tanto na pesquisa, quanto na área de desenvolvimento de produto, engenharia de fabricação e experimental. Um reflexo desta nova faceta de aplicação da tecnologia de prototipagem rápida foi sua denominação para Manufatura Aditiva (MA) (ASTM F2792-10).

$\mathrm{Na}$ área da engenharia aplicada à saúde, a integração entre o desenvolvimento do projeto do produto e as tecnologias provenientes da manufatura aditiva está progressivamente contribuindo para a obtenção de produtos com alto grau de personalização, atendendo necessidades específicas de pacientes dentro de um processo de projeto e manufatura integrado. Esse segmento, fortemente ligado às áreas de pesquisa e desenvolvimento, inovação e processos de alta tecnologia está gradativamente se fixando na sociedade, com o objetivo de atender às demandas regionais, que requerem personalização dos produtos. Este segmento de aplicação, com maior especialização em todos os aspectos técnicos gerará produtos em quantidades menores, com alto valor agregado e com características exclusivas.

Apesar dos constantes e expressivos desenvolvimentos das máquinas comerciais de MA, raros são os casos em que elas estão perfeitamente adaptadas para aplicações em pesquisa, principalmente no tocante à flexibilidade para implementação de tecnologias emergentes e no acesso aos protocolos de controle e funcionamento da tecnologia implementada na máquina. Essas características dificultam o uso de máquinas comerciais como 
base para desenvolvimento de novas tecnologias e aplicações em ambiente de pesquisa.

As máquinas comerciais utilizadas em manufatura aditiva possuem tecnologias encapsuladas (devido ao serviço de garantia e manutenção) e dependência de materiais (normalmente importados). Essas condições praticamente inviabilizam o uso dessas máquinas em ambientes de pesquisa, que requerem tecnologia aberta, tanto para acesso aos mecanismos de impressão tridimensional, hardware e programas computacionais.

Soluções construtivas viáveis, que permitam o controle do processo de deposição tridimensional, podem contribuir de forma significativa, para a obtenção de protótipos com características dimensionais mais controladas, seja pelo uso de aditivos ou reforçadores, ou pelo melhor entendimento entre os parâmetros de controle da máquina e as variáveis dos processos.

A inserção da manufatura aditiva, nas áreas de pesquisa e desenvolvimento que inclui as universidades e centros de pesquisa, inclui o pleno entendimento da interação máquina-processo e deve estar muito além de sua simples operacionalização. Essa afirmação indica um segmento em aberto no Brasil e também no mundo, que inclui várias frentes de pesquisa e desenvolvimento:

a) há necessidade de melhorias no projeto estrutural da máquina de forma a aumentar seu volume de trabalho e gerar uma impressão realmente tridimensional com sistemas de movimentação com maiores graus de liberdade e;

b) desenvolvimento de soluções construtivas para cabeçotes intercambiáveis, que permitam melhor controle do processamento de polímeros, bem como sua deposição.

Com enfoque no projeto de cabeçotes intercambiáveis para impressora 3-D portáteis voltadas para pesquisa, há várias demandas, como por exemplo: 
- Utilização de matéria-prima em estado de pó, que aumentaria a variedade de materiais poliméricos e cerâmicos, bem como os campos de aplicações.

- Reutilização de material descartado em máquinas comerciais.

- O uso de bicos injetores intercambiáveis também poderia ser explorado, pois o último influi na homogeneidade do filamento, variação espessura de camada/acabamento da superfície da peça e produtividade da máquina.

Essas aplicações se estendem por várias áreas de pesquisa e tecnologia como, por exemplo: engenharia tecidual, engenharia biomédica e processamento de polímeros. Na engenharia tecidual uma aplicação é a obtenção de geometrias com características controladas, ou scaffolds. Esses são arcabouços para crescimento celular, e têm sido utilizados por pesquisadores de todo o mundo na realização de testes com células-tronco e tipos de células específicas que se reproduzem dentro desta estrutura tridimensional e a análise das condições físico-químicas neste cenário bem como resultados de testes in vivo e in vitro tem mostrado o potencial deste campo.

\subsection{Objetivo}

O objetivo desse trabalho é validar experimentalmente um cabeçote intercambiável de rosca baseado na tecnologia FDM, para uma impressora 3-D desktop experimental e, em complementação apresentar soluções de melhorias de projeto, para redução de sua massa.

Para esse estudo foram feitas: análises térmicas do conjunto barrilrosca, para se determinar o perfil de temperatura ao longo do conjunto de extrusão utilizando a poliamida e o PCL, bem como controlar a dissipação de calor nas regiões de interesse; deposição de materiais poliméricos sob a forma 
de filamentos e geração de scaffolds cujos experimentos foram projetados (DOE). Algumas das estruturas geradas em PCL foram avaliadas por meio de análises de degradação térmica. Foram realizadas também por meio de MEV, análises morfológicas para verificação de diâmetro em filamentos extrudados com o sistema em estudo. Também foram analisadas da mesma maneira análises morfológicas em scaffolds fabricados em Nylon ® 12 e PCL e testes preliminares com extrusão de materiais poliméricos com carga de material cerâmico mostraram resultados viáveis para geração de protótipos com aplicações em bioengenharia. 


\section{2 - EMBASAMENTO TEÓRICO}

\section{1 - Considerações sobre Manufatura Aditiva}

Na Manufatura Aditiva (MA), um modelo físico "tridimensional" é gerado por meio de adição de material, a partir de arquivo digital com extensão ".stl" (Stereolithography). Este arquivo pode ser importando de modelos tridimensionais gerados em programas CAD ou por imagens médicas computadorizadas (Wohlers, 2012). Uma das características técnicas da Manufatura aditiva é a possibilidade de geração de objetos com formatos complexos, que dificilmente poderiam ser obtidos por processo de fabricação convencional, como usinagem e conformação plástica.

Há uma grande diversidade de processos para a manufatura aditiva. Uma forma de classificá-los é considerar a matéria-prima e como a peça é construída. De acordo com Luo et al. (2002) e Gibson et al. (2010), os principais processos de MA podem ser classificados de acordo com a natureza da matéria-prima:

- Resinas fotossensíveis (acrílicas e elastoméricas);

- Materiais sólidos (termoplásticos, madeira, papel, acrílico);

- Materiais em pó (cerâmico, plástico, metal, elastômero).

Também se podem destacar a amplitude de aplicações que vem sendo encontrada em diversas áreas ou setores de atividades, exemplificadas na Tabela 2.1. 
Tabela 2.1: Aplicações de MA em setores de atividades. Fonte: (Oliveira, 2008)

\begin{tabular}{|c|c|}
\hline Aplicação de Pesquisa, & Saúde - Cirurgias \\
Desenvolvimento e Ensino. & Medicina \\
\hline Arqueologia & Veterinária \\
Paleontologia & Odontologia \\
Geologia & Bioengenharia \\
Antropologia & \\
Biologia molecular & \\
Engenharia & \\
Matemática & Serviços - Design \\
\hline Indústria & Artes \\
\hline Automobilísticas & Arquitetura \\
Aeroespacial & Desenho Industrial \\
Eletrodoméstico & \\
Jóias e brindes & \\
Embalagens & \\
\hline
\end{tabular}

Outro dado importante refere-se à projeção econômica deste segmento e a Figura 2.1 mostra uma estimativa de crescimento em bilhões de dólares, para o mercado mundial de MA até o ano de 2025.

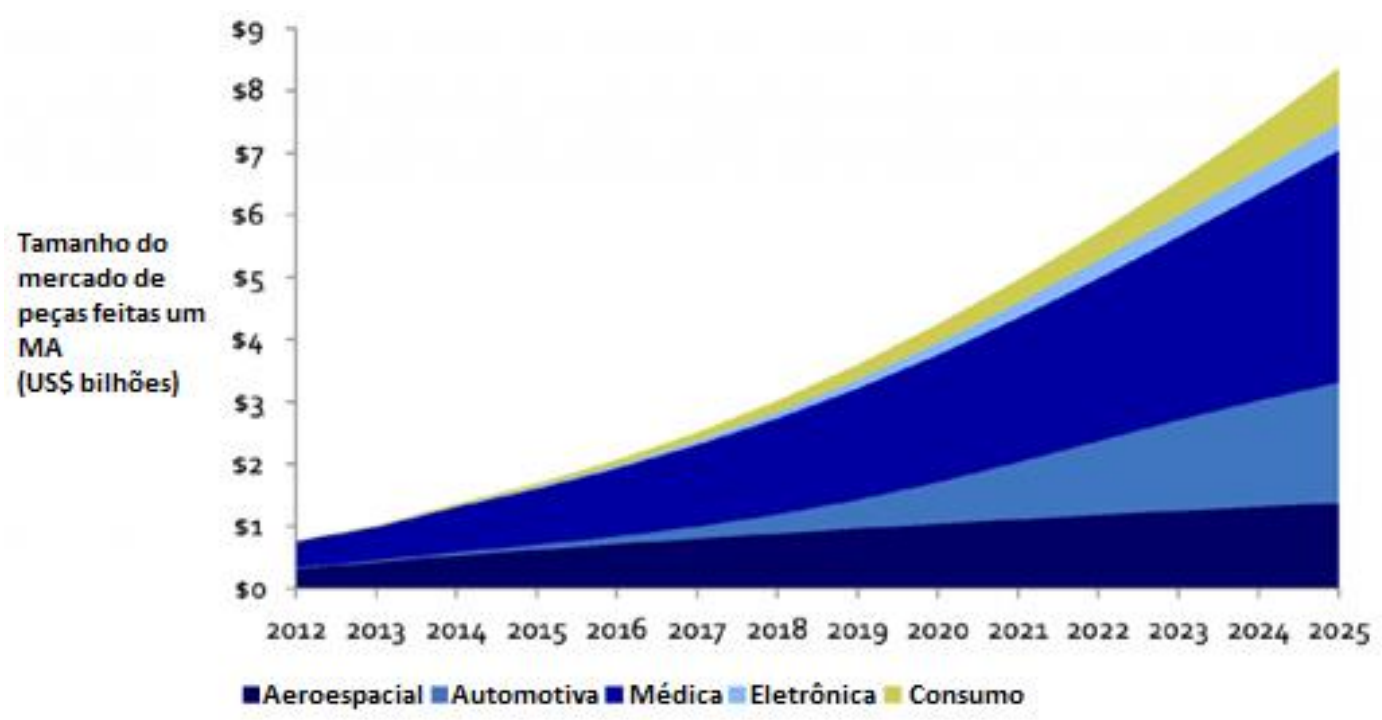

Figura 2.1 - Estimativa de crescimento para o mercado de MA (Fonte: Lux Research Inc., Acesso: 12/11/2013) apud Pallarolas (2013).

Além da variedade de aplicações e potencialidade econômica é também observada uma tendência de pesquisa que foca na ampliação das faixas dimensionais em que se aplica a referida tecnologia conforme Figura 2.2. $\mathrm{Na}$ escala meso, é a escala na qual estão inclusas a maioria das técnicas de 
manufatura aditiva convencionais, ou seja, é onde se encontra a grande maioria de peças, protótipos e produtos utilizados em MA atualmente. $\mathrm{Na}$ escala macro, há uma tendência de crescimento evidenciada no interesse de se obter, por exemplo, construções habitacionais inteiras feitas por MA. Outra tendência pode ser evidenciada nas escalas micro e nano. Com a possibilidade de construção de micro robôs e micro mecanismos se entende que as resoluções de fabricação de suas minúsculas peças definirão a precisão e aplicabilidade desses sistemas e o avanço da MA nessa direção a deixa como uma potencial ferramenta da promissora e já conhecida nanotecnologia.

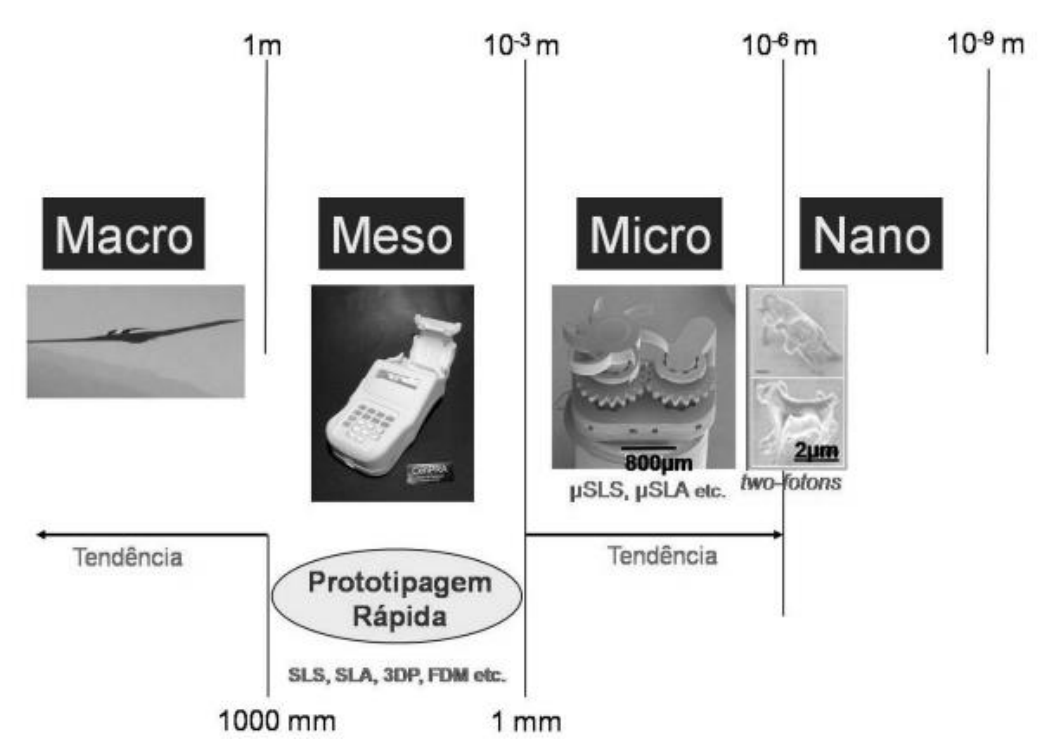

Figura 2.2: Limites dimensionais atuais (escala meso) e futuro dimensional das tecnologias PR. Escala macro: um avião autônomo de 28 metros de envergadura com partes construídas em PR e, posteriormente, coladas (Integração da Lockheed Martin). Escala micro: um sistema mecânico com engrenagens menores que $1 \mathrm{~mm}$ de diâmetro. Escala nano: uma peça na forma de boi com as dimensões de um glóbulo vermelho Oliveira (2008)

\section{2 - Técnicas de manufatura aditiva}

Existem várias maneiras de se realizar a MA, com vários processos que vem sendo desenvolvidos ao longo dos anos e em geral eles têm em comum a deposição camada à camada e a formação de sólido à partir de modelo CAD. 
Os processos em MA se diferenciam pela matéria prima que utilizam e características específicas de transformação da matéria prima e sua deposição. Seguem-se os principais processos utilizados atualmente.

\subsection{1 - Processos de Fotopolimerização}

O processo de fotopolimerização consiste na polimerização de uma resina líquida fotocurável, que se solidifica como resultado de irradiação eletromagnética. A grande maioria dos polímeros comerciais é curável na faixa do espectro ultravioleta.

\section{A) Processos de cura por ponto}

A terminologia mais usada para a cura por ponto de foto polímeros é a estereolitografia. Neste processo as peças são construídas ponto a ponto, linha por linha, camada por camada numa cuba de resina líquida foto curável, como mostrado na figura 2.3.

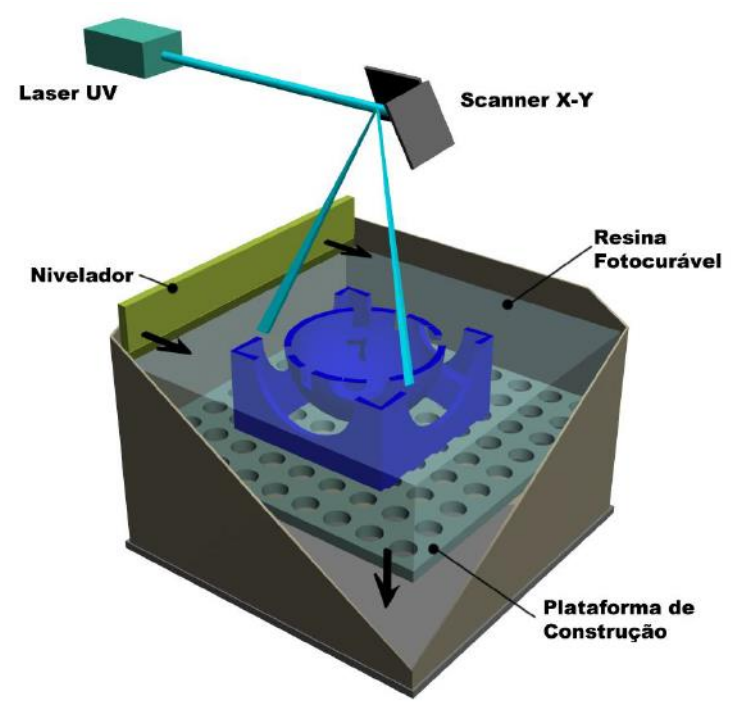

Figura 2.3 - Esquema do processo de estereolitografia Cortesia: Centro de Tecnologia da Informação Renato Archer.

Inicialmente uma fina camada é formada no topo, através de um mecanismo de recobrimento. Um raio laser focado precisamente, desenha a 
seção transversal da camada, na superfície de resina líquida. A resina é curada por toda a trajetória feita pelo laser, criando uma camada sólida que fica aderida na plataforma. A plataforma é deslocada para um nível inferior, por um sistema de movimentação e uma nova camada é feita sobre a camada recémformada. Um exemplo comercial desta tecnologia é a iPro ${ }^{\mathrm{TM}} 9000 \mathrm{XL}$ da empresa 3D Systems Corporation.

B) Processos de cura por camada

Para superar as limitações de velocidade pela cura de polímero usando uma fonte de energia por ponto, foi desenvolvido um processo que utiliza projetores DLP (Digital Light Processor) para curar camadas inteiras em um único passo. Alguns exemplos comerciais desta tecnologia são a $U L T R A^{2}$ da empresa EnvisionTEC GmbH, a V-Flash e a ZBuilder® Ultra da empresa $3 D$ Systems Corporation. Cada camada de foto-polímero é curada com luz ultravioleta imediatamente após a impressão, resultando na produção de modelos completamente curados, dispensando assim após-cura. As estruturas de suporte são construídas num material tipo gel, o qual é removido à mão e com jatos de água.

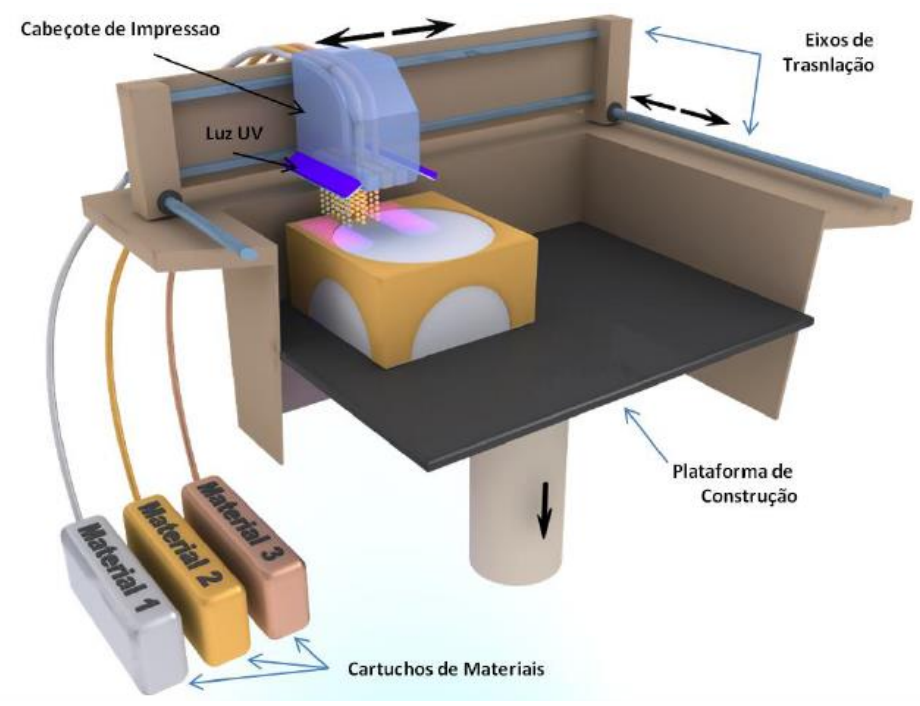

Figura 2.4 - Modo de funcionamento de uma técnica de MA, Multijet. 
A máquina Connex $500 \AA$ é a primeira da Objet $\Theta$ que fornece capacidade multi-material. Apenas dois fotos polímeros diferentes podem ser impressos em um momento, no entanto, ajustando-se automaticamente a máquina pode imprimir, funcionalmente, até 25 diferentes materiais, variando a relação de composição dos dois fotos polímeros. Peças geradas com tecnologia multijet podem ter um aspecto transparente ou opaco conforme apresentado na Figura 2.5 .

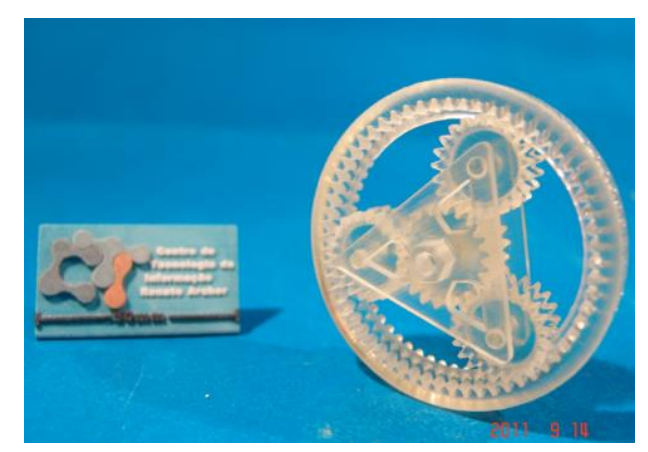

Figura 2.5: Peça construída por MA na máquina Connex $350 \AA$.

\subsection{2 - Processo de impressão por aglutinante}

No Instituto de Tecnologia da Universidade de Massachusetts, (Massachusetts Institute of Technology, EUA), professores e alunos desenvolveram e patentearam a tecnologia básica para o processo de impressão por aglutinante, Gibson (2010). Este processo foi chamado de impressão tridimensional, ou impressão 3D. Neste processo, o aglutinante líquido é depositado seletivamente, por spray ou impressão na forma de finas gotas, através de um cabeçote de impressão montado sobre uma base de pó, Figura 2.6. Depois da deposição o aglutinante solidifica, e por meio de uma reação química adere às partículas de pó entre elas e também com as partículas da última camada. O cabeçote, normalmente o mesmo utilizado por impressoras de jato de tinta, contém vários bicos de injeção paralelos, possibilitando que o cabeçote de impressão preencha uma área de definida a cada impressão. 


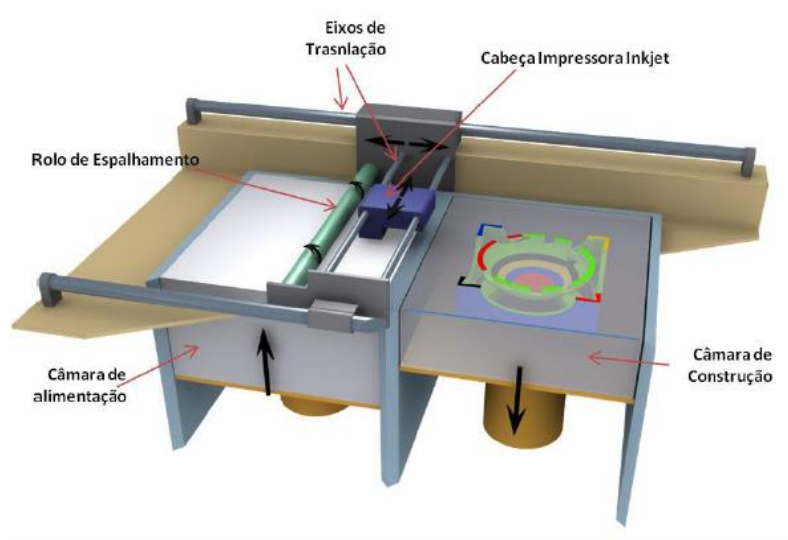

Figura 2.6- Representação esquemática do processo de impressão 3D Cortesia: Centro de Tecnologia da Informação Renato Archer.

O cabeçote de impressão se desloca sobre a área, que contém pó e onde será gerada a peça. As áreas da base de pó, que ficam foram da geometria da peça, se mantêm soltas e servem de suporte para as outras camadas que serão impressas subsequentemente. Depois da formação de uma camada, a plataforma se desloca para baixo, em uma distância prédefinida, e expõe uma nova superfície de pó. O aglutinador é impresso novamente, de acordo com a seção transversal correspondente. O processo inteiro ocorre em temperatura ambiente. As vantagens desta tecnologia estão relacionadas com a facilidade de operação e custo reduzido de operação e manutenção. A grande desvantagem deste processo é a limitação de geometria, resolução e acabamento superficial. Um exemplo comercial desta tecnologia é a ZPrinter 850 da empresa 3D Systems Corporation, figura 2.7.

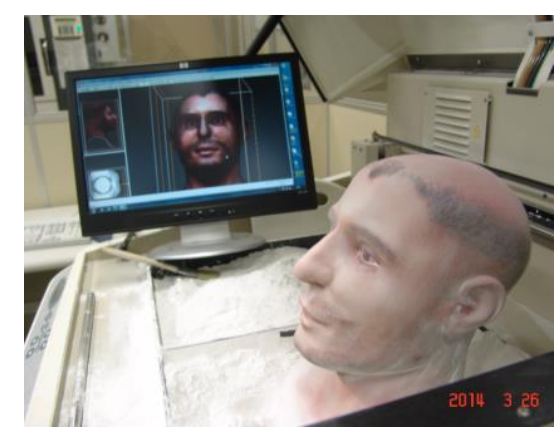

Figura 2.7: Reconstrução de rosto de Santo Antônio em processo de MA em gesso com tecnologia de impressão por aglutinante. Fonte: Centro de Tecnologia da Informação Renato Archer, DT3D. 


\subsection{3 - Processo de sinterização/fusão de pó}

Neste processo uma fina camada de pó fundível por calor é depositada numa plataforma de construção usando um rolo de contra rotação, para seu espalhamento. Este processo é feito dentro de uma câmara fechada preenchida com gás inerte, que é mantida a uma temperatura elevada abaixo do ponto de fusão do material em pó. Esse procedimento minimiza a quantidade de energia requerida pelo laser no processo e previne 0 empenamento da peça durante sua construção conforme ilustrado pela figura 2.8 .

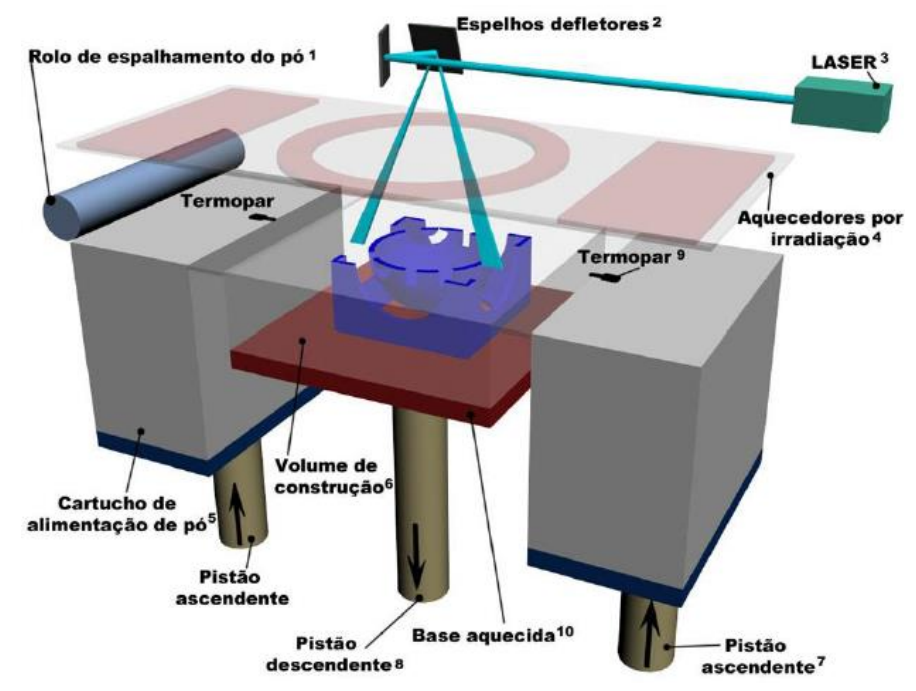

Figura 2.8 - Representação esquemática de um mecanismo de sinterização e fusão de pó a laser. Cortesia: Centro de Tecnologia da Informação Renato Archer.

Um laser precisamente focado ou um raio de elétrons é direcionado sobre a base de pó, que é amolecido e percorre a trajetória da seção transversal da peça. O pó no contorno está solto e funciona como suporte para camadas a serem feitas posteriormente. Após a obtenção de uma camada, a plataforma se desloca e deixa à mostra uma nova camada de pó, para a criação de uma nova camada com contorno da peça.

A) Processo de sinterização de polímeros à base de pó 
A tecnologia básica para a fusão de polímeros à base de pó foi desenvolvida na Universidade do Texas em Austin nos EUA, entre os anos 80 e 90, Gibson (2010). O processo SLS (Selective Laser Sintering) foi originalmente desenvolvido para produzir protótipos de material termoplástico em pó, figura 2.9. Esse princípio foi estendido para as cerâmicas e metal, para a fabricação e ferramentas e partes funcionais. Parâmetros importantes do processo se relacionam com: intensidade e precisão do laser, escaneamento, características do pó e temperaturas envolvidas no processo. A principal vantagem desse processo é a versatilidade com a qual a sinterização com laser pode utilizar diferentes materiais, como polímeros, cerâmicas e até metais. Estes processos não requerem suporte externo, o que economiza tempo na construção e limpeza da peça. A precisão e o acabamento superficial das peças sinterizadas a laser dependem do tamanho da partícula do pó, da região de foco do laser e da espessura da camada sinterizada, conforme descrito por Inforçatti Neto (2013).
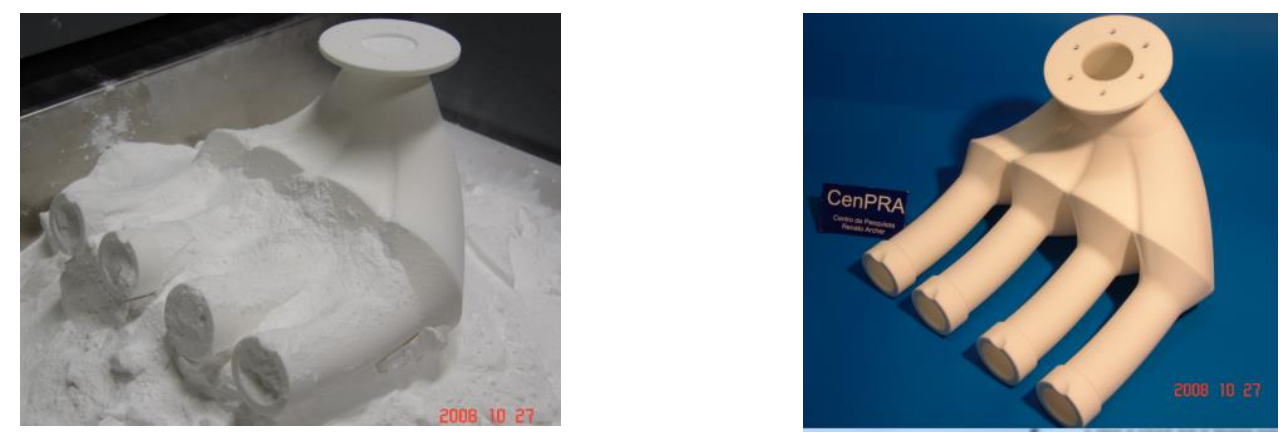

Figura 2.9: Coletor de admissão fabricado em tecnologia de aglutinante e pós e pela tecnologia SLS. (Projeto Fórmula SAE® USP São Carlos).

B) Processo de fusão de metais à base de pó

A fusão de metais à base de pó é uma técnica de MA que tem sido bem sucedida no que diz respeito à formação de peças sólidas com geometrias complexas e com possibilidade de uso de material metálicos na forma de liga. Estes métodos utilizam alta energia, com exceção do EBM (Electron Beam Melting), Gibson(2007), um rígido controle de atmosfera e novas estratégias de escaneamento. A técnica de MA, DMLS (Direct Metal Laser Sintering) foi 
desenvolvida pelo Instituto Fraünhofer de Tecnologia à Laser, em Aachën na Alemanha (Inforçatti Neto, 2013). Este processo foi bem sucedido aplicado a alguns tipos de metais e cerâmicas. Este processo também é conhecido como Fusão Seletiva à Laser e têm fornecido precisão e rugosidade superficiais abaixo de $50 \mu \mathrm{m}$.
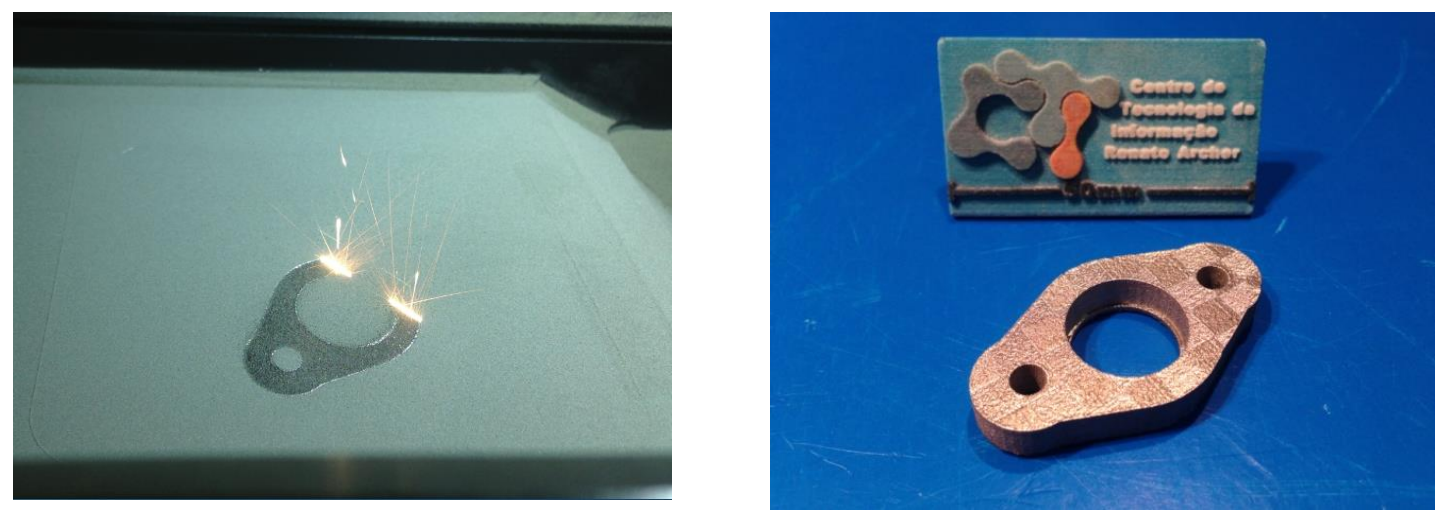

Figura 2.10: Mancal de rolamento em aço inox sendo fabricado em máquina de MA de metais por laser, Concept Laser® (Fonte: CTI, 2014)

Uma nova variação nos processos de fusão de metais a laser, à base de pó, é a EBM, traduzido como Fusão por Feixe de Elétrons conforme ilustrado pela Figura 2.11. Este processo faz uso de um feixe de elétrons como fonte de calor em substituição ao laser e foi desenvolvido pela Universidade de Tecnologia de Chalmers na Suécia (Inforçatti Neto, 2013). Neste processo, um feixe de elétrons é focado em uma superfície de pequena espessura, com uma pré-distribuição de pó, dentro de uma câmara com vácuo, causando fusão localizada e re-solidificação. Alguns benefícios do EBM, em relação ao processo a laser são: alta eficiência de conversão de energia, maior facilidade de manipulação do feixe, quanto à focalização e deslocamento, com movimentação mais rápida. A desvantagem do EBM é que os materiais de sinterização devem ser eletricamente condutivos e, há a necessidade de criação de ambientes a vácuo. 


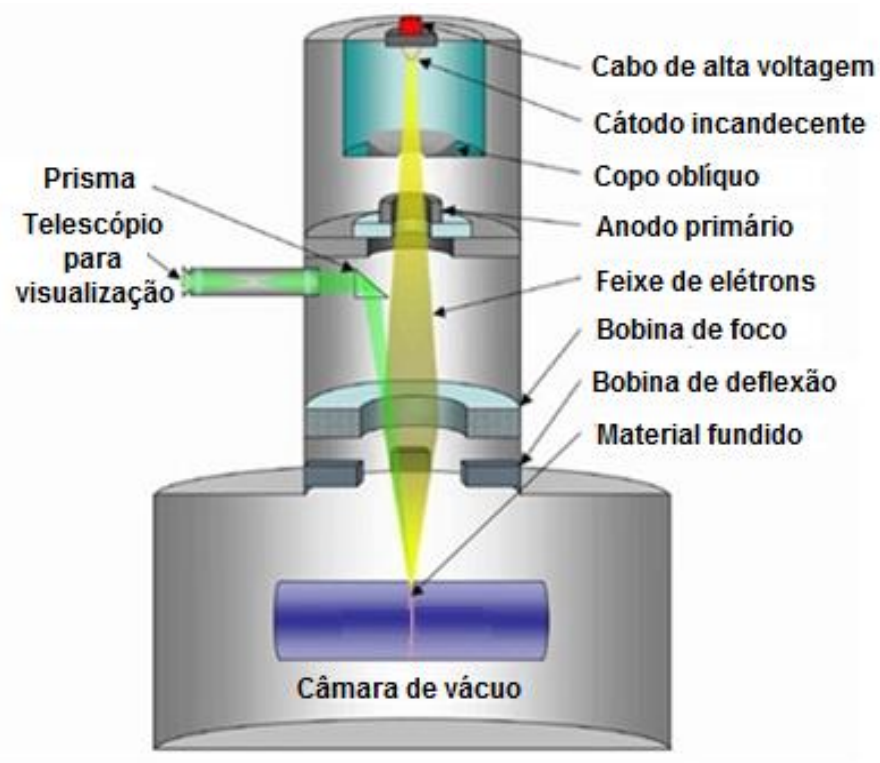

Figura 2.11: Esquema de funcionamento do processo de sinterização por feixe de elétrons. Fonte: http://www.mechanicalengineeringblog.com/ (2014)

O processo LENS ("Laser Engineering Net-Shape" ou "Volume Laser Cladding") é fundamentado na adição através da fusão de partículas que são aspergidas com um gás inerte sobre o foco de um potente feixe de laser. Este por sua vez, funde as partículas que ao solidificarem umas nas outras formam as camadas. Podem ser utilizadas ligas de titânio: Ti-6Al-2Sn-4Zr-2MO, Ti48Al-2Cr-2Nb, Ti-22Al-23Nb e aços como o H13. Os componentes fabricados por esta técnica de manufatura aditiva e possuem baixa porosidade, no entanto a precisão dimensional é pequena (Pallarolas, 2013). A Figura 2.12 apresenta uma simplificação do processo LENS.

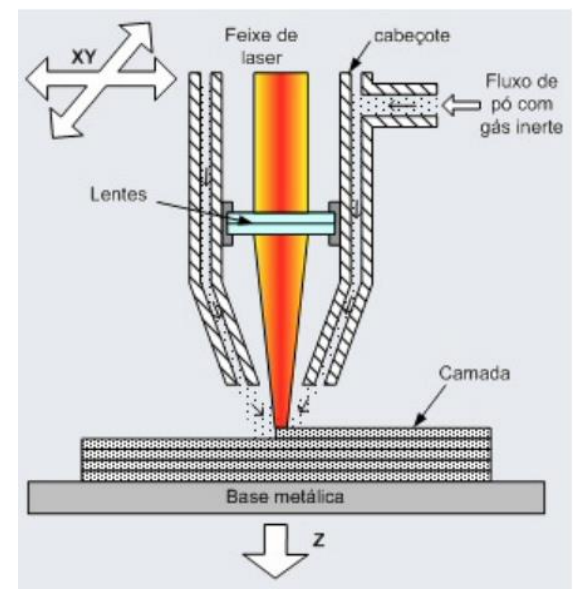

Figura 2.12 - Processo de MA, LENS. Fonte: CIMJECT, 2013 
Com intuito de melhorar a qualidade da superfície das peças fabricadas em processo LENS, é comum o pós-processo de acabamento e fresamento por usinagem. Como desvantagens podem-se citar, limitações geométricas para superfícies complexas além da necessidade do uso de uma base para o início da fabricação de objetos. As aplicações principais, até o momento, são voltadas para a obtenção de componentes de ligas especiais e restauração de matrizes capacidade dessa tecnologia produzir peças densas é sua maior vantagem sobre outros processos de manufatura aditiva. Além da formação de microestruturas finas e refinadas, as peças podem ser geradas com geometrias complexas incluindo cavidades internas, características que não se obtém com processos convencionais. Como limitações desse processo pode-se citar: baixa resolução e acabamento superficial, baixa velocidade de construção, em relação a outras tecnologias de manufatura aditiva. Os processos de sinterização podem então, ser resumidos de acordo com a tabela 2.2:

Tabela 2.2: Processos de sinterização em MA. (Fonte: Oliveira, 2008).

\begin{tabular}{|c|c|c|c|}
\hline $\begin{array}{c}\text { Fabricante/ tipo de } \\
\text { material }\end{array}$ & 3D systems & EOS & DSM Somos \\
\hline \multirow[t]{2}{*}{ Metais } & \multirow{2}{*}{$\begin{array}{l}\text { Laserform ST-200: } \\
\text { aço inox com } \\
\text { recobrimento } \\
\text { polimérico para } \\
\text { insertos rápidos. }\end{array}$} & $\begin{array}{l}\text { DirectMetal } 50 \& \\
\text { 20: mistura de } \\
\text { níquel, bronze e } \\
\text { fosfato de cobre }\end{array}$ & - \\
\hline & & $\begin{array}{c}\text { DirectSteel } 50 \text { \& } \\
\text { 20: aço P20 }\end{array}$ & - \\
\hline Cerâmicas & $\begin{array}{c}\text { Sandform: } \\
\text { cerâmica recoberta } \\
\text { com um ligante } \\
\text { polimérico. }\end{array}$ & $\begin{array}{l}\text { LaserCron: areia } \\
\text { especial para } \\
\text { fabricar cascas } \\
\text { para fundição. }\end{array}$ & - \\
\hline \multirow[t]{3}{*}{ Polímeros } & $\begin{array}{l}\text { Duraform: } \\
\text { poliamida para } \\
\text { protótipos. }\end{array}$ & $\begin{array}{l}\text { PA 2200: } \\
\text { poliamida para } \\
\text { protótipos. }\end{array}$ & \multirow{3}{*}{$\begin{array}{c}\text { DSM201: pó } \\
\text { com } \\
\text { características } \\
\text { de } \\
\text { elastômeros } \\
\text { para } \\
\text { protótipos } \\
\text { flexíveis. }\end{array}$} \\
\hline & $\begin{array}{c}\text { Duraform } \\
\text { GF:poliamida } \\
\text { com } \\
\text { fibra de vidro } \\
\text { para } \\
\text { protótipos }\end{array}$ & $\begin{array}{c}\text { PA } 3200 \text { GF: } \\
\text { poliamida com } \\
\text { fibra de vidro } \\
\text { para } \\
\text { protótipos }\end{array}$ & \\
\hline & $\begin{array}{l}\text { Castform: } \\
\text { poliestireno para } \\
\text { modelos de } \\
\text { fundição. }\end{array}$ & $\begin{array}{l}\text { PrimeCast: } \\
\text { poliestireno para } \\
\text { modelos de } \\
\text { fundição. }\end{array}$ & \\
\hline
\end{tabular}




\subsection{4 - Processos baseados em fusão}

O processo de manufatura aditiva baseado em fusão de filamento (FDM) utiliza normalmente termoplásticos como material de deposição. O processo FDM utiliza um cabeçote de fusão, que se movimenta na direção $X$ e $Y$. Através desse cabeçote se desloca um filamento que é aquecido e extrudado em estado semi-fundido por um bico injetor. Este material é depositado sobre uma plataforma, de acordo com a geometria da peça. Após a deposição, a camada se solidifica, Figura 2.13.

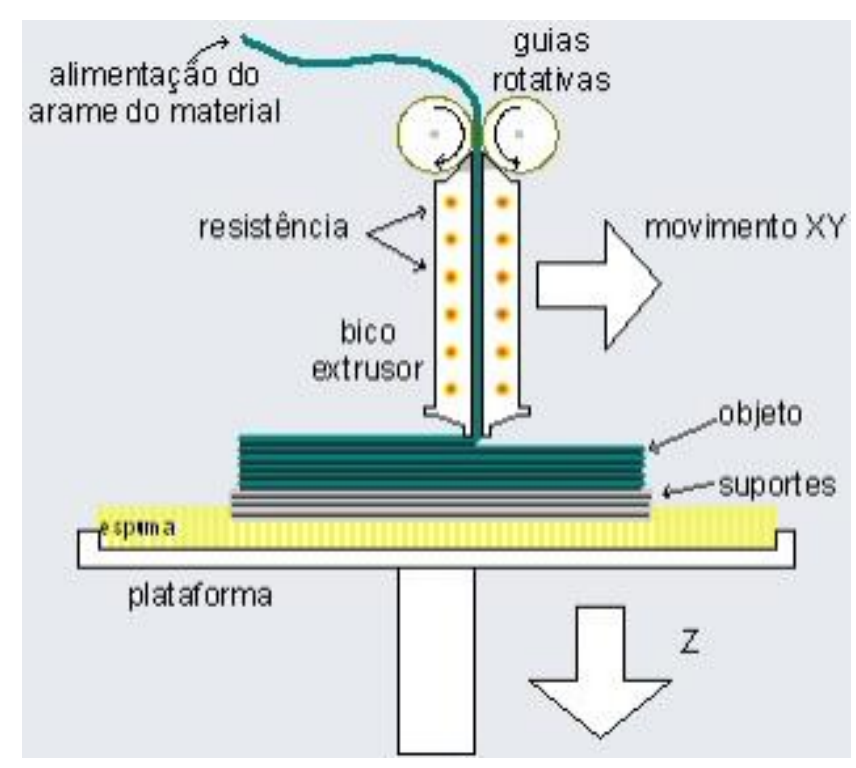

Figura 2.13: Esquema simplificado do processo FDM. Fonte: CIMJECT (2013).

Uma grande variedade de materiais pode ser usada como materiais de construção, tendo como exemplo, poliolefinas, poliamidas, polifenilsulfonas,

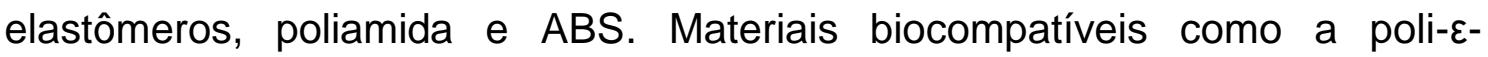
caprolactona $(P C L)$ têm sido utilizados para aplicações em engenharia teciduais. (Senedese, 2011).

Essa tecnologia encontrou uma forte demanda na área industrial principalmente devido às propriedades dos materiais utilizados e baixo custo das máquinas de nível de entrada ou de menor custo (Gibson, 2010). 
A grande maioria das máquinas do tipo desktop de impressão 3D utilizam essa tecnologia que como vantagem apresenta simplicidade de construção com movimentação nas coordenadas $(x, y, z)$, da manutenção, e ainda, com possibilidade de utilização de uma gama termoplásticos. Com a variação dos bicos de injeção e velocidade de deposição pode-se alterar a qualidade da superfície das peças através da variação da altura da camada. Como desvantagem pode-se colocar que para a utilização de termoplásticos com alto índice de contração é necessária utilização de câmara aquecida para se evitar o empenamento na solidificação. Para a fabricação do filamento para alimentar o sistema, é utilizado o processo de extrusão por rosca, o que dificulta a utilização de novos materiais que precisam ser pré processados nessa máquina. Gibson aponta como desvantagens da tecnologia FDM o tempo de construção de peças, a acuracidade e a densidade do material. As peças também apresentam anisotropia apresentando diferentes resistências mecânicas em diferentes direções.

\section{3 - Processo de extrusão por rosca}

A extrusão de polímeros, na qual um polímero é liquefeito e carreado até um molde ou matriz, forma a base da maioria das técnicas de processamento de polímeros (Deng, 2014). Segundo Rauwendaal (2001), a primeira extrusora de material termoplático foi construída em 1935 por Paul Troester, na Alemanha. As extrusoras, largamente usadas na indústria de termoplásticos, apresentam-se na forma de rosca simples/ única ou múltipla, conforme ilustrado na Figura 2.15 e Figura 2.16, respectivamente. Segundo Rauwendaal (2001), a extrusora de rosca única é o tipo mais usado de extrusora na indústria de polímeros e como vantagens desta é destacado o relativo baixo custo, robustez e confiabilidade, e favorável relação desempenho/custo.

Em relação aos tipos de rosca utilizados para extrusão de termoplásticos, Raquez et al (2008) cita que: "A extrusora de rosca única é normalmente utilizada para trabalhos simples como derretimento, plastificação e descarga para produção de filmes, tubos e perfis. A extrusora de rosca dupla, 
de acordo com suas características específicas, pode ser utilizada para operações como homogeneização, dispersão de pigmentos e aditivos, formação de ligas, mistura reativa, concentração e devolatilização, polimerização. A maior diferença entre a extrusora de rosca única e dupla é o mecanismo de transporte. Embora, em máquinas de rosca única, isso dependa de forças de friç̧ão na zona de alimentação de sólidos e forças viscosas na zona de derretimento, com rosca dupla isso é altamente dependente da configuração geométrica das roscas, e seu caráter de deslocamento positivo".

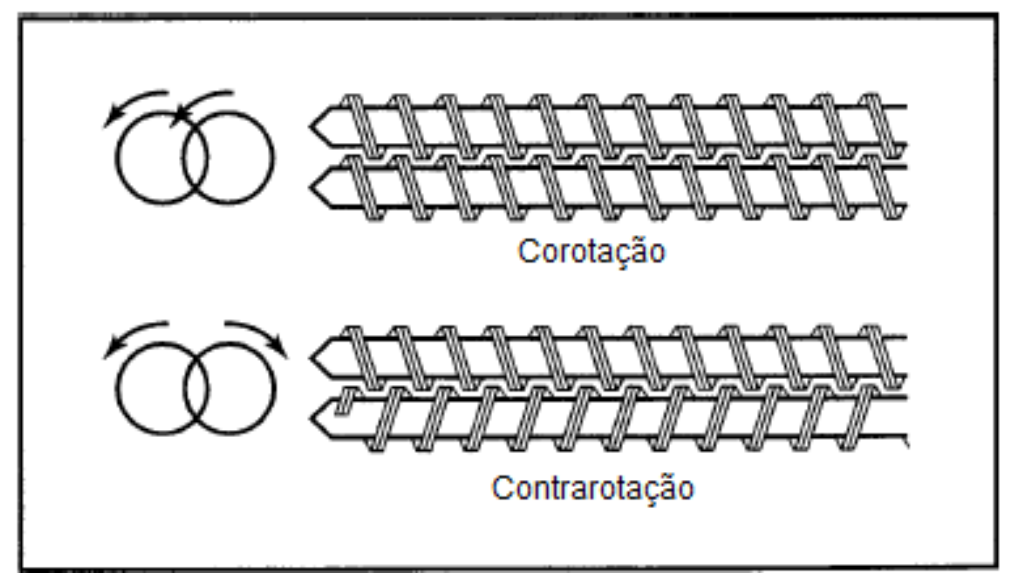

Figura 2.14: Parafusos de extrusão rosca dupla (Fonte: Drobny, 2007).

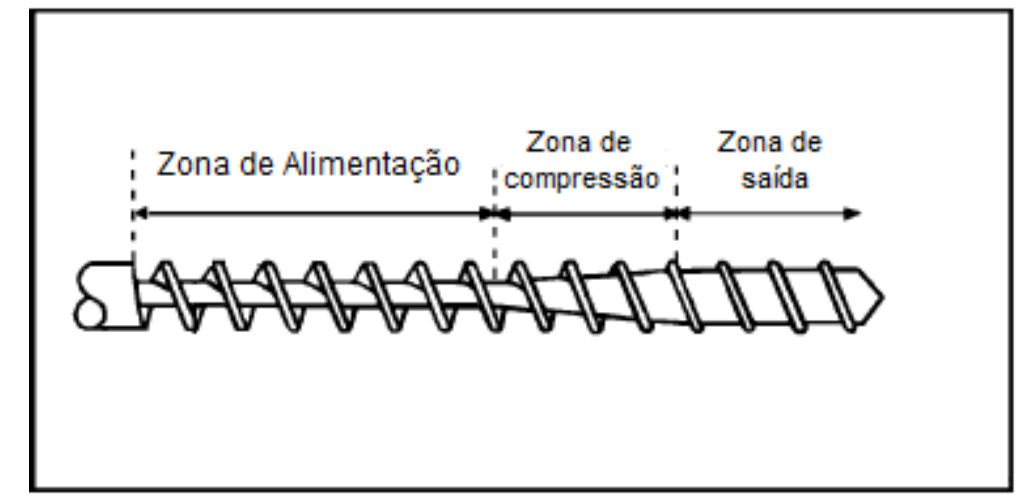

Figura 2.15: Parafuso de extrusão rosca simples (Fonte: Drobny, 2007)

O processo de extrusão é dividido em várias fases e Gibson (2010) cita essas fases do processamento por extrusão no contexto da MA como:

- Carregamento de material

- Liquefação do material

- Aplicação de pressão para mover o material contra a matriz de extrusão. 
- Extrusão

- Deposição de acordo com movimentação controlada e pré-definida

- Adesão do material a ele mesmo ou materiais secundários de construção para formação de estrutura sólida.

- Inclusão de estruturas de suporte para possibilitar a formação de geometrias complexas.

A Figura 2.16 apresenta uma extrusora convencional industrial, na qual o sistema é acionado por meio de um conjunto correia, redutor e motor. Esse sistema de transmissão aciona a rosca de extrusão, que alimentada por meio de um silo de alimentação, carreia o material, que derrete devido ao calor dos aquecedores, até o bico ou matriz de extrusão, cujo formato determina o perfil obtido do material extrudado.

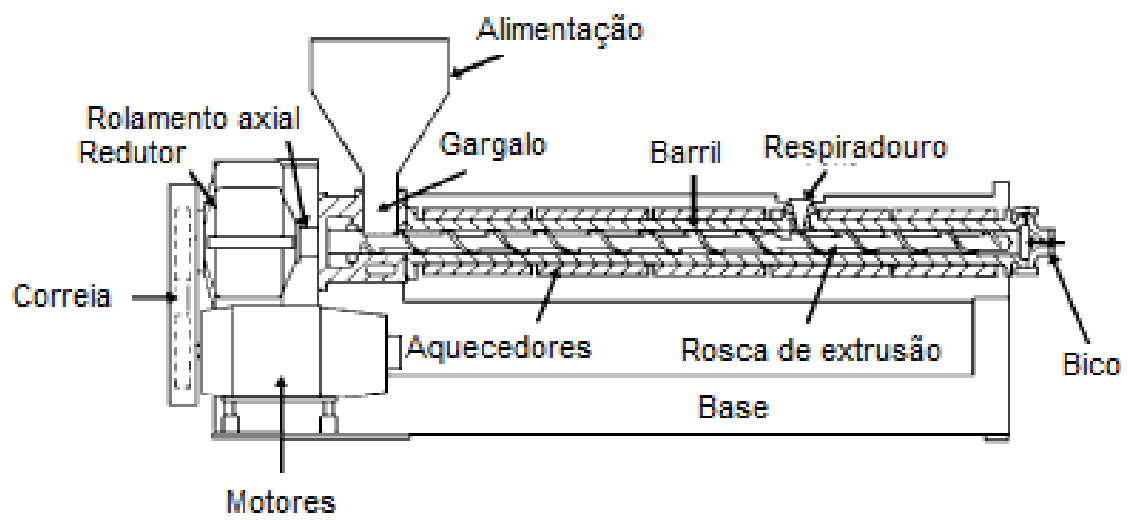

Figura 2.16 - Esquema de extrusora industrial convencional com barril ventilado (Fonte: Drobny, 2007)

Sabendo-se a história, os tipos e os princípios básicos de funcionamento, com intuito de entender o projeto do cabeçote em estudo são expostos na próxima seção mais detalhadamente, os aspectos técnicos da extrusão.

\subsection{1 - Considerações sobre o perfil de roscas de extrusão}

Segundo Kelly et al (2006), um "bom" projeto da rosca de extrusão é de crítica importância para a otimização do processamento. A geometria da rosca afeta a taxa de saída de material, proporção de derretimento, mistura, homogeneidade da temperatura e eficiência do processo. Para melhor 
entender o processo de extrusão é necessária à exposição de cada parâmetro de processo, características geométricas do sistema e características dos materiais a serem extrudados. Como características de processo têm-se temperatura da resistência, rotação da rosca de extrusão, gradiente de pressão interna, taxa de saída de material (mássica ou volumétrica) e tempo de residência. As principais características de uma monorosca de extrusão são comprimento, relação comprimento/diâmetro ou L/D, os respectivos comprimentos de alimentação, compressão e saída, largura do filete, passo da rosca e profundidade da rosca em cada seção (Kelly et al., 2006). As características geométricas da rosca do sistema, em estudo são esquematicamente representadas na Figura 2.17, que corresponde à rosca projetada neste trabalho, que será discutida no item 4.1.

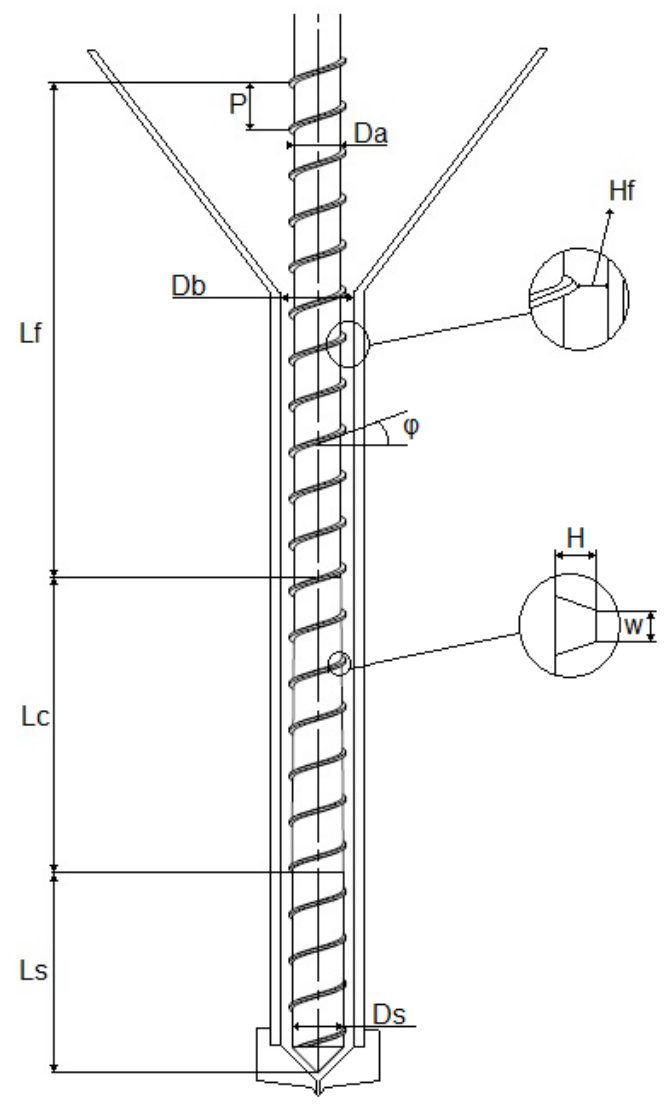

$\mathrm{H}_{\mathrm{f}}$ - Folga entre filete e barril

$P$ - Passo da rosca

$\mathrm{D}_{\mathrm{a}}$ - Diâmetro da rosca na zona de alimentação

$D_{b}$ - Diâmetro do barril

$D_{s}$ - Diâmetro de saída

$\mathrm{X}_{\mathrm{c}}$ - Taxa de compressão

$\mathrm{L}$ - Comprimento do parafuso de extrusão

W - Largura do filete

$\mathrm{H}$ - Altura do filete

$L_{f}$ - Comprimento na zona de alimentação

$L_{c}$ - Comprimento na zona de compressão

$L_{s}$ - Comprimento na zona de saída

$\boldsymbol{\phi}$ - Ângulo de hélice do filete da rosca

Figura 2.17: Parâmetros geométricos para mini-extrusora (Fonte: autor, 2014) 
Segundo Deng et al, 2014, a escolha do parafuso de extrusão geralmente depende do material processado. No caso foi adotada uma monorosca padrão com passo quadrado, ou seja, passo igual ao diâmetro de saída do parafuso $\left(D_{s}\right)$. Segundo Rauwendaal(2001), esta geometria de rosca é a mais utilizada para o processo de extrusão na indústria, e tem a capacidade de funcionar para vários materiais, mas não de forma otimizada, assim não provendo a melhor produtividade, mistura ou plastificação para cada material em específico. Essa geometria, para uma primeira tentativa de projeto, é interessante, pois apesar de suas limitações, ela é simples sendo possível de ser fabricada por usinagem convencional e apresenta vários parâmetros de projeto como comprimento das zonas de extrusão, relação L/D, folgas H's, com proporções de projeto indicadas por Rauwendaal (2001).

Um parâmetro geométrico importante é a taxa de compressão Xc que é a profundidade da zona de alimentação dividida pela profundidade da zona de saída e determina o quão rápido o material será comprimido dentro do barril conforme ele flui no mesmo. Uma compressão muito rápida pode acarretar o travamento da rosca de extrusão em funcionamento por aumento da porção de material sólido na zona de compressão. Já uma zona de compressão muito longa no caso em questão também não é desejável, pois aumenta o volume e peso total do cabeçote de extrusão.

Em relação ao processo de extrusão, segundo Deng (2014), a qualidade do mesmo pode ser indicada pela pressão de derretimento, temperatura, viscosidade, ou a taxa de saída de material no final do processo. O mesmo autor coloca que o controle da temperatura de liquefação, e a homogeneidade térmica se apresentam como fatores chave da qualidade do produto e consumo de energia. Esta afirmação corrobora com uma vantagem deste projeto que é o uso de resistência microtubular de temperatura controlada e também aponta a importância do estudo de distribuição térmica nas zonas do cabeçote com análise de elementos finitos e validação experimental. 
Um outro fator já citado e importante no processo é a taxa de saída de material da extrusora que está diretamente ligada à capacidade produtiva do processo, Béreaux et al(2009). Segundo Béreaux et al(2009), a taxa de saída de material é a primeiramente e principalmente função da geometria da rosca enquanto o desenvolvimento da pressão, o pico de pressão em particular, são funções da viscosidade do polímero.

O tempo de residência é uma característica do processo que representa o tempo em que o material fica dentro da extrusora. É um fator inversamente dependente da rotação da extrusora no processo. Segundo Raquez et al (2008), a habilidade de uma extrusora de trabalhar com materiais de alta viscosidade sem nenhum solvente resulta em uma drástica redução de custos com matéria-prima.

A pressão interna do barril é normalmente proporcional à velocidade de extrusão, ou rotação da rosca. Qualquer aumento na temperatura irá reduzir a pressão e viscosidade. No processo de extrusão, a pressão de extrusão pode ser controlada pela resposta rápida na velocidade de rotação da rosca. Em contrapartida, a resposta da mudança de temperatura é bem mais lenta (Deng et al, 2014).

A temperatura do fluxo de polímero liquefeito é um parâmetro chave de processo. Segundo Bur et al (2004), ela afeta muitos parâmetros críticos do material incluindo viscosidade, densidade da resina, dinâmica de degradação. No caso, ela é somente controlada pela resistência microtubular que envolve a parte final do barril de extrusão.

\section{4 - Conceitos sobre planejamento de experimentos}

Um planejamento ou projeto experimental consiste de um conjunto de testes, para os quais são realizadas alterações pré-definidas nas variáveis de entrada de um processo ou sistema, de forma que possam ser observadas e identificadas causas das mudanças nas respostas (Montgomery, 1991 apud 
Silveira, 2003). O projeto ou processo em estudo pode ser representado por um modelo simplificado, como apresentado na Figura 2.18.

Fatores controláveis

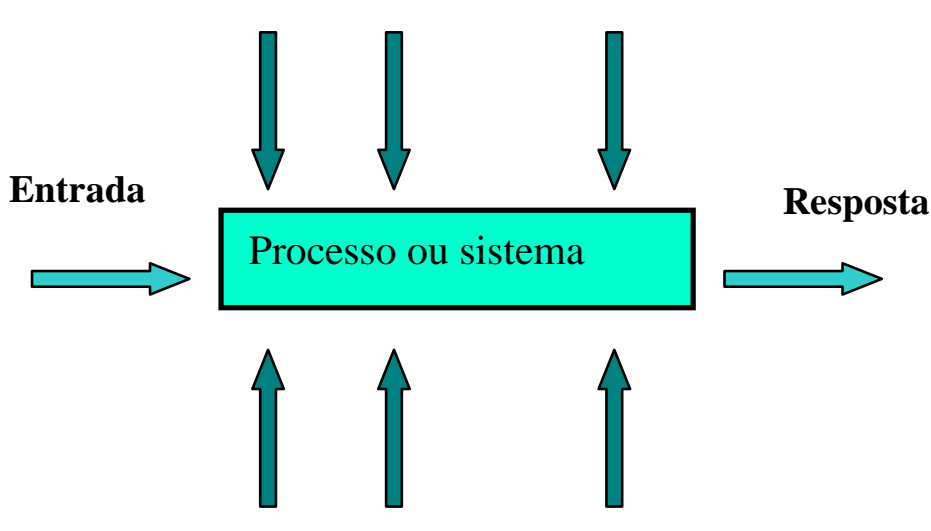

Fatores não-controláveis

Figura 1: Modelo de controle um sistema genérico.

O sistema atua como uma função, desconhecida inicialmente, que age sobre as variáveis conhecidas de entrada, e produz como saída as respostas observadas.

Uma análise envolvendo a teoria de planejamento de experimentos pode ser dividida em duas abordagens: análise dos efeitos da variação dos fatores sobre a resposta (respostas) de interesse, com Análise da Variância (ANOVA) dos Efeitos e com a redução do número de fatores, a busca por uma função aproximada da relação entre esse conjunto de fatores e a resposta, e finalmente a busca de valores ótimos, por meio de métodos de otimização. A utilização do projeto experimental em diferentes fases do ciclo de vida do produto contribui para um menor tempo de desenvolvimento do produto, melhorando seu desempenho e confiabilidade, bem como possivelmente reduções nos custos.

As Figuras 2.19 (a); (b) e (c) representam diferentes configurações para o preenchimento do cubo experimental, com diferentes níveis experimentais. 


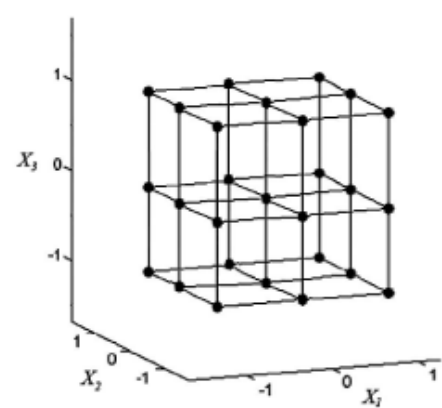

(a)

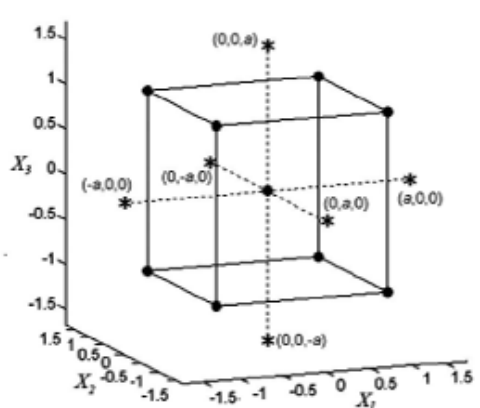

(b)

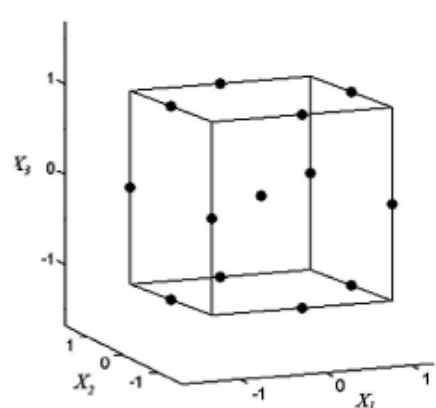

(c)

Figura 2.19: Cubo experimental para 3 fatores, que representa o espaço de projeto estudado. (a) Planejamento fatorial em 3 níveis; (b) planejamento composto central; (c) estratégia para preenchimento mais homogêneo do espaço amostral.

Para um planejamento fatorial completo, com dois níveis e três fatores $\left(2^{3}\right)$ seriam geradas 8 linhas de corridas experimentais. Uma opção, quando há restrições de experimentos experimentais ou computacionais, é o uso de planejamento fracionários, nos quais busca-se informações da relação entre fatores e resposta, utilizando-se metade ou frações da matriz experimental, uma vez que essas frações comuns são matrizes ortogonais. Essas matrizes têm uma propriedade de equilíbrio, que cada estabelecimento de um parâmetro de projeto ocorre com todas as configurações de todos os outros parâmetros de projeto, o mesmo número de vezes. Essa propriedade de equilíbrio é mantida, enquanto for minimizado o número de testes as serem executados.

Segundo Silveira (2003), a escolha de uma estratégia para o caso da pesquisa de extremos consiste em se estudar o maior número possível de fatores, mas considerando o mínimo de níveis. Portanto, não haveria a necessidade de se encontrar as matrizes ortogonais, já que não haveria um número exorbitante de experimentos. Neste caso, a interação entre os fatores pode ser tratada com menor enfoque. A combinação dos diferentes fatores fornece as respostas máximas e mínimas do sistema, como já foi dito anteriormente. As interações estão relacionadas ao efeito principal, mas o estudo é feito com um número significativo de fatores em relação às suas interações. 
Os planejamentos $2^{k}$ ou $\mathrm{N}^{k}$ tem como base o número de níveis e $\mathrm{o}$ expoente se refere ao número de fatores ou parâmetros de controle e devem ser variáveis independentes. No exemplo citado anteriormente de um planejamento do tipo $2^{3}$, há 3 fatores e 2 níveis pré-estabelecidos totalizando 8 combinações desses parâmetros, associados aos efeitos principais $\left(X_{1}, X_{2}\right.$, e $\left.X_{3}\right)$, efeitos de iterações de segunda ordem $\left(X_{1} * X_{2}, X_{1} \times X_{3}\right.$ e $\left.X_{2} * X_{3}\right)$ e efeitos de interação de terceira ordem $\left(X_{1^{*}} X_{2^{*}} X_{3}\right)$. Se houvesse três níveis, o número mínimo de ensaios subiria para $3^{3}$, ou seja, 27 experimentos.

\section{5 - Considerações sobre o método de elementos finitos aplicado a problemas de transferência de calor}

A análise numérica por método dos elementos finitos é comumente realizada para resolver uma grande quantidade de problemas de engenharia (Huebner, 2001). Seu conceito básico é definido com um método baseado na divisão de um corpo ou estrutura em pequenos elementos, chamados elementos finitos e suas propriedades são formuladas e combinadas para obter a solução para todo o corpo (Krishnamoorthy,1991). Essa discretização reduz o problema a um número finito de incógnitas dividindo a região da solução em elementos e expressando o campo de variáveis de incógnitas em termos de funções aproximadoras adotadas nos elementos, (Huebner,2001).

A análise térmica significa primariamente o cálculo das temperaturas dentro do corpo. Para um problema em regime permanente (independente da variação do tempo), a formulação global de elementos finitos é dada pela equação (1):

$$
K_{t} T=Q
$$


Sendo a matriz $K_{t}$, depende da condutividade do material, T um vetor de nós de temperaturas pontuais do corpo sólido, e $Q$ é um vetor de cargas térmicas.

A condutividade térmica e outras propriedades podem depender da temperatura, neste caso a equação 1 pode ser colocada como função da temperatura, ao invés de uma matriz de constantes, tornando-se para este caso um problema não linear. Quando o fenômeno da radiação é considerado, o problema se torna não linear, devido ao fato do fluxo de calor que atravessa as regiões de fronteira depender de diferenças entre temperaturas absolutas elevadas à quarta potência, ao invés de simples diferenças de temperatura.

Considerando um material isotrópico os fluxos de calor gerados não estão necessariamente em um plano cartesiano, mas em eixos perpendiculares e podem a partir da equação (2):

$$
\left\{\begin{array}{l}
f_{x} \\
f_{y} \\
f_{z}
\end{array}\right\}=-\boldsymbol{k}\left\{\begin{array}{l}
\partial T / \partial x \\
\partial T / \partial y \\
\partial T / \partial z
\end{array}\right\}
$$

Sendo $\mathrm{k}$, representada por uma matriz $3 \times 3$ de condutividades térmicas e $\partial T / \partial a$, a derivada da temperatura na direção genérica $a$.

O fundamento para a análise térmica utilizando o programa ANSYS $\AA^{\text {é a }}$ equação de equilíbrio térmica obtida pelo princípio de conservação de energia, dada pela equação (3). A solução de elementos finitos é obtida pelo cálculo das temperaturas nodais que são utilizadas com intuito de obter outras respostas térmicas.

Considerando um elemento diferencial de volume e escrevendo a equação de equilíbrio de energia (taxa de entrada) - (taxa de saída) $=($ taxa de crescimento), pode-se obter a equação (3): 


$$
-\left[\frac{\partial}{\partial x} \frac{\partial}{\partial y} \frac{\partial}{\partial z}\right]\left\{\begin{array}{l}
f_{x} \\
f_{y} \\
f_{z}
\end{array}\right\}+q_{v}=c \rho \frac{\partial T}{\partial t}
$$

sendo $q_{v}$ é a taxa de geração interna de calor por unidade de volume, c é o calor específico; $\rho$ é a densidade em massa e t é o tempo. O problema pode ser considerado em regime permanente se: $\frac{\partial T}{\partial t}=0$.

Quando o estado não é regime permanente, mudanças de temperatura na unidade de volume de material são resistidas pela massa térmica que depende da densidade $(\rho)$ do material e seu calor específico. A equação (1) aumentada se torna a equação (4):

$$
K_{t} T+C \dot{T}=Q \text { sendo } \mathrm{Q}=\mathrm{Q}(\mathrm{t})
$$

Na qual $\dot{T}=\partial T / \partial t$

Em geral, as cargas térmicas $Q$ são dependentes do tempo. A matriz $C$ pode ser chamada de matriz de capacidade térmica, sendo construída pelos elementos de matrizes de capacidade calorífica $(C)$, cada pela equação (5):

$$
C=\sum c \text { sendo, } c=\int N^{t} N \rho c d V
$$

A integração ocorre sobre os elementos de volume e, $\mathrm{N}$ representa a função de forma.

O procedimento formal faz uso das funções de forma, cujas propriedades governam as capacidades dos elementos. Interpolando a temperatura sobre as temperaturas nodais dos elementos $T_{e}$, obtém-se as temperaturas sob a forma da expressão (6):

$$
T=\left[\begin{array}{llll}
N_{1} N_{2} & \ldots & N_{n}
\end{array}\right]\left\{\begin{array}{c}
T_{1} \\
T_{2} \\
\vdots \\
T_{n}
\end{array}\right\} \text { ou } T=N T_{e}
$$


A forma de interpolação determina a complexidade do campo de temperaturas que o elemento representa. Em coordenadas cartesianas, os gradientes de temperaturas em um sólido podem ser representados pelo sistema de equações (7):

$$
\left\{\begin{array}{l}
\partial T / \partial x \\
\partial T / \partial y \\
\partial T / \partial z
\end{array}\right\}=\left[\begin{array}{llll}
\partial N_{1} / \partial x & \partial N_{1} / \partial x & \cdots & \partial N_{n} / \partial x \\
\partial N_{2} / \partial y & \partial N_{2} / \partial y & \cdots & \partial N_{n} / \partial y \\
\partial N_{3} / \partial z & \partial N_{3} / \partial z & \cdots & \partial N_{n} / \partial z
\end{array}\right]\left\{\begin{array}{c}
T_{1} \\
T_{2} \\
\vdots \\
T_{3}
\end{array}\right\}
$$

Esses conceitos regem as análises térmicas de regime transiente, que foram feitas no sistema de extrusão apresentadas no item 4.4. 


\section{3 - REVISÃO DO ESTADO DA TÉCNICA}

Para situar o estado da técnica, em relação ao desenvolvimento desse cabeçote de extrusão intercambiável para impressora portátil 3-D, do tipo monorosca de seção variável e ressaltar sua característica de inovação nesse tipo de aplicação cabe apresentar a impressora experimental Fab@CTI, na qual foi montado e testado neste trabalho. Anteriormente, a esse trabalho foram desenvolvidos dois cabeçotes intercambiáveis: seringa (Inforçatti Neto, 2011) e FDM.

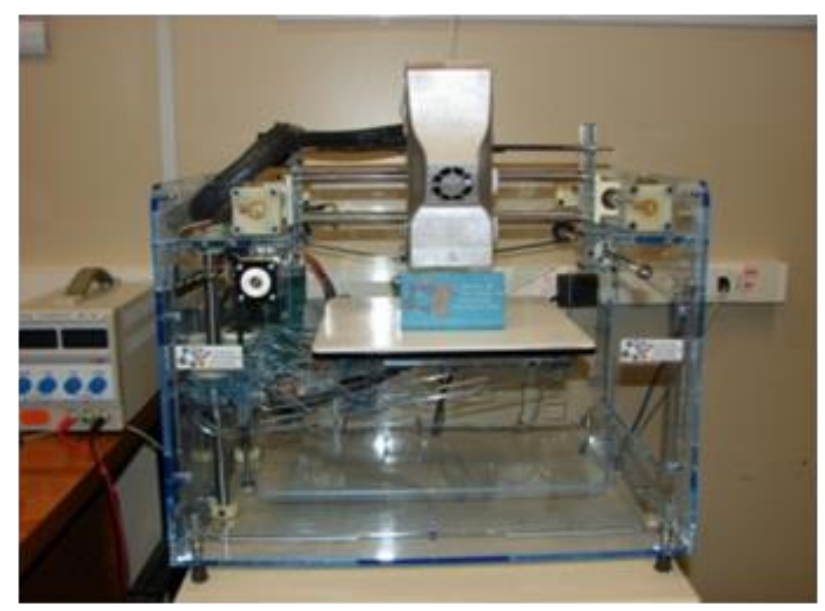

Figura 3.1 - Máquina desktop de impressão 3D Fab@CTI.

Com o projeto original da Fab@Home, foi proposto o cabeçote de extrusão por seringa ou êmbolo (Figura 3.2, esquerda), que é caracterizado pela extrusão à frio de material na forma de pasta que é empurrado por um êmbolo sendo este controlado por um sistema que acopla um parafuso a um motor de passo, cujo controle de velocidade de rotação determina a velocidade de movimentação do êmbolo e, consequentemente, de deposição de material.

Uma vez que a demanda inicial para projeto na área médica deveria ser atendida, o cabeçote por extrusão de filamentos baseado na tecnologia FDM (Fused Deposition Modeling), Stratasys ${ }^{\circledR}$, foi montado no CTI, com o intuito de realizar a deposição de material de caráter biocompatível Figura 3.2. 


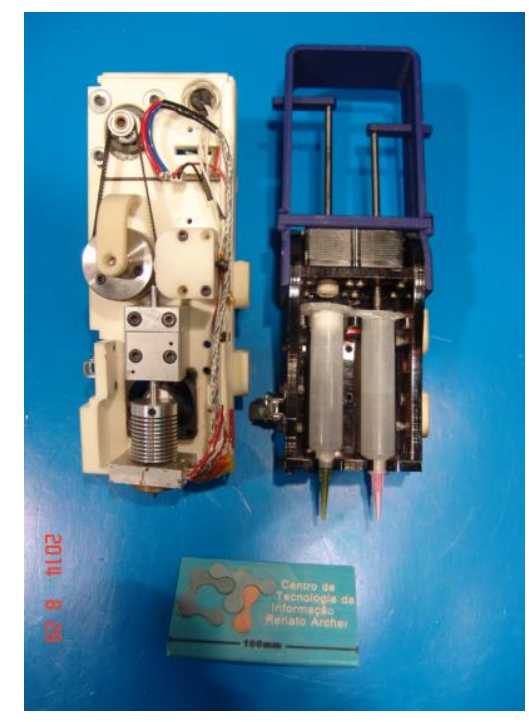

Figura 3.2 - Cabeçotes para impressão 3D em máquina desktop utilizados na Fab@CTI.

As tecnologias referidas anteriormente citadas encontram suas soluções relatadas sob a forma de patentes. Foram pesquisadas soluções construtivas referentes à tecnologia FDM para máquinas de manufatura aditiva, nas bases de dados: Derwent (www.derwent.com), USPTO (http://www.uspto.gov) e INPI (www.inpi.gov.br)

A patente número US 8287959 B2, com co-autoria da empresa Stratasys denominada "Syringe tip assembly and layered deposition systems utilizing the same" (Batchelder, 2012), com data de aprovação 16/10/2012 representa uma das soluções mais utilizadas para impressoras tridimensionais de pequenas dimensões e baixo custo, Figura 3.3 (a). A patente de número US 6.866.807 B2 aprovada em 15/03/2005 intitulada "High-Precision Modelling Filament" assinada também com co-autoria da empresa Stratasys consiste em um sistema de modelagem de filamento composto por um sistema de extrusão de rosca simples com seção variável, que alimenta um cabeçote de FDM. Um sistema de controle atua após a saída do filamento do sistema de extrusão para corrigir o desvio-padrão do diâmetro do filamento. A Figura 3.3 ilustra o sistema esquematizado. 

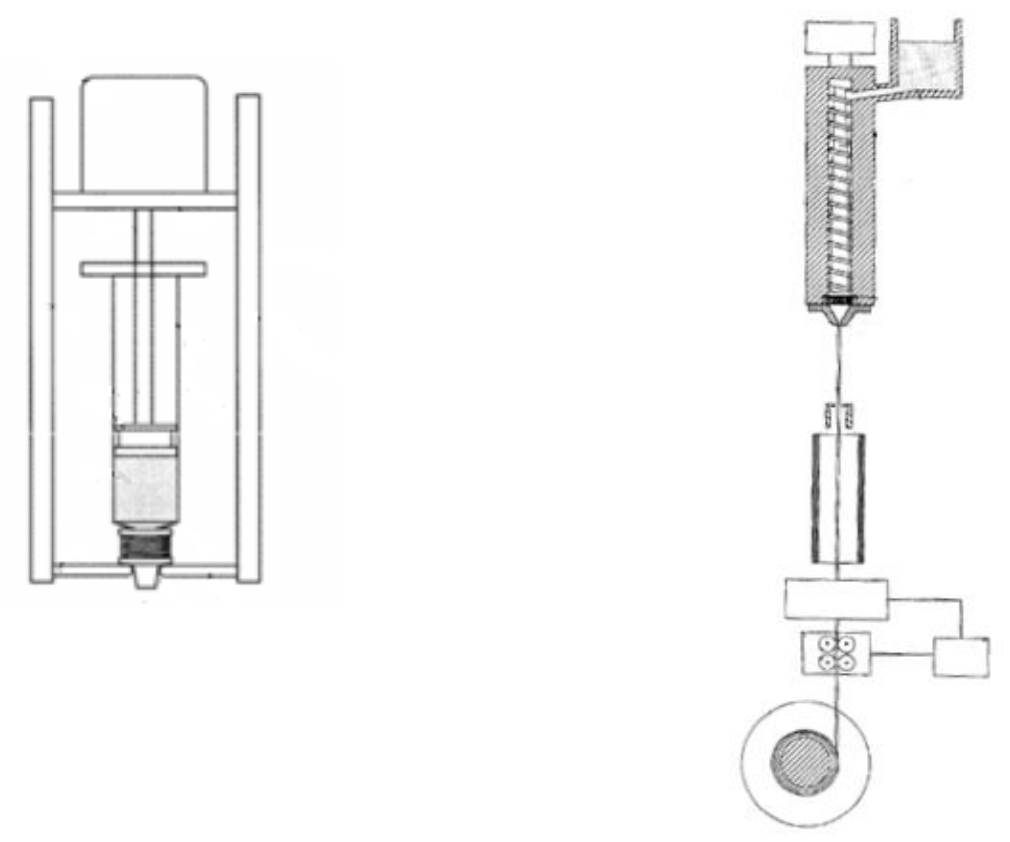

(a)

(b)

Figura 3.3 - (a) Desenho de patente do cabeçote de injeção por seringa e (b)

Desenho esquemático da patente - High-Precision Modelling Filament

A patente número PT 104247 B, depositada em 04/11/2008 em Portugal sob o título "Processo e Equipamento de fabrico rápido por bioextrusão", figura 3.4 (a), consiste em equipamento e processo de prototipagem rápida por bioextrusão destinado para a produção de próteses ósseas aplicadas no ramo médico, especificamente scaffolds. Nesta solução, o parafuso de extrusão funciona apenas como um sistema de transporte, uma vez que o material já é inserido na rosca sob a forma amolecida ou fundida necessitando o aquecimento prévio e pressurização do fluxo para o mesmo ser transportado para as zonas do parafuso. Este projeto apresentou validação demonstrando eficiência na produção de scaffolds utilizados para a área de crescimento celular em engenharia tecidual.

O desenvolvimento chamado "mini-screw extruding spray head", apresentado em artigo, Bin Liu et al(2010), apresenta a solução de parafuso de extrusão também na direção vertical, porém com alimentação de polímero na forma de filamento, Figura 3.4(b). 


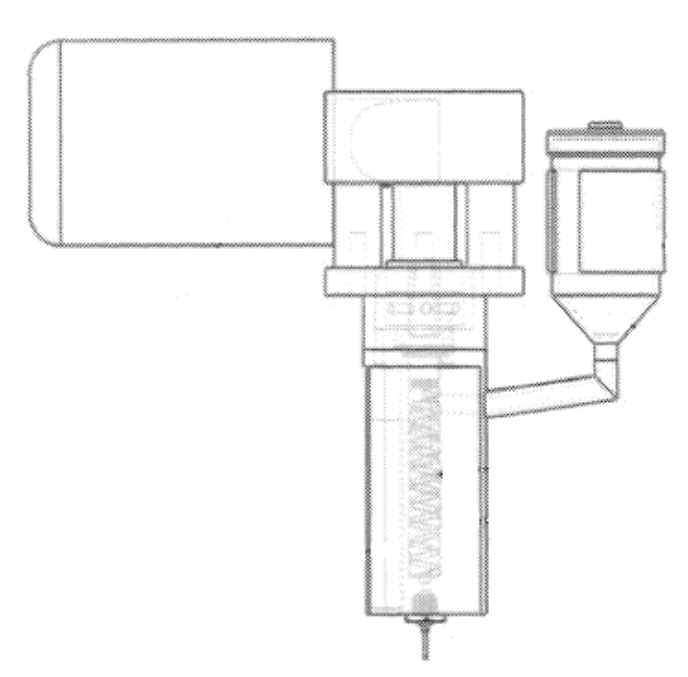

a)

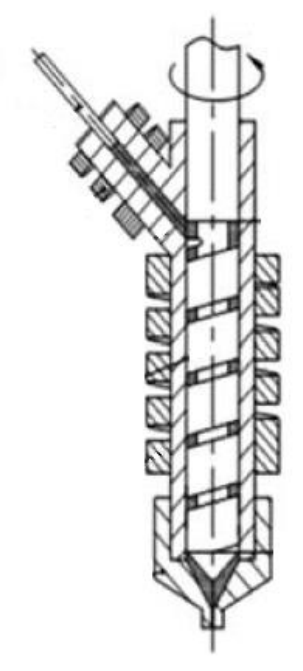

b)

Figura 3.4 - a) Desenho esquemático da patente - Processo e Equipamento de fabrico rápido por bioextrusão b) Desenho esquemático da patente "mini-screw extruding spray head"

Com o intuito de realizar a deposição de filamentos fundidos utilizando um cabeçote alimentado por material na forma de pellets. Cheng (2010) propôs uma solução bastante similar, com rosca de extrusão posicionada também na forma vertical conforme a figura 3.5 ilustra. Esta solução apresenta semelhanças com o projeto em estudo uma vez que utiliza rosca de extrusão, e aquecimento por resistência microtubular, porém e não apresenta sistema de redução de velocidade e é feita para extrusão de material na forma de pellet.

Há a apresentação de metodologia de cálculo para verificação do fluxo de material e dimensionamento de componentes, porém não houve a apresentação de validação do projeto com produção efetiva de filamentos, adesão de camadas e fabricação de protótipos de qualquer tipo. 


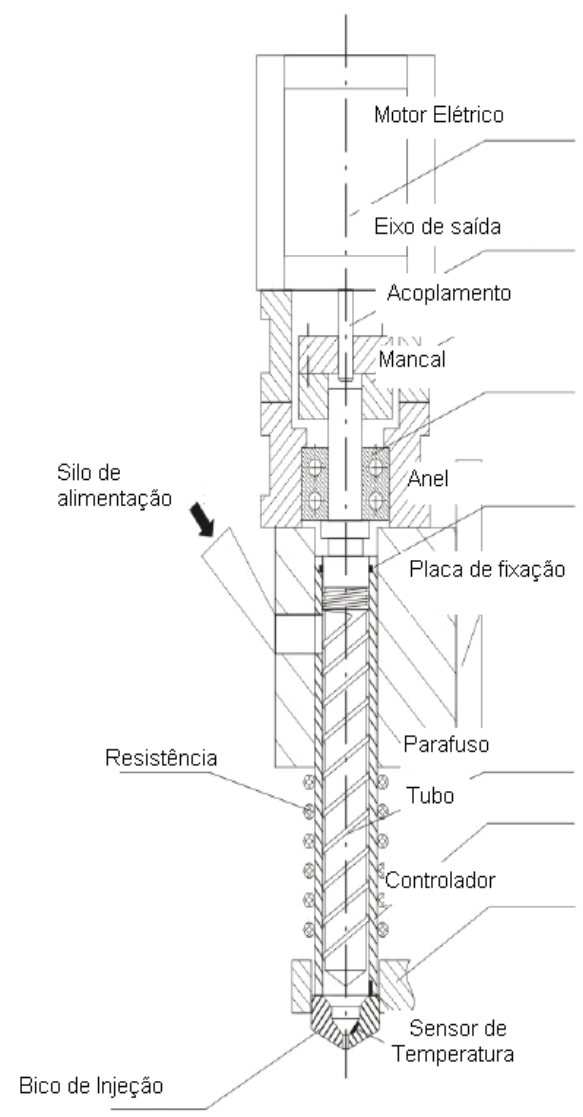

Figura 3.5 - Desenho esquemático da patente de um cabeçote alimentado por material na forma de pellets proposto por Cheng (2010).

Ao se verificar as soluções prévias ainda se visualiza a possibilidade de realizar um projeto inovador com alimentação em pó e validação para materiais poliméricos e compósitos (polímero/cerâmico) para produção de modelos em manufatura aditiva. 


\section{4 - ESTUDO DE CASO}

Inforçatti Neto (2013) apresentou o projeto de viabilidade técnica do cabeçote de extrusão em estudo. Uma análise de QFD completa foi realizada com intuito de satisfazer os requisitos dos usuários realizando-se a correlação com as soluções de engenharia. Dentro do sequenciamento do projeto como um todo, é importante destacar qual parte do projeto está sendo desenvolvido neste trabalho conforme indicado na Figura 4.1.

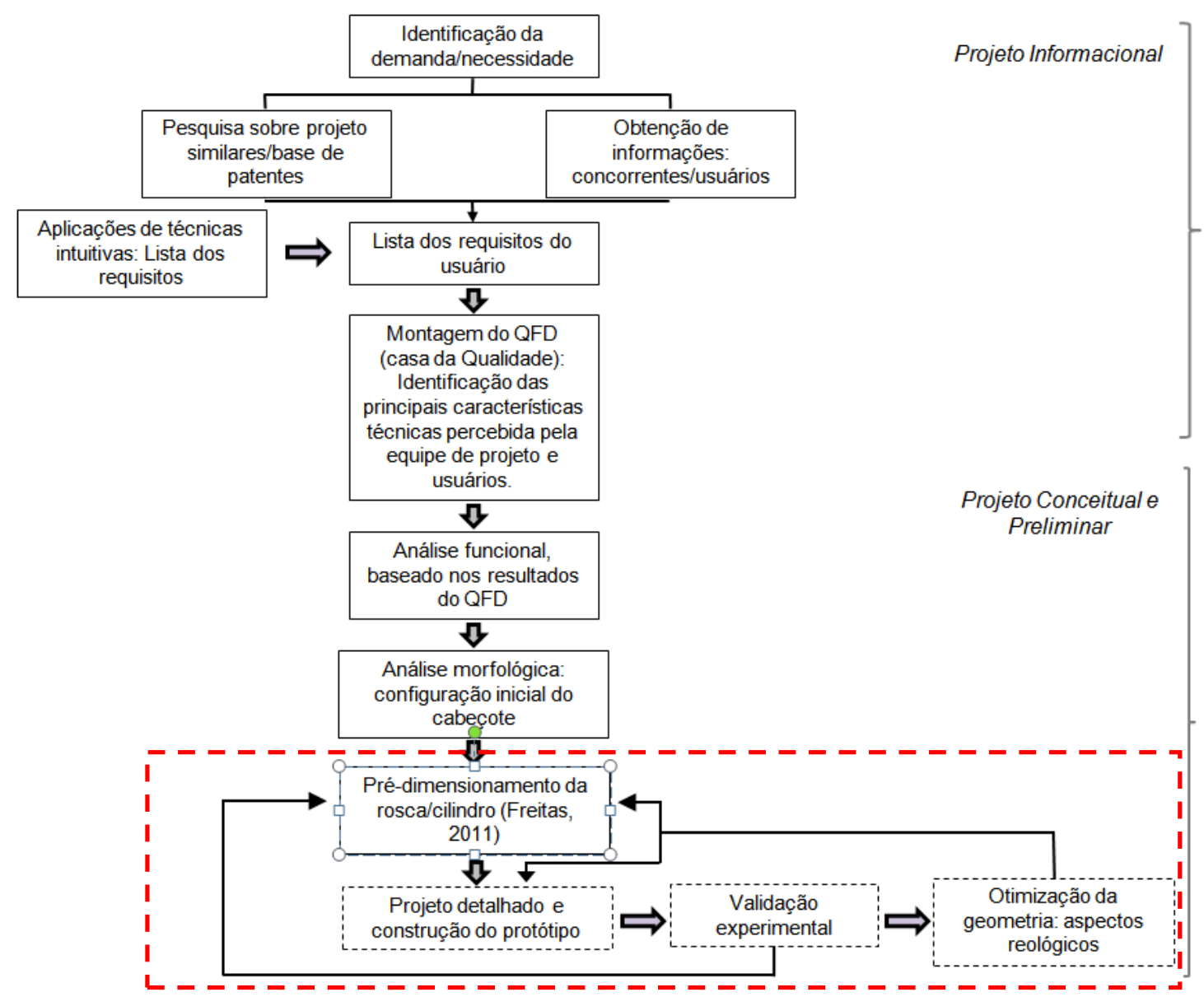

Figura 4.1: Projeto do cabeçote de extrusão com destaque na parte vermelha desenvolvida neste trabalho, adaptado de (Inforçatti Neto, 2013)

O cabeçote gera e realiza a deposição de filamentos, caracterizando o processo como um tipo de FDM, porém para produzir estes filamentos, o dispositivo considera o princípio largamente utilizado na indústria de polímeros e alimentos que é a extrusão por rosca. O projeto do cabeçote se diferencia da 
aplicação dada na indústria por diversas razões, como dimensões muito reduzidas, posição de extrusão de material na vertical, aplicação para impressão 3D.

As vantagens que este projeto proporciona para o uso em manufatura aditiva são:

- A possibilidade de introdução de material na forma de pó, com possibilidade de uso de pequenas quantidades de matéria-prima, opção adequada para produção de pequenas peças em máquinas desktop.

- Possibilidade de mistura de materiais. No caso de polímeros, essa mistura é largamente utilizada e seu resultado é um material com características físicoquímicas que podem diferir dos materiais originais, sendo o produto dessa mistura denominado blenda.

- Uso de mais de um material, refletindo em flexibilidade do cabeçote e aumentando a versatilidade da máquina, pois com o uso de vários polímeros diferentes em um mesmo cabeçote, abre-se a gama de aplicações para as peças geradas, aproveitando-se das características específicas de cada polímero como resistência mecânica, custo, facilidade de processamento, entre outras.

- Possibilidade de uso de aditivos, introduzidos junto com o material em pó, sendo que os aditivos podem ter várias funções, como melhor o desempenho de extrusão ou alterar propriedades do material depois de solidificado.

Além dessas vantagens o cabeçote construído apresenta algumas particularidades como:

- Várias peças do cabeçote foram construídas com tecnologias de manufatura aditiva como, por exemplo, a estrutura em Nylon $12 \mathrm{PA} \circledast$ obtido de processo SLS. Apoio aletado e engrenagens do redutor construídas com tecnologia DMLS. Partes da carcaça do redutor foram feitas em máquina com tecnologia Polyjet, Connex®. Isso torna o dispositivo inserido no ideal de se utilizar, quando vantajoso e oportuno, as tecnologias de manufatura aditiva 
para demonstrar o desenvolvimento e capacidades das mesmas dentro do contexto já exposto do uso em projetos inovadores.

O Nylon 12 PA® utilizado como matéria prima para validação experimental do cabeçote é rejeito de processo SLS, e seu reaproveitamento mostra a capacidade de reciclagem de material, uma vez que este esteja na forma de pó.

Como desvantagens é possível citar:

- peso atual, que gera vibrações e impede o aumento da velocidade de deposição.

- necessidade em carregar o sistema com material até sair pelo bico que introduz um tempo de pré-processo.

- dificuldade de limpeza do cabeçote quando se troca de material

\section{1 - Dimensionamento do par cilindro-rosca de extrusão}

Há muitos mecanismos usados para bombear líquidos com baixa e alta viscosidade. De acordo com White e Potente (2003) para líquidos de alta viscosidade dois princípios são usualmente empregados: (1) bombeamento de deslocamento positivo onde os fluidos preenchem câmaras fechadas e este é movido através do movimento mecânico de partes da máquina (extrusora no processamento de termoplástico); e (2) compressores, neste caso o fluido preenche uma região entre duas superfícies, onde uma está em movimento. 0 movimento relativo entre as duas superfícies bombeia o fluido através do canal, gradualmente pressurizado e forçado contra um bico. O segundo mecanismo tem algumas soluções técnicas desenvolvidas ao longo dos anos, mas a máquina mais simples é o compressor de tambor ou extrusora de tambor inventada por Gabrielli (1952) apud White e Potente (2003). Nesse dispositivo, o material bombeado é introduzido num espaço anular entre o tambor giratório e o barril em volta. A rotação do tambor empurra o líquido para uma posição onde há uma barra deslizante que direciona o líquido em um bico. O líquido é pressurizado e o gradiente de pressão é desenvolvido ao longo do 
comprimento do canal entre o tambor e o barril. Considerando a velocidade linear $(U)$ no tambor e a folga uniforme $(H)$ entre o barril e o tambor com comprimento $(\mathrm{W})$, a saída ideal para bombeamento de fluido é dada pela equação (8):

$$
Q=\frac{1}{2} H W U
$$

A presença do bico no final do fluxo de material induz a um contrafluxo ao longo da cavidade anular se um fluido newtoniano é considerado. Esse efeito é proporcional ao gradiente de pressão e inversamente proporcional à tensão de cisalhamento, então o fluxo de saída é obtido pela equação (9):

$$
Q=\frac{1}{2} H W U-\frac{K \Delta p}{\eta}
$$

O termo $\frac{K \Delta p}{\eta}$, representa o contrafluxo(Qback).

Por isso, a extrusão por parafuso de rosca única tem um comportamento similar ao compressor de parafuso onde o fluido é bombeado (usualmente termoplástico) e empurrado ao longo de uma rosca helicoidal. A equação (9) representa o fluxo ao longo da hélice e não ao redor do tambor. Considerando a taxa de fluxo de material em termos de rosca e barril de extrusão planificados com sistema de coordenadas fixo com eixos 1, 2, 3 no núcleo do canal da rosca de extrusão, no qual 1 está na mesma direção que o canal definido pelos filetes de rosca; 2 está ao longo do raio do eixo de extrusão e 3 é transversal ao filete da rosca como representado na figura 4.2.

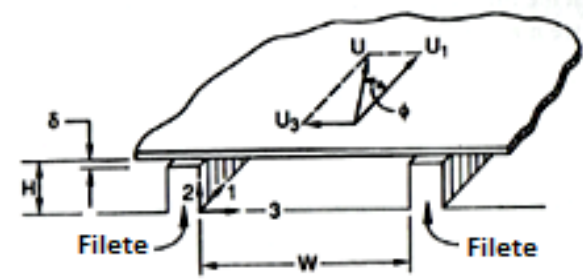

Figura 4.2: Sistema de coordenadas no barril de extrusão. (White e Potente, 2003). 
Nesse sistema de coordenadas a rosca é estacionária e o barril se move com velocidade:

$$
U=U_{1} e_{1}+U_{3} e_{3}
$$

Sendo a velocidade (U) corresponde a velocidade (U1) desenvolvida ao longo do canal da rosca com valor positivo e (U3) a velocidade transversal, com valor negativo. Portanto, U1 e U3 são obtidos em termos da taxa de rotação da rosca e diâmetro do parafuso, dados pela equação (11) e (12):

$$
\begin{aligned}
& U_{1}=\pi D N \cos \phi \\
& U_{3}=-\pi D N \sin \phi
\end{aligned}
$$

Sendo, $\phi$ é o ângulo de hélice da rosca; $N$ é o número de rotações e $D$ o diâmetro da rosca. Então, considerando o fluxo ao longo do canal da rosca com perfil de velocidade linear e negligenciando o arrasto do núcleo do parafuso e filetes da rosca, uma primeira aproximação para o fluxo rosca/barril é dado pela equação 13:

$$
Q=m\left[\left(\frac{1}{2}\right) \pi H W D N \cos \phi\right]
$$

Uma aproximação mais detalhada considerando a influência das variáveis de projeto da rosca no fluxo, como profundidade de canal, largura e ângulo de hélice sobre características de fluido/material fundido como pressurização é apresentada na equação 14, White e Potente (2003):

$$
Q=\frac{1}{2} \pi^{2} D^{2} N H \cos \phi-\frac{\pi H^{3} D}{12 \eta \rho} \frac{\partial p}{\partial z} \sin ^{2} \phi
$$

Onde, $\rho$ representa a densidade do fluído: 
Dessa equação, outras relações físicas e matemáticas podem ser obtidas como forças de atuação sobre a rosca e filetes, tensões na rosca/filetes; taxa de fluxo ao longo dos canais da rosca, gradiente de pressão e contrafluxo mesmo considerando a hipótese de fluido não newtoniano, as dependências da variação de temperatura e efeitos de não uniformidade que constituem vários aspectos do projeto da rosca de extrusão.

Freitas (2011) desenvolveu o pré-dimensionamento da monorosca do sistema de extrusão do cabeçote. Para o cálculo da geometria da monorosca de extrusão, partiu-se de uma geometria padrão proposta por Rauwendaal, que atende a extrusão básica de vários materiais poliméricos, sendo a mais utilizada comercialmente. Estudando seus parâmetros e levando em consideração as limitações de projeto, como volume de trabalho, peso e taxa de saída de material compatível com prototipagem rápida em máquinas desktop, propõe-se o Roteiro Resumido para projeto de um parafuso/rosca de extrusão:

1) Definição dos parâmetros de projeto;

2) Definição do diâmetro e comprimento do parafuso;

3) Relação L/D em cada seção;

4) Definição da folga radial em cada seção e;

5) Esboço do sistema.

Dados de entrada: Resistência à torção - estática

- Potência do motor $=125 \mathrm{~W}$

- Rendimento $=90 \%$

- Potência aplicada na rosca $=0,1125 \mathrm{~kW}$

- Redução= $1: 0$

- Rotação de entrada na rosca $(n)=60$ rpm

- Torque aplicado na rosca: 20 N.m

a) Restrições de projeto 
- Motor - deve ser de passo, devido ao sistema de controle já instalado e tem limitação de torque (1 N.m)

- Volume do Cabeçote - $70 \times 70 \times 200 \mathrm{~mm}$, que representa o volume para se acoplar cabeçotes na Fab@CTI.

- Peso - Limitado, devido à deflexão das guias que pode tirar a precisão do modelo.

- Resistência mecânica: fratura do parafuso de potência, desgaste dos materiais das peças, instabilidades dinâmicas.

- Processo: Travamento do parafuso, degradação do material de extrusão, corrosão, alimentação não contínua ("empelotamento").

- Dissipação Térmica: para o motor (gera restrição de funcionamento 60응 Celsius), para a peça (causa não solidificação do filamento extrudado), para a máquina (gera dilatação das guias, fusos, problemas com elevação da temperatura em cabos elétricos).

b) Pré-dimensionamento (mecânico)

A Figura 4.3 representa o fluxograma simplificado do dimensionamento da rosca simples de extrusão da impressora 3-D.

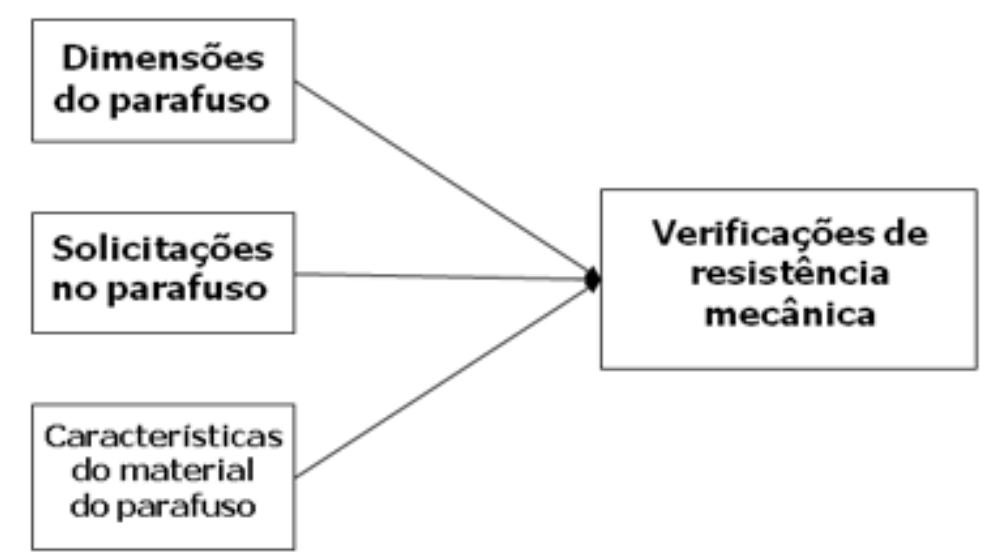

Figura 4.3 - Fluxograma simplificado para cálculo de resistência mecânica no parafuso de extrusão. 
O procedimento para o dimensionamento do conjunto cilindro-rosca de extrusão está baseado em Rauwendaal (2001) e é exposto com mais detalhes em Freitas (2011). Resumidamente, expõe-se o diagrama de cálculo, figura 4.4, que foi construído baseado na metodologia de cálculo que resultou no projeto do dispositivo.

As dimensões do parafuso são obtidas da geometria de rosca padrão Rauwendaal (2001), sendo D o diâmetro da rosca:

- O comprimento total L é de 20 à 30D. Ou seja, sabendo-se o comprimento devido ao volume de trabalho do sistema pode-se inferir um diâmetro.

- O comprimento da seção de alimentação é de 4 à 8D.

- O comprimento da seção de saída é de 6 à 10D.

- O número de filetes paralelos é 1 .

- O passo da rosca tem o mesmo comprimento que o diâmetro da rosca, o que é conhecido como rosca de passo quadrado (square pitch) e resulta num ângulo de hélice de $17,66^{\circ}$.

- A largura do filete é $0,1 \mathrm{D}$

- Profundidade do canal da seção de alimentação é de 0,10 a 0,15D

- A taxa de compressão tem valor de 2 a 4.

Já as solicitações máximas de tensão por tração, compressão e cisalhamento no parafuso são obtidas através do material utilizado, no caso, ao aço inox 304.

O gradiente de pressão é obtido da fórmula $\Delta \mathrm{P}=\frac{\text { Vnec. } 8 \eta}{\pi \cdot\left(\frac{D}{2}\right)^{4}} \cdot \mathrm{z}$ em que z é a distância entre o início da zona de compressão e o fim da zona de saída. 


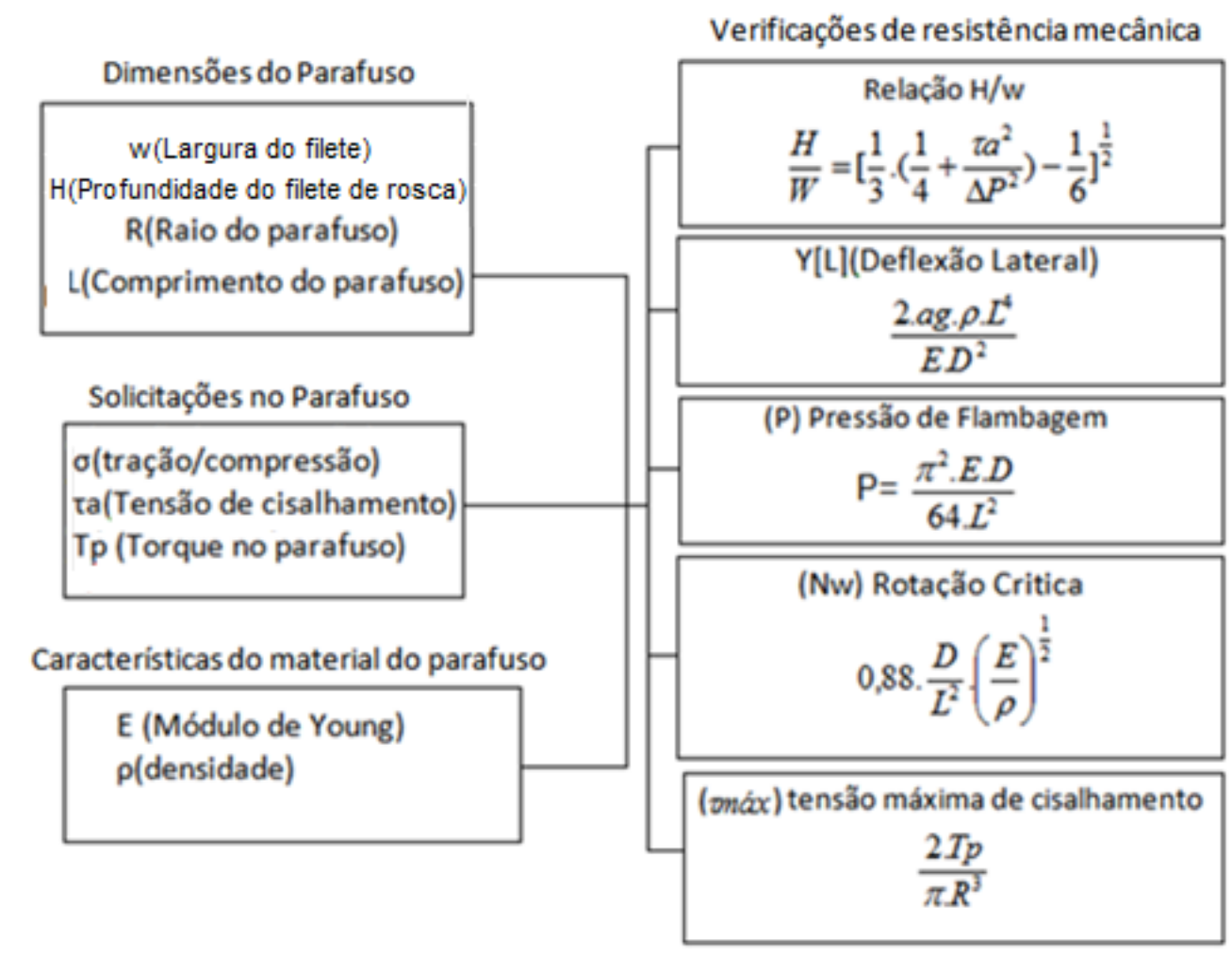

Figura 4.4 - Fluxograma de cálculo para a mono-rosca de extrusão.

Como resultado dos cálculos apresenta-se os valores calculados e os valores utilizados no projeto na tabela 4.1.

Tabela 4.1 - Resumo das principais características do par rosca-barril.

\begin{tabular}{|c|c|c|c|c|c|c|}
\hline & $\begin{array}{c}\text { Resistência } \\
\text { ao } \\
\text { cisalhamento } \\
\text { alimentação }\end{array}$ & $\begin{array}{c}\text { Profundidade } \\
\text { Máxima do } \\
\text { canal de }\end{array}$ & $\begin{array}{c}\text { Relação } \\
\mathrm{H} / \mathrm{w}\end{array}$ & $\begin{array}{c}\text { Deflexão } \\
\text { lateral }\end{array}$ & Flambagem & $\begin{array}{c}\text { Rotação } \\
\text { Crítica }\end{array}$ \\
\hline $\begin{array}{c}\text { Valores } \\
\text { calculados }\end{array}$ & $772,5 \mathrm{MPa}$ & $0,72 \mathrm{~mm}$ & 546,2 & $\begin{array}{c}0,00236 \mathrm{~m} \\
\mathrm{~m}\end{array}$ & $68 \mathrm{MPa}$ & $\begin{array}{c}2536,82 \\
\mathrm{RPM}\end{array}$ \\
\hline $\begin{array}{c}\text { Valores } \\
\text { utilizados }\end{array}$ & $386 \mathrm{MPa}$ & $0,6 \mathrm{~mm}$ & 1 & - & $68 \mathrm{MPa}$ & $60 \mathrm{RPM}$ \\
\hline
\end{tabular}

Considerando-se as dimensões impostas pelo projeto da Fab@CTI, adota-se a dimensão de altura $110 \mathrm{~mm}$, referente ao comprimento do parafuso de extrusão. Utilizando a recomendação do motor NEMA 23, escolheu-se um motor desta categoria e da curva de torque obtêm-se uma rotação de 1200 rpm, para um torque de 1 N.m. Para o pré-dimensionamento do parafuso de 
extrusão em aço AISI 304, foram considerados os seguintes parâmetros e respectivos valores, representados na Tabela 4.2 .

Tabela 4.2 - Parâmetros de projeto, valores adotados e calculados.

\begin{tabular}{|c|c|}
\hline Parâmetros de Projeto & /alores adotados \\
\hline R (Raio da rosca) & $3,5.10^{-3} \mathrm{~m}$ \\
\hline G (Aceleração da gravidade) & $9,81 \mathrm{~m} / \mathrm{s}^{2}$ \\
\hline E (Módulo de Young) & $1,1.10^{5} \mathrm{MPa}$ \\
\hline$\rho$ (Densidade do material) & $4430 \mathrm{~kg} / \mathrm{m}^{3}$ \\
\hline Parâmetros de Projeto & Valores calculados \\
\hline$\sigma$ (Tensão de tração ou compressão) & $1150 \mathrm{MPa}$ \\
\hline$\tau$ (Tensão de cisalhamento) & $772,5 \mathrm{MPa}$ \\
\hline бesc (Tensão de escoamento) & $1030 \mathrm{MPa}$ \\
\hline $\mathrm{T}_{\mathrm{p}}$ (Torque na rosca) & 26 N.m \\
\hline$\Delta \mathrm{p}$ (Gradiente de pressão) & $8,63 \cdot 10^{-4} \mathrm{MPa}$ \\
\hline Y(L) (Deflexão Lateral da rosca) & $2,36 \cdot 10^{-6} \mathrm{~m}$ \\
\hline L (Comprimento da rosca) & $1,1 \cdot 10^{-1} \mathrm{~m}$ \\
\hline $\mathrm{H}_{\max }$ (Profundidade máxima do canal da rosca) & $7,23.10^{-4} \mathrm{~m}$ \\
\hline Hmax (Profundidade máxima do canal de alimentação) & $7,23.10^{-4} \mathrm{~m}$ \\
\hline Razão H/w (Profundidade/canal) & 546,2 \\
\hline Flambagem (devido à tensão de compressão) & $68 \mathrm{MPa}$ \\
\hline Velocidade de rotação crítica & 2536,8 RPM \\
\hline
\end{tabular}

Tanto o procedimento de cálculo quanto os resultados do mesmo e valores adotados são expostos aqui, pois alguns destes valores serão utilizados nas seções posteriores. Uma vez com as dimensões do sistema é proposta o seguinte projeto de cabeçote de extrusão por rosca de seção variável conforme ilustrado na Figura 4.5. 


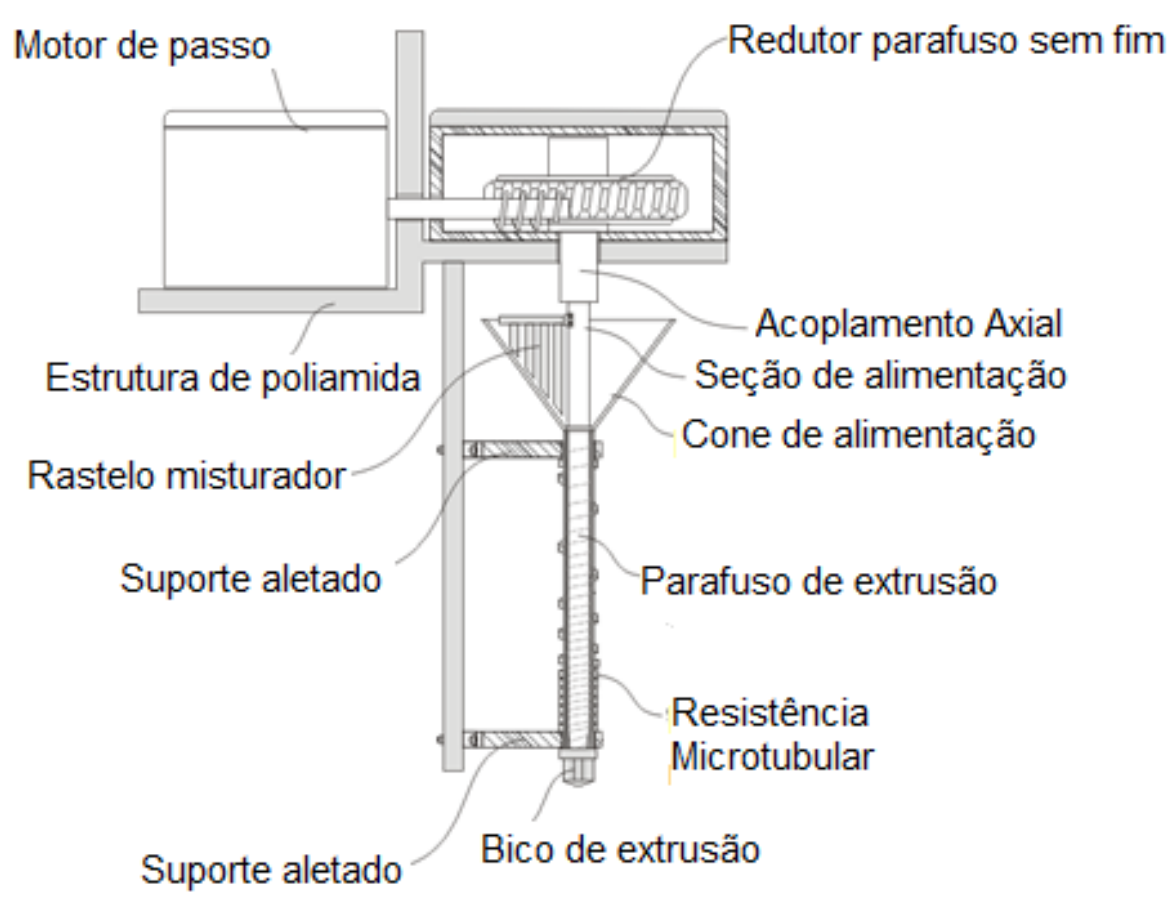

Figura 4.5 - Desenho esquemático dos elementos que compõem o cabeçote de extrusão desenvolvido (autor, 2014).

Com o intuito de entender as relações existentes entre os parâmetros de processo e características geométricas anteriormente citadas foi realizado um estudo anterior ao projeto da rosca de extrusão variando-se os parâmetros de entrada de uma equação empírica e verificando-se uma resposta. Rauwendaal (2001) estabelece esta equação que relaciona a taxa de saída de material (resposta) com os parâmetros geométricos da rosca de extrusão (entrada). Este estudo é apresentado em Freitas (2011), no qual foi gerada uma planilha com variações possíveis com o projeto do cabeçote em específico, com base em um planejamento fatorial $\left(2^{5}\right)$, gerado a partir do programa Optima (Silveira; Cavalca, 2003). Um estudo preditivo parecido foi feito em Liu et al,(2010). 
Tabela 4.3 - Níveis de cada parâmetro dos experimentos.

\begin{tabular}{|c|c|c|c|}
\hline Parâmetros & Mínimo & Intermediário & Máximo \\
\hline $\begin{array}{c}\text { D- Diâmetro da } \\
\text { rosca }(\mathrm{mm})\end{array}$ & 7 & 8,5 & 10 \\
\hline $\begin{array}{c}\text { N- Número de } \\
\text { rotações por } \\
\text { segundo do } \\
\text { parafuso de } \\
\text { extrusão }\left(s^{-1}\right)\end{array}$ & 0,5 & 1,08 & 1,66 \\
\hline $\begin{array}{c}\text { L- comprimento de } \\
\text { derretimento }(\mathrm{mm})\end{array}$ & 64 & 72 & 80 \\
\hline $\begin{array}{c}\text { w- Largura do filete } \\
\text { da rosca(mm) }\end{array}$ & 0,5 & 0,75 & 1 \\
\hline $\begin{array}{c}\text { Xc-Taxa de } \\
\text { compressão }\end{array}$ & 1,5 & 2,25 & 3 \\
\hline
\end{tabular}

As respostas investigadas foram:

Viscosidade do PCL: $\quad \eta: m\left(\frac{\pi D N}{H f}\right)$

Seno do ângulo de hélice $\quad \sin \varphi=\left(\frac{n}{2 n+2}\right)^{\frac{1}{2}}+\hat{w}\left(\frac{n+2}{4 n}\right)$

Velocidade do material $\quad v b=\pi \cdot D \cdot N \cdot \cos \varphi$

Folga na região de saída $\quad H r=\left[\frac{6 m \cdot v b^{n}}{(n+2) g z \cdot \tan \varphi}\right]^{\frac{1}{n+1}}$

Gradiente de pressão

$$
\mathrm{gz}=\frac{\text { Vnec. } 8 \eta}{\pi \cdot\left(\frac{D}{2}\right)^{4}}
$$


$\dot{V}=0,5 \cdot \pi \cdot D \cdot H r \cdot(\pi \cdot D \cdot \operatorname{sen} \varphi \cdot \cos \varphi-p w \cdot \cos \varphi)-\frac{H^{3} \cdot P}{12 \cdot \eta \cdot L} \cdot\left(\pi \cdot D \cdot \operatorname{sen}^{2} \varphi-p w \cdot \operatorname{sen} \varphi\right)$

Tabela 4.4 - Respostas obtidas a partir da combinação dos fatores

de projeto da monorosca.

\begin{tabular}{|c|c|c|c|c|c|c|c|c|c|c|c|}
\hline $\begin{array}{l}\text { № } \\
\text { exp. }\end{array}$ & $\begin{array}{c}\mathrm{D} \\
(\mathrm{mm})\end{array}$ & $\begin{array}{l}\text { Rot/ } \\
\text { seg, }\end{array}$ & $\begin{array}{c}\mathrm{L} \\
(\mathrm{mm})\end{array}$ & $\begin{array}{c}W \\
(\mathrm{~mm})\end{array}$ & Xc & $\begin{array}{c}\eta \\
(\mathrm{Pa} . \mathrm{s})\end{array}$ & $\begin{array}{c}\varphi \\
\text { (Graus) }\end{array}$ & $\begin{array}{c}v b \\
(\mathrm{~m} / \mathrm{s})\end{array}$ & $\begin{array}{l}\mathrm{Hr} \\
(\mathrm{m})\end{array}$ & $\begin{array}{c}\mathrm{Gz} \\
(\mathrm{Pa} / \mathrm{m})\end{array}$ & $\left(m^{\frac{V}{3}} / s\right)$ \\
\hline 1 & 7 & 0,5 & 64 & 0,5 & 1,5 & 78423,58 & 29,01123 & 0,009616 & 0,003985 & 15969666 & $3,06813 \mathrm{E}-07$ \\
\hline 2 & 10 & 0,5 & 64 & 0,5 & 1,5 & 78423,58 & 28,60554 & 0,013791 & 0,010582 & 3834317 & $1,59683 \mathrm{E}-06$ \\
\hline 3 & 7 & 1,66 & 64 & 0,5 & 1,5 & 260366,3 & 29,01123 & 0,031925 & 0,003378 & 53019291 & $2,79829 \mathrm{E}-07$ \\
\hline 4 & 10 & 1,66 & 64 & 0,5 & 1,5 & 260366,3 & 28,60554 & 0,045785 & 0,008971 & 12729932 & $1,47895 \mathrm{E}-06$ \\
\hline 5 & 7 & 0,5 & 80 & 1 & 1,5 & 78423,58 & 30,37531 & 0,009486 & 0,003839 & 15969666 & $3,07142 \mathrm{E}-07$ \\
\hline 6 & 10 & 0,5 & 80 & 1 & 1,5 & 78423,58 & 29,55465 & 0,013664 & 0,010309 & 3834317 & $1,64296 \mathrm{E}-06$ \\
\hline 7 & 7 & 1,66 & 80 & 1 & 1,5 & 260366,3 & 30,37531 & 0,031494 & 0,003255 & 53019291 & $2,75026 \mathrm{E}-07$ \\
\hline 8 & 10 & 1,66 & 80 & 1 & 1,5 & 260366,3 & 29,55465 & 0,045365 & 0,008739 & 12729932 & $1,48795 \mathrm{E}-06$ \\
\hline 9 & 7 & 0,5 & 64 & 0,5 & 1,5 & 78423,58 & 29,01123 & 0,009616 & 0,003985 & 15969666 & $3,06813 \mathrm{E}-07$ \\
\hline 10 & 10 & 0,5 & 64 & 0,5 & 1,5 & 78423,58 & 28,60554 & 0,013791 & 0,010582 & 3834317 & $1,59683 \mathrm{E}-06$ \\
\hline 11 & 7 & 1,66 & 64 & 0,5 & 1,5 & 260366,3 & 29,01123 & 0,031925 & 0,003378 & 53019291 & $2,79829 \mathrm{E}-07$ \\
\hline 12 & 10 & 1,66 & 64 & 0,5 & 1,5 & 260366,3 & 28,60554 & 0,045785 & 0,008971 & 12729932 & $1,47895 \mathrm{E}-06$ \\
\hline 13 & 7 & 0,5 & 80 & 1 & 1,5 & 78423,58 & 30,37531 & 0,009486 & 0,003839 & 15969666 & $3,07142 \mathrm{E}-07$ \\
\hline 14 & 10 & 0,5 & 80 & 1 & 1,5 & 78423,58 & 29,55465 & 0,013664 & 0,010309 & 3834317 & $1,64296 \mathrm{E}-06$ \\
\hline 15 & 7 & 1,66 & 80 & 1 & 1,5 & 260366,3 & 30,37531 & 0,031494 & 0,003255 & 53019291 & $2,75026 \mathrm{E}-07$ \\
\hline 16 & 10 & 1,66 & 80 & 1 & 1,5 & 260366,3 & 29,55465 & 0,045365 & 0,008739 & 12729932 & $1,48795 \mathrm{E}-06$ \\
\hline 17 & 7 & 0,5 & 64 & 0,5 & 3 & 39211,79 & 29,01123 & 0,009616 & 0,005911 & 7984833 & $3,07809 \mathrm{E}-07$ \\
\hline 18 & 10 & 0,5 & 64 & 0,5 & 3 & 39211,79 & 28,60554 & 0,013791 & 0,015696 & 1917158 & $1,43364 \mathrm{E}-06$ \\
\hline 19 & 7 & 1,66 & 64 & 0,5 & 3 & 130183,1 & 29,01123 & 0,031925 & 0,005011 & 26509646 & $3,2534 \mathrm{E}-07$ \\
\hline 20 & 10 & 1,66 & 64 & 0,5 & 3 & 130183,1 & 28,60554 & 0,045785 & 0,013306 & 6364966 & $1,62413 \mathrm{E}-06$ \\
\hline 21 & 7 & 0,5 & 80 & 1 & 3 & 39211,79 & 30,37531 & 0,009486 & 0,005695 & 7984833 & $3,46236 \mathrm{E}-07$ \\
\hline 22 & 10 & 0,5 & 80 & 1 & 3 & 39211,79 & 29,55465 & 0,013664 & 0,015291 & 1917158 & $1,72682 \mathrm{E}-06$ \\
\hline 23 & 7 & 1,66 & 80 & 1 & 3 & 130183,1 & 30,37531 & 0,031494 & 0,004828 & 26509646 & $3,41329 \mathrm{E}-07$ \\
\hline 24 & 10 & 1,66 & 80 & 1 & 3 & 130183,1 & 29,55465 & 0,045365 & 0,012963 & 6364966 & $1,77441 \mathrm{E}-06$ \\
\hline 25 & 7 & 0,5 & 64 & 0,5 & 3 & 39211,79 & 29,01123 & 0,009616 & 0,005911 & 7984833 & $3,07809 \mathrm{E}-07$ \\
\hline 26 & 10 & 0,5 & 64 & 0,5 & 3 & 39211,79 & 28,60554 & 0,013791 & 0,015696 & 1917158 & $1,43364 \mathrm{E}-06$ \\
\hline 27 & 7 & 1,66 & 64 & 0,5 & 3 & 130183,1 & 29,01123 & 0,031925 & 0,005011 & 26509646 & $3,2534 \mathrm{E}-07$ \\
\hline 28 & 10 & 1,66 & 64 & 0,5 & 3 & 130183,1 & 28,60554 & 0,045785 & 0,013306 & 6364966 & $1,62413 \mathrm{E}-06$ \\
\hline 29 & 7 & 0,5 & 80 & 1 & 3 & 39211,79 & 30,37531 & 0,009486 & 0,005695 & 7984833 & $3,46236 \mathrm{E}-07$ \\
\hline 30 & 10 & 0,5 & 80 & 1 & 3 & 39211,79 & 29,55465 & 0,013664 & 0,015291 & 1917158 & $1,72682 \mathrm{E}-06$ \\
\hline 31 & 7 & 1,66 & 80 & 1 & 3 & 130183,1 & 30,37531 & 0,031494 & 0,004828 & 26509646 & $3,41329 \mathrm{E}-07$ \\
\hline 32 & 10 & 1,66 & 80 & 1 & 3 & 130183,1 & 29,55465 & 0,045365 & 0,012963 & 6364966 & $1,77441 \mathrm{E}-06$ \\
\hline
\end{tabular}

Com os níveis definidos e combinados em um arranjo ortogonal, fez-se um programa que calculou os resultados da Tabela 4.4. Analisando-se estes resultados podem-se tirar as seguintes conclusões. 
- Vazão de material $(\dot{V})$ : com os dados da tabela, vê-se que a vazão de material é muito influenciada pelo diâmetro do parafuso, sendo diretamente proporcional.

- Viscosidade do material (n): já a viscosidade teve como fator claro de influência a rotação do parafuso, sendo esses fatores diretamente proporcionais.

- Ângulo de hélice $(\varphi)$ : o ângulo ótimo da hélice da rosca, pouco se alterou com a variação dos experimentos para todos os parâmetros de entrada tendo-se valores de ângulos entre 28,6 e 30,4․

- Gradiente de pressão (gz): o gradiente de pressão ao longo da rosca de extrusão apresentou seus valores mais altos para as combinações de menores diâmetros com maiores rotações.

- Folga do Filete $\mathrm{H}(\mathrm{Hr})$ : apresentou valores ótimos maiores para a combinação de maiores rotações com maiores diâmetros.

Esses resultados obtidos pela variação dos valores de entrada na equação são importantes para prever a influência dos parâmetros de entrada com a resposta. Entretanto, o próprio autor Rauwendaal (2001) aponta que existe grandes variações nos resultados obtidos à partir da equação e num experimento real devido à incertezas como propriedades inconsistentes entre os parâmetros geométricos e físicos dos grãos, atrito entre a rosca e o barril e mudanças incontroláveis dentro do barril $e$ isso pode acarretar em uma qualidade inconsistente no produto final com o aparecimento de degradação térmica, propriedades mecânicas inferiores, instabilidade dimensional, baixo acabamento superficial. Portanto, para uma avaliação mais profunda da qualidade do processo e projeto, a verificação das características do filamento extrudado e protótipos em várias situações, variando-se os parâmetros de processo em método estabelecido como planejamento de experimentos é necessária e este é um dos estudos expostos nesse trabalho.

Outra avaliação importante para verificação do sistema é o aparecimento ou não de degradação térmica. A degradação térmica de polímeros é 
usualmente evidenciada por variações de peso molecular como consequência à exposição ao processamento em alta temperatura e a relevantes cargas mecânicas, Capone et al(2006). No caso em questão os dois mecanismos podem ocorrer sendo importantes a avaliação de degradação um aspecto importante para validação do sistema.

Outro problema que pode ocorrer é o aparecimento de cristas perpendiculares ao filamento extrudado, geralmente repetitivas e onduladas, fenômeno denominado pele de cação ou "sharkskin". Elas ocorrem em um nível de tensão crítica de pelo menos $0,14 \mathrm{MPa}$ para a maioria dos polímeros comuns extrudados através de capilares. Além deste fenômeno, quando em alta taxas de saída de material pode ocorrer a fratura do extrudado. Esta pode ser causada por instabilidade por vortex na entrada de fluxo, instabilidade elástica ao longo do fluxo próximo ao bico, fenômeno de deslizamento/travamento ou vários desses mecanismos ocorrendo ao mesmo tempo (Vlachopoulos et al, 2003)

Esta última seção apresentada tem o papel de inteirar e contextualizar o projeto em estudo com seus aspectos técnicos, cálculos de dimensionamento e possíveis problemas a ocorrer e serve como motivação para o estudo térmico e DOE, estudos estes feitos para ampliar o entendimento do funcionamento do sistema projetado, suas capacidades e limitações.

\section{2 - Cálculo do sistema de redução}

\subsubsection{Cálculo do torque no motor}

Para o cálculo do torque necessário para extrusão, foram levados em consideração ensaios de reometria com o material $\mathrm{PCL}$, que dentre os materiais preliminares elegidos para serem utilizados no cabeçote, é o que apresenta maior viscosidade e exige maior torque, sendo assim o mais crítico para os cálculos.

Considerou-se o fluxograma representado pela Figura 4.6. 


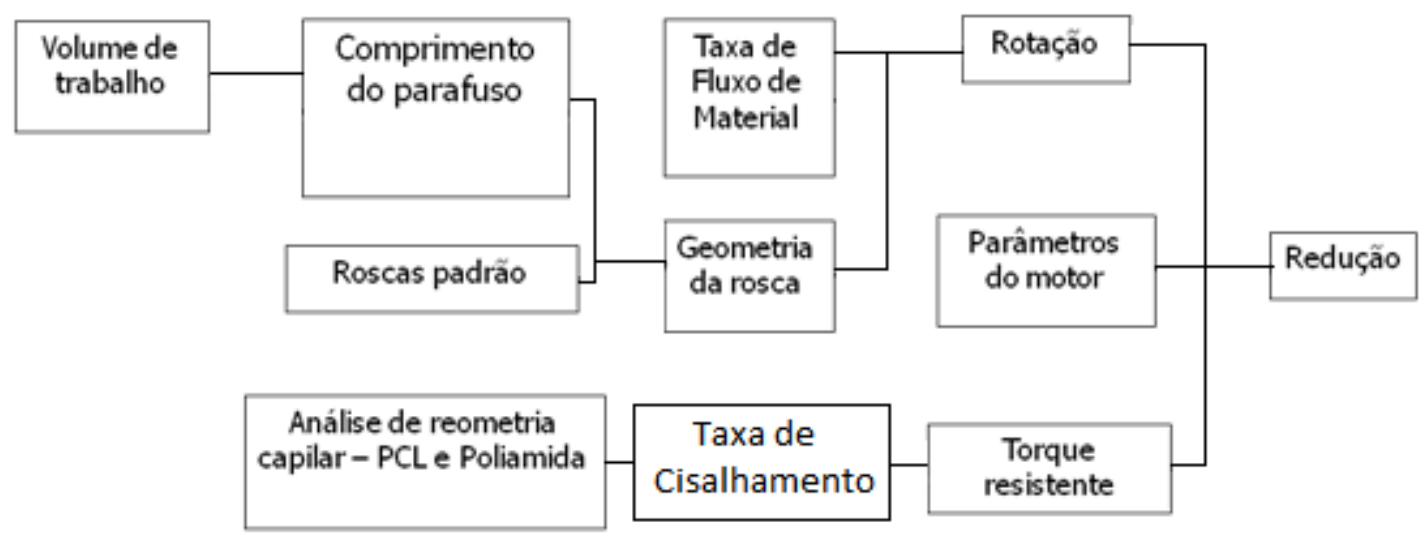

Figura 4.6 - Fluxograma para o cálculo do torque do motor, considerando a poliamida.

Os cálculos detalhados para levantamento de requisitos técnicos do redutor podem ser consultados em Freitas (2011).

Com estes cálculos, verificou-se que deve ser introduzido um redutor de velocidades acoplado ao motor. Este redutor deve ter redução de 1:20 para alcançar-se a faixa de rotações e torque desejados. Após a montagem e funcionamento do projeto verificou-se que esta primeira solução de redutor (coroa/parafuso-sem-fim) apesar de ter possibilitado o funcionamento e ter tido êxito nas primeiras validações com diferentes materiais de extrusão, apresentou o inconveniente de adicionar alto peso e inércia ao sistema o que afeta claramente a qualidade de deposição e precisão da máquina. Na seção 12 deste trabalho são expostas propostas de melhorias para redução de peso do cabeçote em estudo e são estudados possíveis redutores que ao serem utilizados reduziriam o peso total do sistema.

\subsection{Analise térmica do cabeçote de extrusão}

O processo de transferência térmica é dividido em três mecanismos: condução, convecção e radiação (Incropera e Dewitt, 2007). Durante o aquecimento do cabeçote de extrusão, estes três processos ocorrem conforme descrito na Figura 4.7 


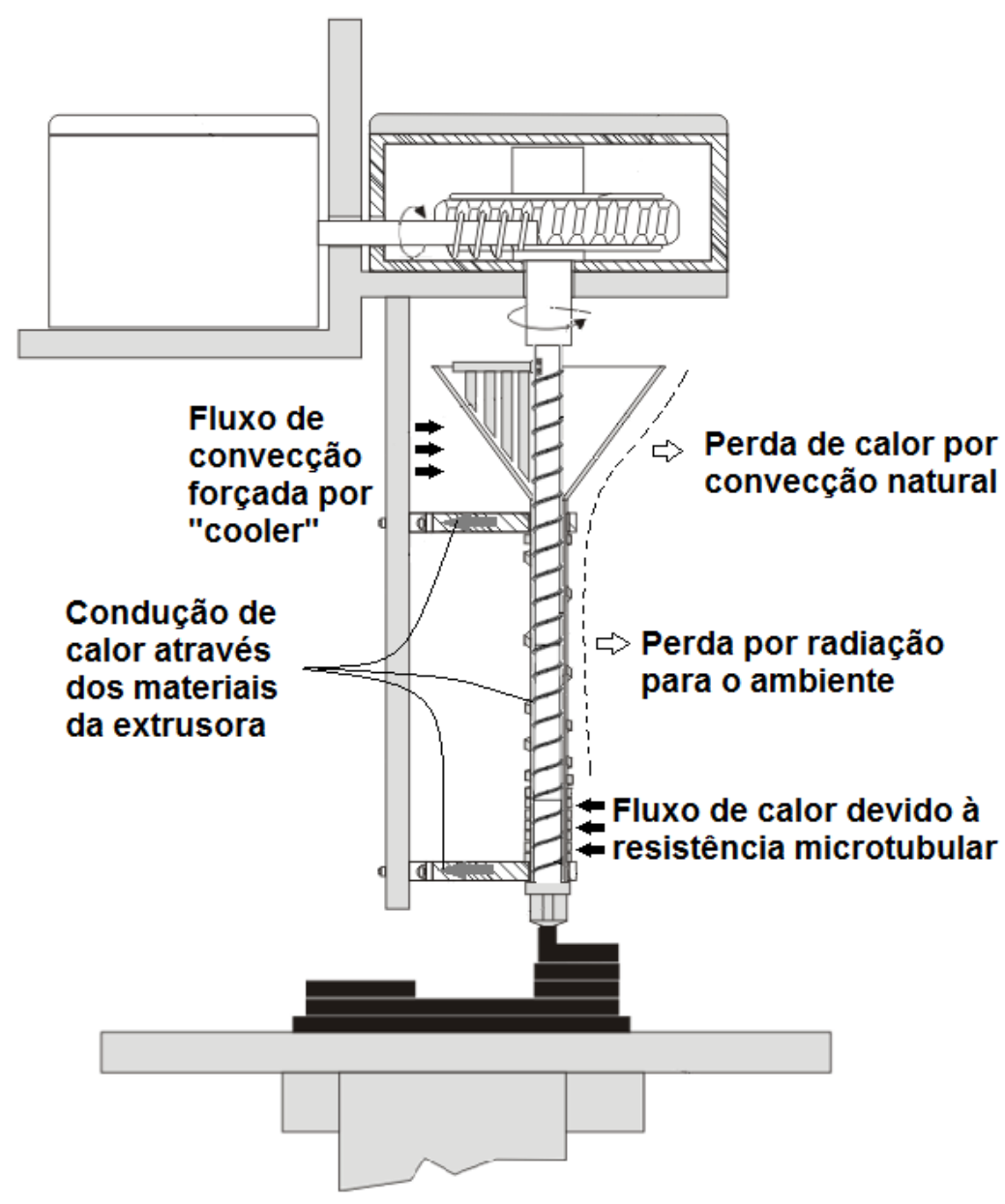

Figura 4.7 - Esquema dos modos de transferência de calor no projeto do cabeçote projetado.

A condução é um processo de transferência de energia que ocorre a partir da partícula mais energética para a menos energética devido às interações entre partículas. Na presença de gradientes de temperatura, como ocorre no caso da distribuição de temperaturas ao longo do corpo de extrusão, a condução ocorre na direção das temperaturas mais baixas.

Para a condução de calor, a equação de fluxo é conhecida como lei de Fourier. A equação unidimensional pode ser expressa de acordo com a equação (20):

$$
q_{x}^{\prime \prime}=-k \frac{d T}{d x}
$$


Em que $q_{x}^{\prime \prime}\left(W / m^{2}\right)$ é o fluxo de calor na direção $\mathrm{x}$ por unidade de área perpendicular, $\mathrm{k}\left(\frac{W}{m . K}\right)$ é o coeficiente de condução de calor, $\mathrm{dT} / \mathrm{dx}$ é o gradiente de temperatura.

Para o caso em estudo, os maiores gradientes de temperatura ocorrem ao longo do corpo de extrusão, também denominado barril de extrusão e também através do dissipador de calor sendo que, em ambos os casos, a análise de elementos finitos permitiu visualizar como ocorreram essas distribuições de temperatura.

A convecção é outro mecanismo de transferência de calor que ocorre neste caso. De acordo com Incropera e Dewitt (2007), a convecção é baseada de dois mecanismos. Além da energia de transferência devido ao movimento molecular (difusão), energia também é transferida pelo movimento macroscópico do fluído. Independente da natureza particular do processo de transferência por convecção, o fluxo de calor é dado pela equação (21);

$$
q^{\prime \prime}=h \cdot\left(T_{s}-T_{\infty}\right)
$$

Em que, $q$ ", o fluxo de calor convectivo $\left(W / \mathrm{m}^{2}\right)$, é proporcional à diferença entre as temperaturas da superfície e do fluído, $T_{S}$ and $T_{\infty}$, respectivamente. Essa expressão é conhecida como Lei de Newton para o resfriamento, e o parâmetro $\mathrm{h}\left(\frac{W}{m^{2}} . K\right)$, é o coeficiente de transferência de calor por convecção. Para o presente trabalho, a convecção ocorre durante todo o processo através da retirada de calor pelo ar ao redor do cabeçote de extrusão, havendo convecção forçada gerada por cooler $(40 \times 40 \mathrm{~mm})$ com coeficiente de convecção $17,5 \frac{\mathrm{W}}{\mathrm{m} \cdot \mathrm{K}}$. Também este é o principal mecanismo de retirada de calor, a convecção, sendo o calor gerado pelo termo resistência microtubular ao redor do barril de extrusão.

Outro mecanismo de troca de calor que atua no processo de extrusão é a radiação térmica, definida como a energia emitida por qualquer matéria que 
tem temperatura diferente de zero. Desprezando a forma da matéria, a emissão pode ser atribuída à mudança das configurações dos elétrons dos átomos ou moléculas constituintes. A energia do campo de radiação é transportada pelas ondas eletromagnéticas, ao contrário do caso de condução e convecção em que há a necessidade de um meio material. Existe um limite superior para a energia emissiva, que é representado pela lei de Stefan-Boltzmann dada pela equação (22):

$$
E_{b}=\sigma \cdot T_{s}^{4}
$$

sendo, $T_{S}$ é a temperatura absoluta $(\mathrm{K})$ da superfície e $\sigma$ é a constante de Stefan-Boltzmann $\sigma=5,67 \times 10^{-8} \mathrm{~W} / \mathrm{m}^{2} . K^{4}$. Esta superfície é chamada de irradiador ideal ou corpo negro.

O fluxo de calor emitido pela superfície real é menor que em um corpo negro na mesma temperatura e é dado pela equação (23):

$$
E=\varepsilon \sigma T_{s}^{4}
$$

sendo $\varepsilon$ a propriedade radiotiva da superfície chamada emissividade e esta tem valores entre $0 \leq \varepsilon \leq 1$. Essa propriedade mostra o quão é eficiente a emissão de energia relativamente à um corpo negro. A radiação pode também ser incidente sobre a superfície provinda do ambiente. Para as emissividades das superfícies metálicas para o dispositivo foram adotadas o valor 1 . Para o caso em estudo, o efeito da radiação ocorre principalmente por perda de energia do corpo aquecido, ou seja, o corpo do cabeçote de extrusão aquecido irradia calor para o ambiente.

O software Ansys ${ }^{\circledR}$ Transient Thermal versão 14 foi usado para as simulações térmicas computacionais com intuito de verificar os gradientes de temperatura ao longo do processo de aquecimento e eficiência do sistema de dissipação de calor com cooler e suporte/dissipador aletado. 
Um problema encontrado no projeto desse dispositivo é relacionado com o calor produzido pela termo-resistência ao redor do barril de extrusão, figura 4.8. O fluxo de calor tende a fluir através do suporte do barril. Quando este é conduzido à estrutura do cabeçote, isso pode não apenas causar o amolecimento do material da estrutura, no caso Nylon $12 \mathrm{PA} \circledast$, como também a dilatação de partes móveis como rolamentos lineares e componentes mecânicos como guias, e fusos ou o mal funcionamento das conexões elétricas.

Nesta seção é estudada a solução da dissipação térmica na direção da parte traseira e superior do barril do cabeçote de extrusão. É proposto o uso de um suporte aletado cuja principal característica é não apenas a dissipação térmica por condução, mas também a perda de calor por convecção forçada para o ambiente gerando um gradiente térmico de perda de calor entre a parte frontal e traseira do suporte aletado. As simulações térmicas por elementos finitos foram realizadas com intuito de predizer a distribuição de temperatura no sistema e testar possibilidades de material e número de aletas nos suportes. Com o objetivo de verificar a predição dada pela análise numérica, um experimento foi conduzido através da medição de pontos do cabeçote com um termopar tipo $\mathrm{J}$ encontrando-se um valor de temperatura que corrobora com as simulações realizadas previamente.

Para a definição de parâmetros de maior importância para a análise numérica, inicialmente, foram levantados quais materiais e processos poderiam ser utilizados para a fabricação dos suportes aletados. Foi considerado o uso de peças de Ti6Al4V devido à disponibilidade de processo de MA do tipo DMLS (Direct Metal Laser Sintering). Outro material escolhido para a simulação foi liga de alumínio devido a possibilidade de fabricação da mesma por usinagem.

Uma vez com os materiais escolhidos, foram feitos quatro modelos $C A D$ e na simulação os seguintes parâmetros foram variados: materiais e quantidade de aletas. No pré-processamento da análise numérica, a temperatura final da resistência microtubular foi definida em $220^{\circ} \mathrm{C}$, pois boa 
parte dos termoplásticos processados tem temperatura de fusão abaixo deste valor, sendo o ABS, um dos materiais que são processados nesta temperatura.

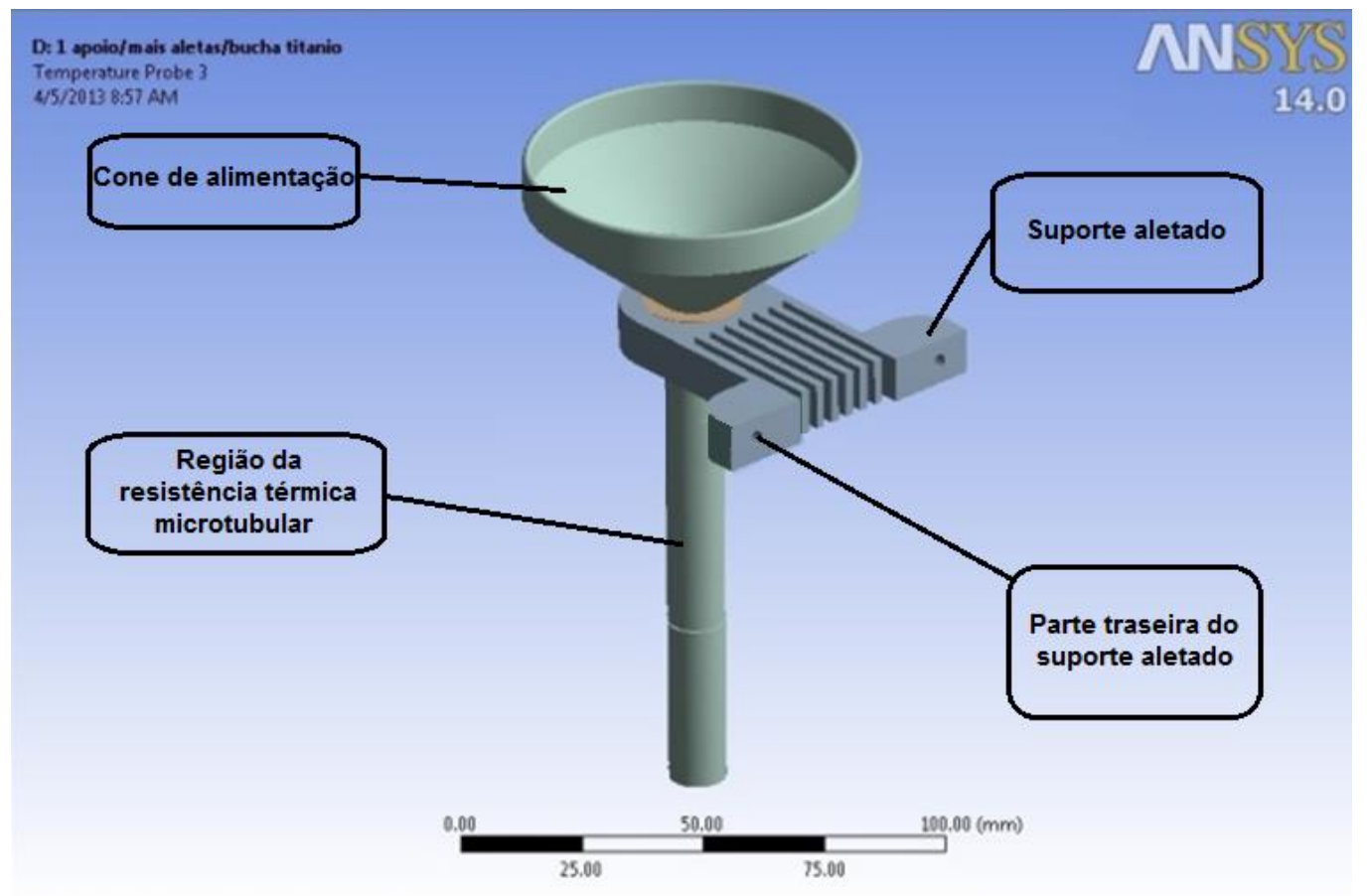

Figura 4.8 - Modelo geométrico do conjunto rosca-barril e silo do cabeçote de extrusão, com os suportes aletados.

A estrutura do cabeçote é feita de Nylon 12 PA que apresenta ponto de fusão à $180^{\circ} \mathrm{C}$, entretanto é necessária uma temperatura de interface do suporte com a estrutura, menor que $95^{\circ} \mathrm{C} \mathrm{com}$ a qual o material apresenta amolecimento sobre uma carga de 1,82 $\mathrm{MPa}$ [3D Systems]. As simulações também têm o objetivo de verificar se o "cooler" utilizado tem a capacidade de refrigerar o suporte aletado no sentido de criar uma queda de temperatura no suporte na qual $220^{\circ} \mathrm{C}$ gerados pela resistência cai para a menor temperatura possível na parte traseira do suporte aletado, sendo a distância da região da resistência até a parte traseira de apenas 40 milímetros.

As propriedades dos materiais usados nas simulações são apresentadas na tabela 4.5. 
Tabela 4.5 - Propriedades dos materiais nas simulações.

\begin{tabular}{|l|c|c|c|}
\hline \multicolumn{1}{|c|}{ Material } & $\begin{array}{c}\text { Densidade } \\
\left(\mathrm{kg} / \mathrm{m}^{3}\right)\end{array}$ & $\begin{array}{c}\text { Condutividade } \\
\text { térmica isotrópica } \\
(\mathrm{W} / \mathrm{m} . \mathrm{K})\end{array}$ & $\begin{array}{c}\text { Capacidade } \\
\text { térmica } \\
(\mathrm{J} / \mathrm{kg} . \mathrm{K})\end{array}$ \\
\hline $\begin{array}{l}\text { Liga de Alumínio } \\
6351\end{array}$ & 2510 & 184,21 & 879,2 \\
\hline Aço Inox 304 & 7750 & 15,1 & 480 \\
\hline Ti-6Al-4V & 4430 & 6,7 & 526,3 \\
\hline
\end{tabular}

O arranjo de simulações com 6 aletas é apresentado na tabela 4.6.

Tabela 4.6 - Dados da simulação.

\begin{tabular}{|c|c|c|c|c|}
\hline Simulação & $\begin{array}{c}\text { Material do } \\
\text { suporte } \\
\text { aletado }\end{array}$ & $\begin{array}{c}\text { Número de } \\
\text { suportes } \\
\text { aletados }\end{array}$ & $\begin{array}{c}\text { Número de } \\
\text { elementos }\end{array}$ & $\begin{array}{c}\text { Número de } \\
\text { nós }\end{array}$ \\
\hline 1 & Ti-6Al-4V & 2 & 88651 & 155398 \\
\hline 2 & Ti-6Al-4V & 1 & 67079 & 118304 \\
\hline 3 & $\begin{array}{c}\text { Liga de } \\
\text { Alumínio 6351 }\end{array}$ & 2 & 31717 & 63269 \\
\hline 4 & $\begin{array}{c}\text { Liga de } \\
\text { Aluminio 6351 }\end{array}$ & 1 & 66970 & 118122 \\
\hline
\end{tabular}

As condições de contorno das simulações são apresentadas na tabela 4.7.

O efeito da transferência de calor que ocorre devido ao polímero fundido fluindo dentro da extrusora é desprezado nessa simulação. $O$ atrito do polímero com a rosca e as paredes do barril, em geral, faz com que haja um aumento da temperatura no sistema. No caso, este aumento pode ser considerável ou não, fazendo parte da pesquisa a comparação dos dados numéricos e experimentais para verificação do grau de influência deste fator. 
Tabela 4.7: Condições de contorno para as simulações numéricas

\begin{tabular}{|c|c|c|}
\hline $\begin{array}{c}\text { Número de suportes } \\
\text { aletados }\end{array}$ & 2 ou 1 & - \\
\hline Número de aletas & 6 ou 3 & $\left(\frac{W}{\mathrm{~m}^{2} / K}\right)$ \\
\hline $\begin{array}{c}\text { Coeficiente de convecção } \\
\text { gerado pelo cooler }\end{array}$ & 17,25 & $\stackrel{\circ}{ } \mathrm{s}$ \\
\hline Temperatura ambiente & 22 & $\stackrel{\circ}{ } \mathrm{C}$ \\
\hline Tempo total de simulação & 1400 & - \\
\hline $\begin{array}{c}\text { Temperatura provida pela } \\
\text { resistência tubular na } \\
\text { região aquecida }\end{array}$ & 220 & - \\
\hline $\begin{array}{c}\text { Emissividade para todos } \\
\text { os metais }\end{array}$ & 70 & \\
\hline Número de "time steps" & 1 & \\
\hline
\end{tabular}

A malha foi gerada por controle automático do ANSYS R14 $\AA$, no qual o programa determina a melhor maneira de distribuir, sendo definidos alguns parâmetros como tamanho dos elementos. A Figura 4.9 exemplifica alguns tipos de elementos utilizados em programas de elementos finitos. Para a análise térmica foi escolhido o elemento tridimensional Tetraedro, com 4 nós. Esse elemento foi escolhido pelo próprio programa Ansys ${ }^{\circledR}$. Para uma análise mais detalhada, com validação experimental elementos bidimensionais, podem apresentar um resultado mais preciso da variação do campo de temperatura.

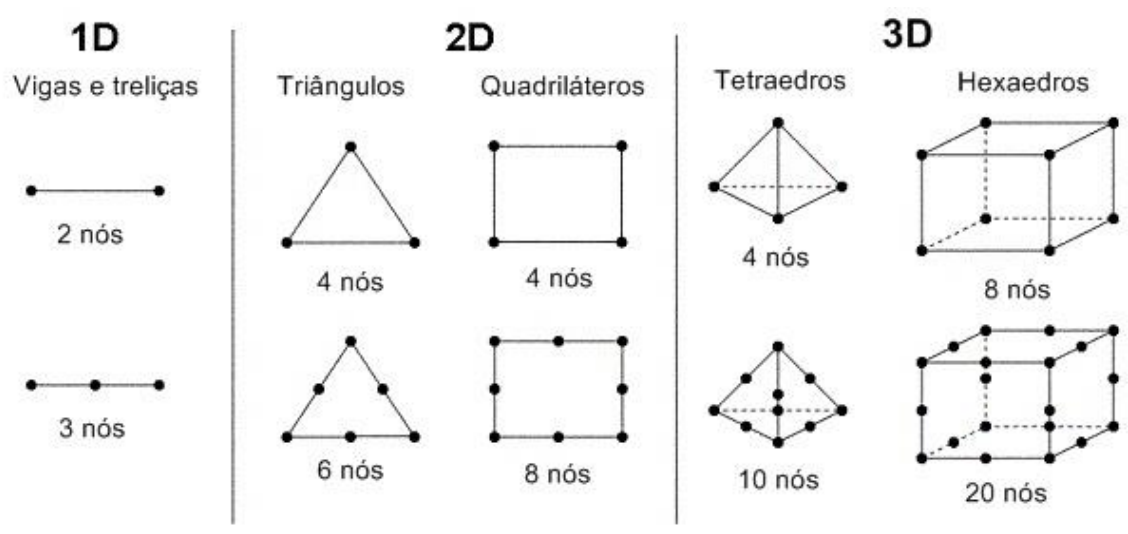

Figura 4.9 - Tipos de elementos contidos em biblioteca de programas de FEM (Adaptado: Azevedo, 2014).

O fluxograma apresentado na Figura 4.10 descreve, as etapas desde o modelamento geométrico até a análise térmica. 


\section{Modelo geométrico (CAD)}

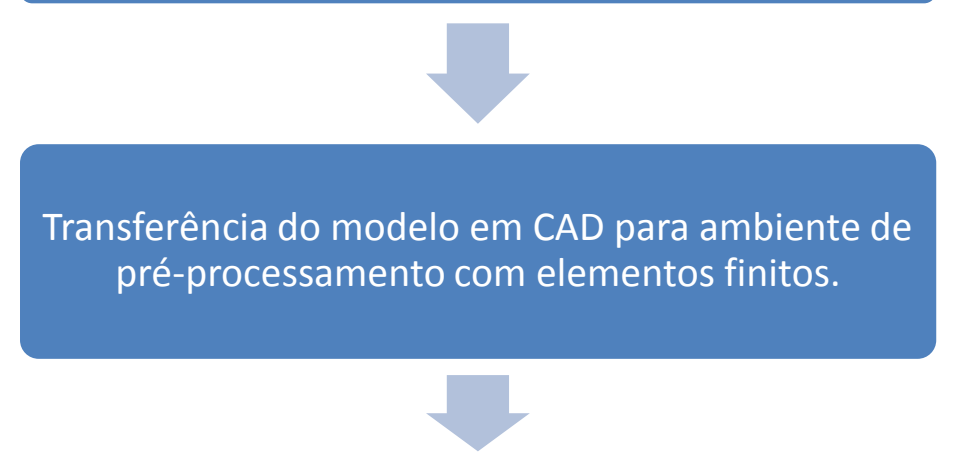

Definição dos materiais utilizados e caracteristicas dos mesmos (ex.: densidade,calor específico, etc)

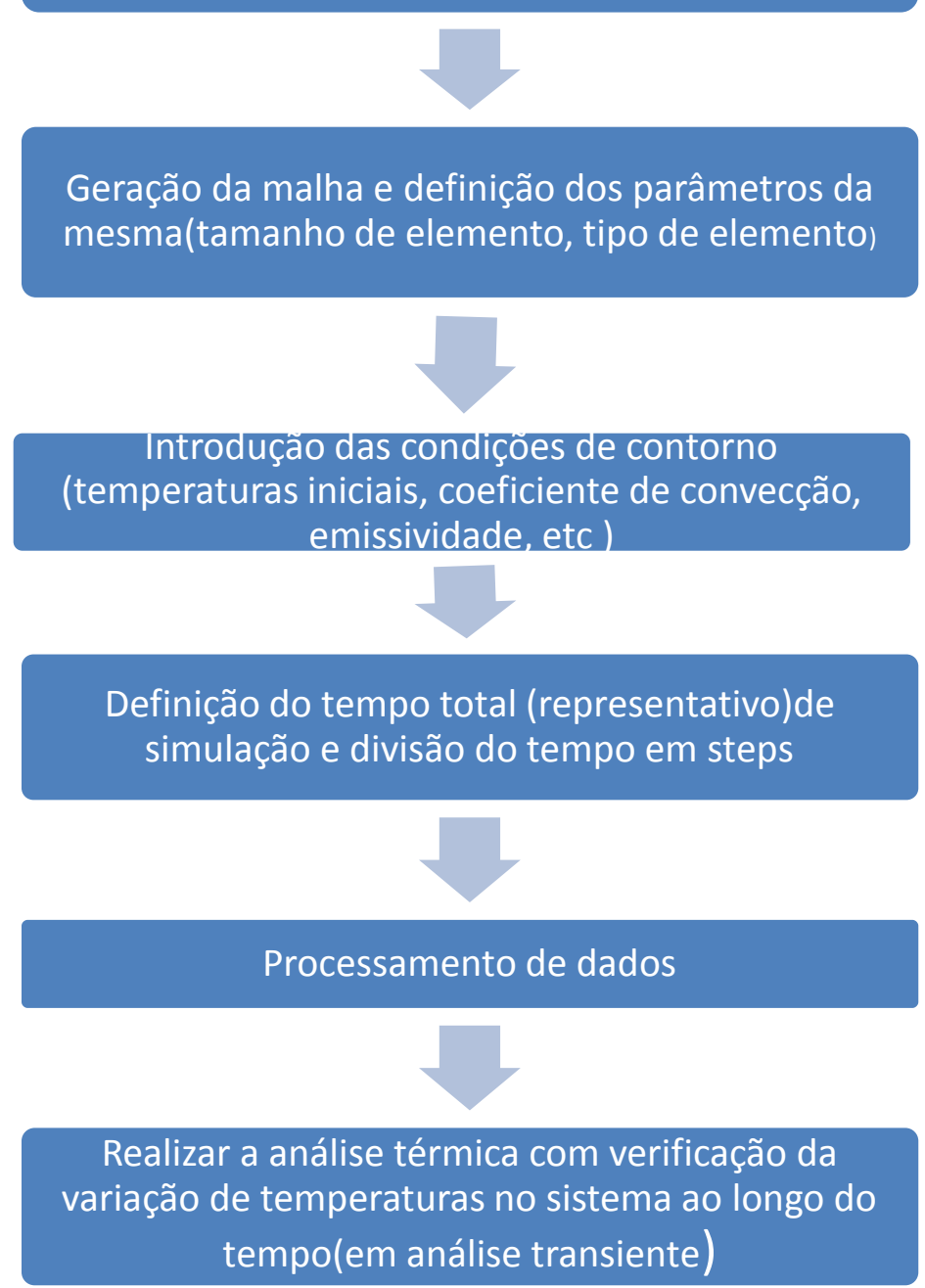

Figura 4.10 - Etapas realizadas para a análise térmica utilizando o programa Ansys $\AA^{\circledR}$ R.14. 


\subsection{Validação experimental da analise térmica e discussões dos resultados}

Um termopar tipo "J" controlado por um controlador de temperaturas Watlow. Um suporte aletado (Figura 5.2) foi fabricado pelo processo DLMS e um experimento foi estruturado com as mesmas condições da simulação 2 , uma vez que será mostrado que esta simulação apresentou resultados satisfatórios, os melhores, em relação à temperatura atingida na parte traseira do dissipador. Montado à máquina desktop de impressão 3D Fab@CTI foi realizado o teste de aquecimento do cabeçote de extrusão utilizando dois termopares tipo "J" acoplado na parte traseira do suporte aletado, para coletar as temperaturas conforme apresentado na Figura 5.2.
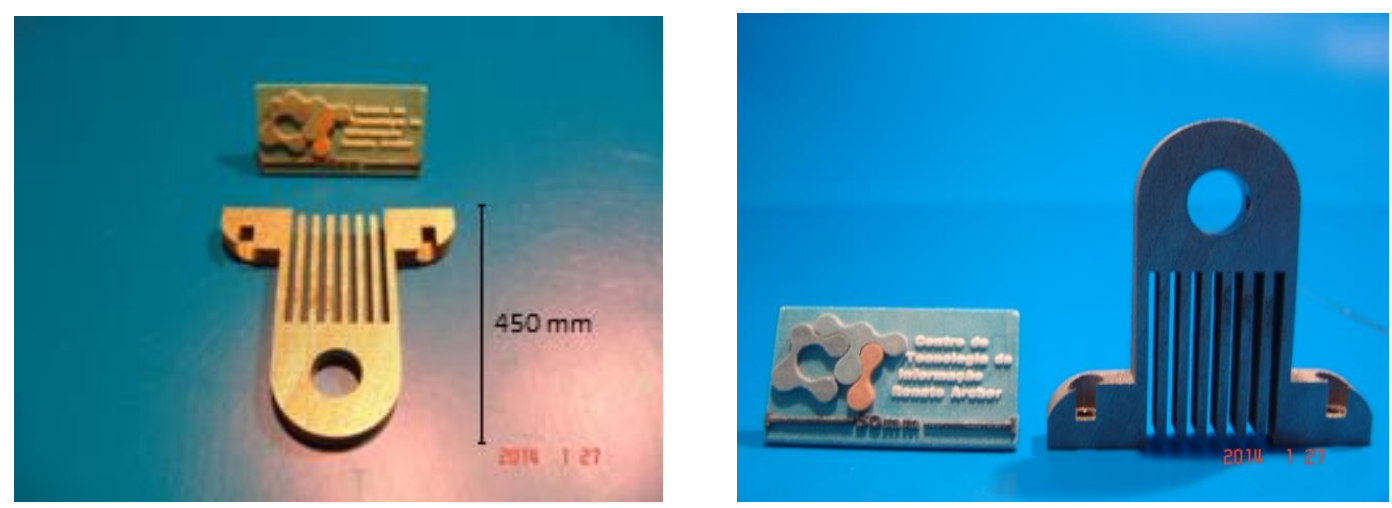

Figura 5.1 - Suporte aletado construído em tecnologia DMLS.

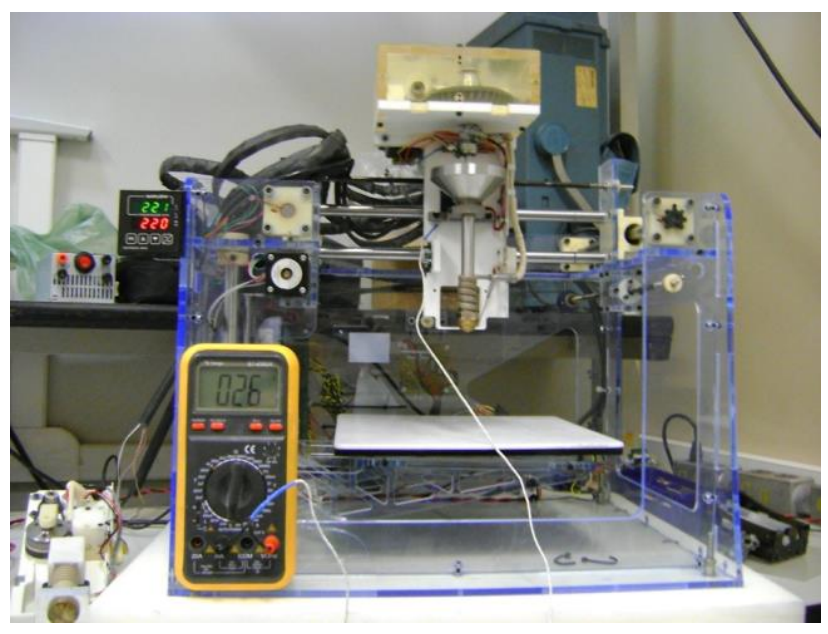

Figura 5.2 -Teste de aquecimento realizado com o cabeçote de extrusão. 
Outro experimento foi realizado com a introdução de material termoplástico Nylon na forma de pó, grão de tamanho $58 \mu \mathrm{m}$ [3D systems], e foi testada a extrusão deste material à quente para verificar a capacidade de geração de filamentos contínuos e peças utilizando o suporte aletado e sistema de refrigeração propostos. A temperatura de extrusão do Nylon foi de $180^{\circ} \mathrm{C}$.

Quatro análises térmicas foram realizadas e a distribuição de temperaturas no regime permanente é mostrada na figura 6.1.

a)

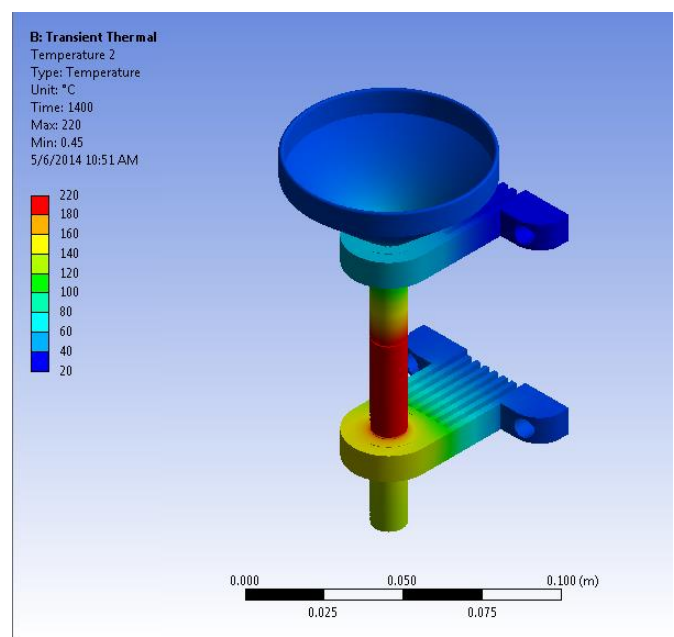

c)

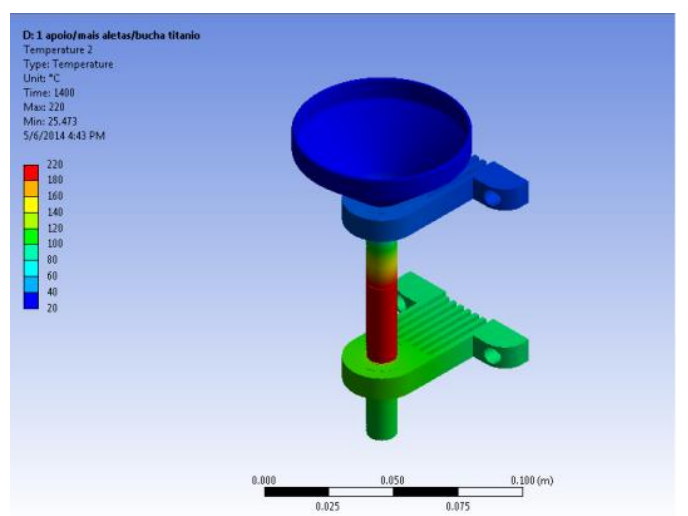

b)

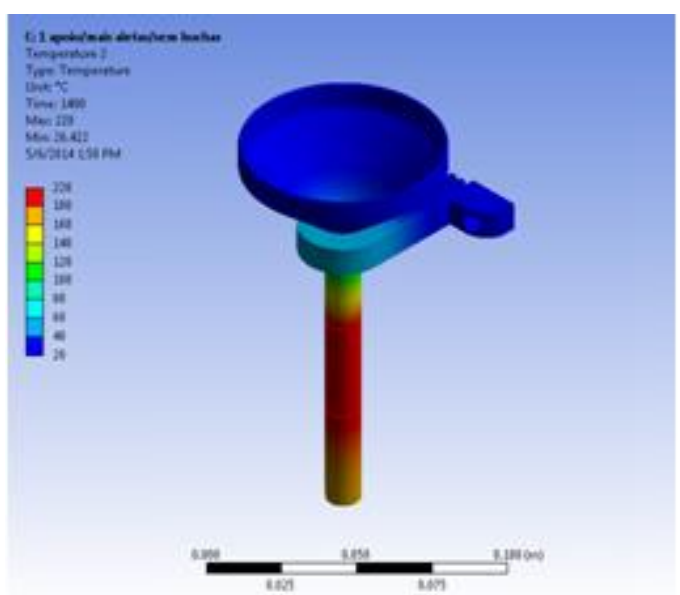

d)

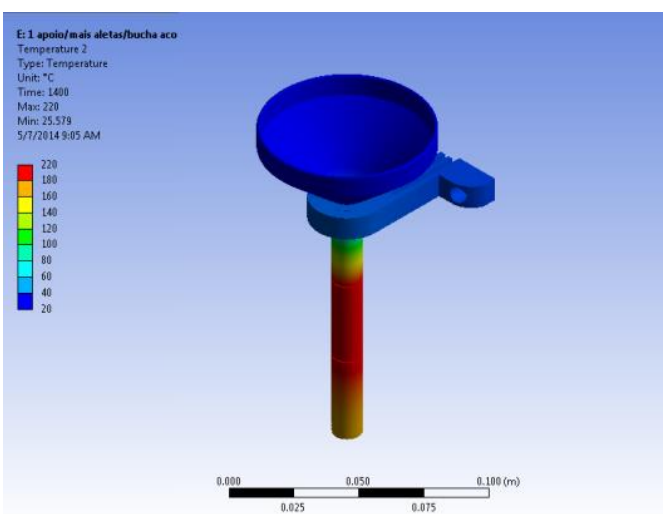

Figura 6.1 - a) Simulação 1 b) Simulação 2 c) Simulação 3 d) Simulação 4

Um resultado interessante é que nenhuma das simulações apresentou altas temperaturas na região cônica de alimentação o que é um bom indicativo 61 
de que o material em pó não irá derreter antes da zona de compressão. Como esperado, a inseração de um segundo suporte aletado, abaixo da resistência térmica (zona em vermelho), na simulação extrai calor do barril de extrusão gerando um gradiente de temperatura decrescente mais forte na direção da saída de material. Além disso, quando o suporte é feito de liga de alumínio, essa extração de calor é mais intensa, causando uma forte queda de temperatura na saída de material, ou seja, a parte mais baixa do barril. Com o intuito de verificar o crescimento de temperatura ao longo do processo de aquecimento, os valores máximos, mínimos e prova 1 e 2(que são as temperaturas nas partes traseiras dos dissipadores inferior e superior, respectivamente) das 4 simulações foram obtidos os gráficos apresentados na Figura $6.2(a)$ até $(d)$.

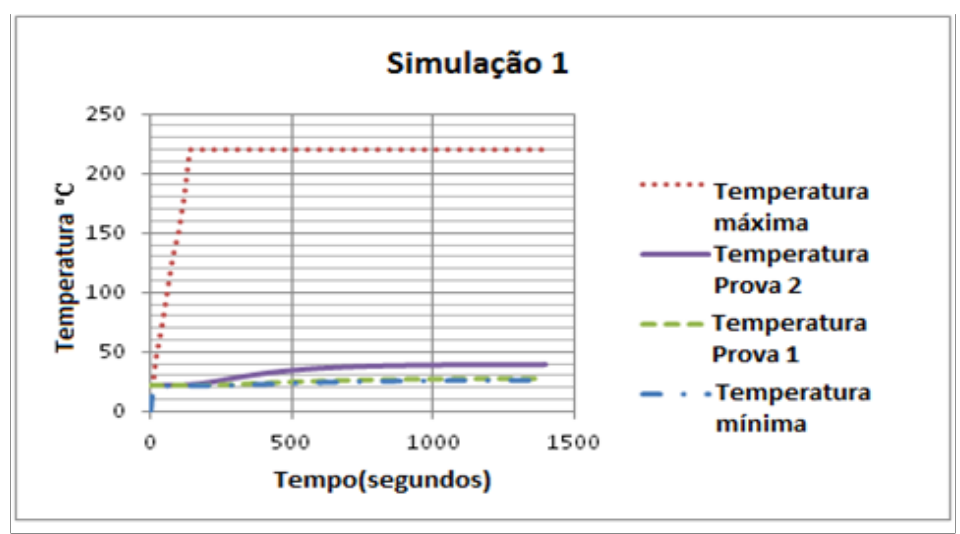

(a)

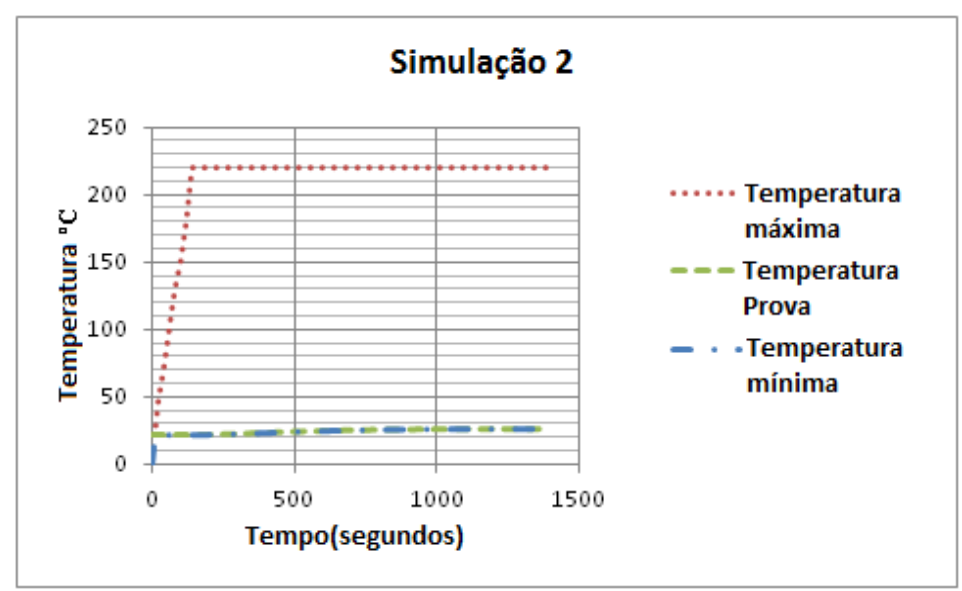

(b) 


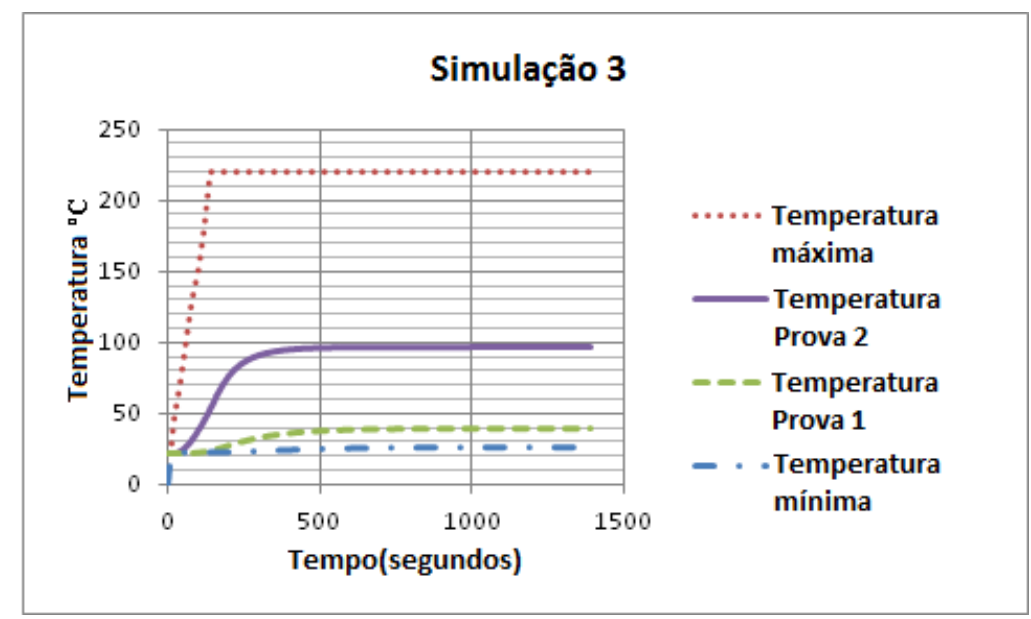

(c)

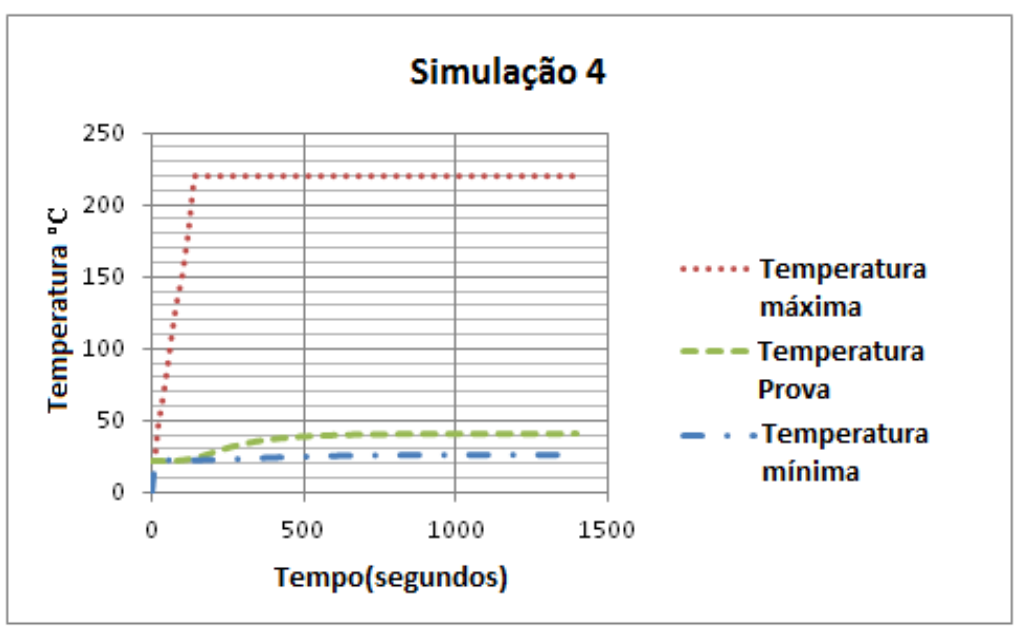

(d)

Figura 6.2 (a); (b); (c); (d): Temperaturas ao longo do tempo nas simulações numéricas

Em todas as simulações as temperaturas máximas representam a temperatura na resistência térmica que é a fonte de energia no sistema. $\mathrm{Na}$ simulação 1 , pode ser visto que a temperatura de prova 1 e 2 são $27,17^{\circ} \mathrm{C}$ e $39,5^{\circ} \mathrm{C}$, respectivamente, que podem ser consideradas temperaturas aceitáveis no que diz respeito à integridade do material da estrutura. Analisando a simulação 2 , pode ser observado que a temperatura de prova é muito próxima da temperatura mínima, 27,27ํㅡ. Esse resultado usando material de liga de titânio Ti-6Al-4V é satisfatório, uma vez que em ambas as condições de projeto as temperaturas alcançadas nos pontos de interesse são baixos. 
Com a simulação em liga de alumínio 6352, temperaturas mais altas foram registradas nas regiões de interesse. Na simulação 3, a temperatura mais alta registrada foi $96,4^{\circ} \mathrm{C}$ que é considerada uma temperatura perigosa, uma vez que uma temperatura de $95^{\circ} \mathrm{C}$ causa um amolecimento do material Nylon 12 PA usado na estrutura. A temperatura de prova 1, no suporte aletado superior, alcançou $40,14^{\circ} \mathrm{C}$ revelando uma possível flexibilidade de decisão de projeto quando se utiliza apenas um suporte, podendo-se escolher tanto a liga de titânio, feita em processo de MA, DMLS, quanto a de alumínio usinado. A simulação 2 foi escolhida para ser testada experimentalmente, pois não apenas apresentou baixa temperatura na região crítica, mas também, com a utilização de apenas um suporte, há uma redução de peso, e caso o cabeçote funcione nesta condição é desnecessário a introdução do segundo suporte inferior.

$\mathrm{Na}$ tabela 6.1, são expostas todas as temperaturas no regime permanente e tempos necessários para alcançar estas condições.

Tabela 6.1: Temperaturas no regime permanente e tempos até atingir o regime permanente.

\begin{tabular}{|l|c|c|c|}
\hline & $\begin{array}{c}\text { Temperatura } \\
\text { Prova 1 }\end{array}$ & $\begin{array}{c}\text { Temperatura } \\
\text { Prova 2 }\end{array}$ & $\begin{array}{c}\text { Tempo para } \\
\text { atingir o regime } \\
\text { permanente }\end{array}$ \\
\hline Simulação 1 & $27,18^{\circ} \mathrm{C}$ & $39,55^{\circ} \mathrm{C}$ & $750 \mathrm{~s}$ \\
\hline Simulação 2 & $27,28^{\circ} \mathrm{C}$ & - & $840 \mathrm{~s}$ \\
\hline Simulação 3 & $36,70^{\circ} \mathrm{C}$ & $96,40^{\circ} \mathrm{C}$ & $850 \mathrm{~s}$ \\
\hline Simulação 4 & $40,14^{\circ} \mathrm{C}$ & - & $800 \mathrm{~s}$ \\
\hline
\end{tabular}

O resultado da medição com o termopar mostra que a temperatura em regime permanente na região da parte traseira do suporte aletado é de $27^{\circ} \mathrm{C}$, figura 6.3. Essa temperatura é muito próxima da encontrada na simulação 2, $27,18^{\circ} \mathrm{C}$. Este resultado é considerado satisfatório para a simulação e experimento uma vez que mesmo com a resistência em uma temperatura de $220^{\circ} \mathrm{C}$ na região da resistência no barril de extrusão, a região crítica e de interesse praticamente não apresentou aquecimento. 
Com os dados coletados foi plotado um gráfico de aquecimento para 0 termopar. No regime permanente também foram medida a temperatura no bico de extrusão $189^{\circ} \mathrm{C}$.

\section{Temperatura na parte traseira do suporte aletado}

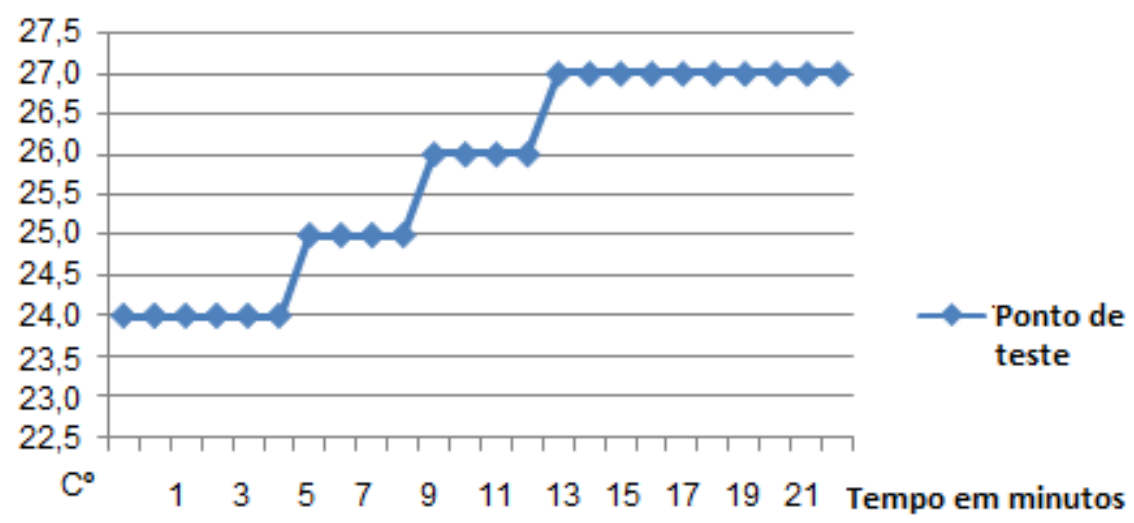

Figura 6.3: Gráfico de aquecimento para o termopar..

Na figura 6.3 pode ser observado que o tempo para se atingir o regime permanente é próximo de 14 minutos, que é mais lento que nas simulações. Isso pode ser atribuído à condutância das superfícies de contato, que é a característica que descreve a facilidade de passar um fluxo de calor entre superfícies de contato podendo-se entender como o inverso da resistividade térmica. Esta característica depende de vários fatores sendo afetado pela rugosidade, pressão entre as superfícies de contato, temperatura do meio que está entre as superfícies, e a diferença de temperatura entre as mesmas, Barzelay (1955).

Bloom (1964), cita que há 7 fatores de maior influência: temperatura ambiente, pressão de contato, condutividades térmicas das superfícies, dureza, módulo elástico, desvios na retilineidade e rugosidade. Os de menor influência, o autor classifica em três: orientação das camadas das superfícies, direção do fluxo de temperatura em materiais diferentes e tempo de contato. Baseado nestas informações, sabe-se que este fator de condutância é muito difícil de ser obtido e o programa ANSYS® trata este fator apenas realizando um cálculo de condutância baseado no fluxo de calor e condutividades térmicas das superfícies em contato. O contato entre as superfícies é definido como perfeito, 
no qual as superfícies são planas e se tocam em todos os pontos, facilitando o aspecto de transferência de calor, gerando uma tendência a facilitar a transferência, reduzindo, portanto o tempo de regime transiente, ou seja, o tempo em que há antes de se estabelecer o regime permanente. Por isso, acredita-se que há essa discrepância entre o tempo até se atingir o regime permanente do experimento, e o tempo das simulações. 


\section{VALIDAÇÃO EXPERIMENTAL DO CABEÇOTE DE EXTRUSÃO}

Nesta seção são apresentados o desenho atual do cabeçote e algumas validações realizadas que expõe seu conceito e sua capacidade de realizar a deposição controlada em máquina desktop. A Figura 7.1 (a) apresenta 0 desenho técnico final da monorosca projetada e a Figura 7.2 (b) apresenta a monorosca de seção variável fabricada.

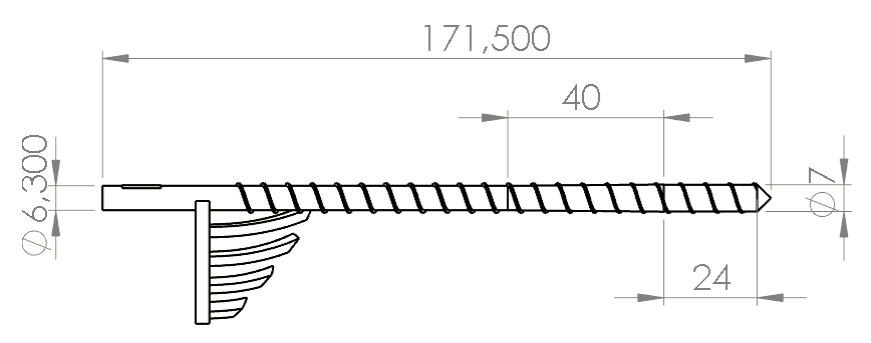

(a)

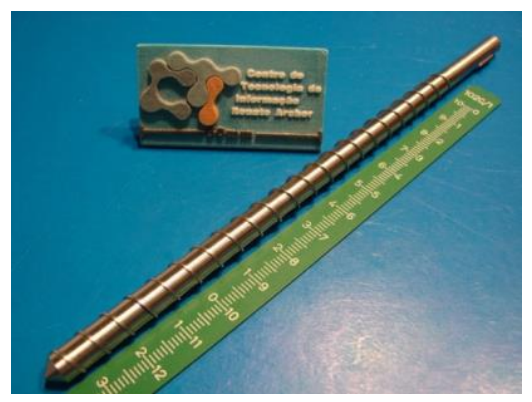

(b)

Figura 7.1: Projeto de rosca de extrusão e rosca fabricada.

Com o projeto da monorosca e do conjunto de extrusão, que incluiu o estudo térmico dos dissipadores foi feito o desenho de conjunto do cabeçote intercambiável de extrusão, apresentado na Figura 7.2. Dessa forma, o protótipo funcional foi fabricado para que se seguissem a fase de testes experimentais.

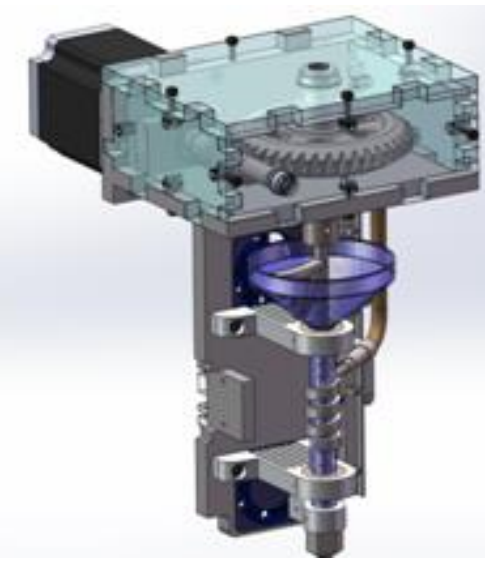

Figura 7.2 - Conjunto do cabeçote de extrusão. 
O primeiro teste está relacionado com a capacidade de extrusão de material polimérico à quente, gerando filamentos contínuos. Neste ponto do projeto é importante ressaltar a atenção dada à capacidade de resistência do parafuso ao torque do mesmo durante o processo de extrusão, à eficiência de dissipação de calor nos apoios aletados e resfriados por cooler e o controle do conjunto do motor/redutor para movimentação do parafuso durante o processo de extrusão ainda sem movimentação do cabeçote. O teste é feito fora da impressora desktop e o material extrudado é Nylon $12 \mathrm{PA} \circledast$ em pó. A extrusão é feita à $120^{\circ} \mathrm{C}$ com rotação de 30 RPM e bico de $0,8 \mathrm{~mm}$ de diâmetro conforme ilustra a figura 7.3 .

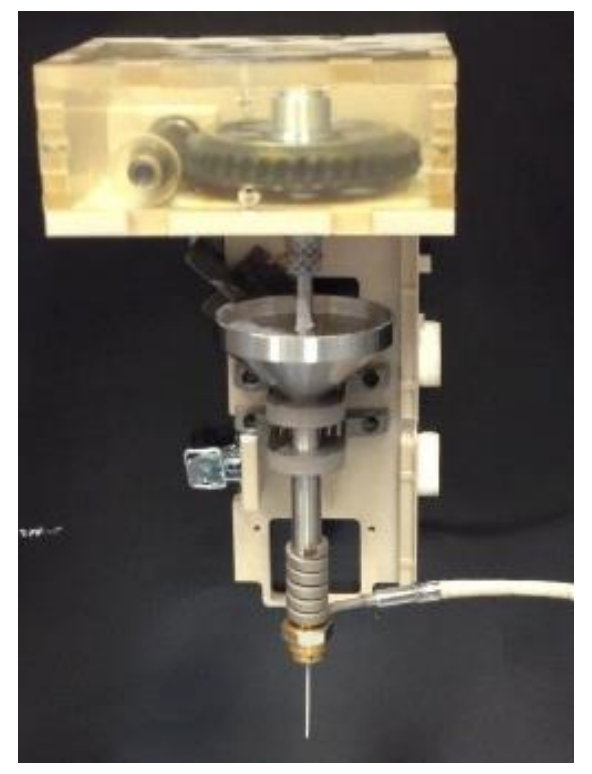

Figura 7.3: Primeira validação do cabeçote: geração de filamentos, a partir de pó de Nylon ${ }^{\circledR} 12$.

Um segundo teste foi conduzido para investigar a capacidade do cabeçote de gerar filamentos contínuos a partir de material na forma de pó. Este teste mostrou que o cabeçote é capaz de produzir filamentos contínuos com pequenas variações no diâmetro, sendo o diâmetro médio de $0,75 \mathrm{~mm}$ ilustrado pela Figura 7.4 . 


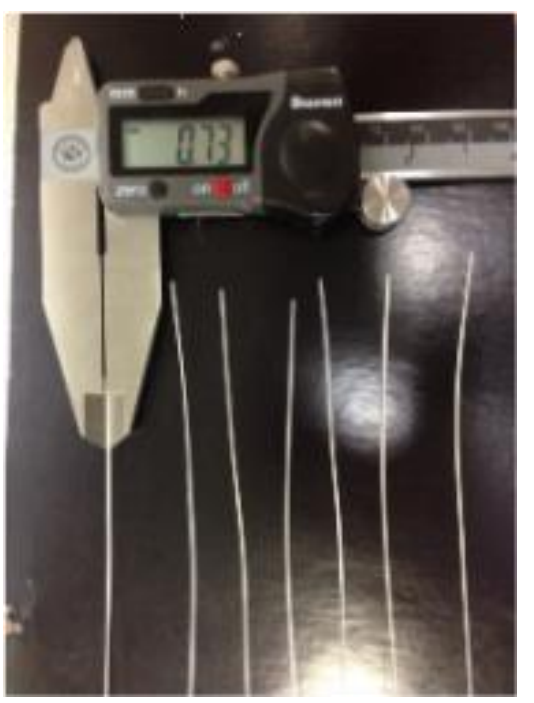

Figura 7.4 - Filamentos extrudados de Nylon $\AA^{\circledR} 12$

Estes testes iniciais são importantes para demonstrar a capacidade de transformar o pó polimérico em polímero derretido, revelando a capacidade da zona de alimentação da rosca de carrear o material até as zonas finais da mesma. A saída de filamentos contínuos é devida ao desempenho adequado do projeto do parafuso com zonas específicas. Nessas seções, a pressão crescente ao longo do barril de extrusão força o polímero amolecido contra o bico de extrusão produzindo os filamentos a serem depositados. Na figura 7.5, é mostrado o cabeçote de extrusão gerando peças com adesão de camadas, o que é requerido nos processos de MA.

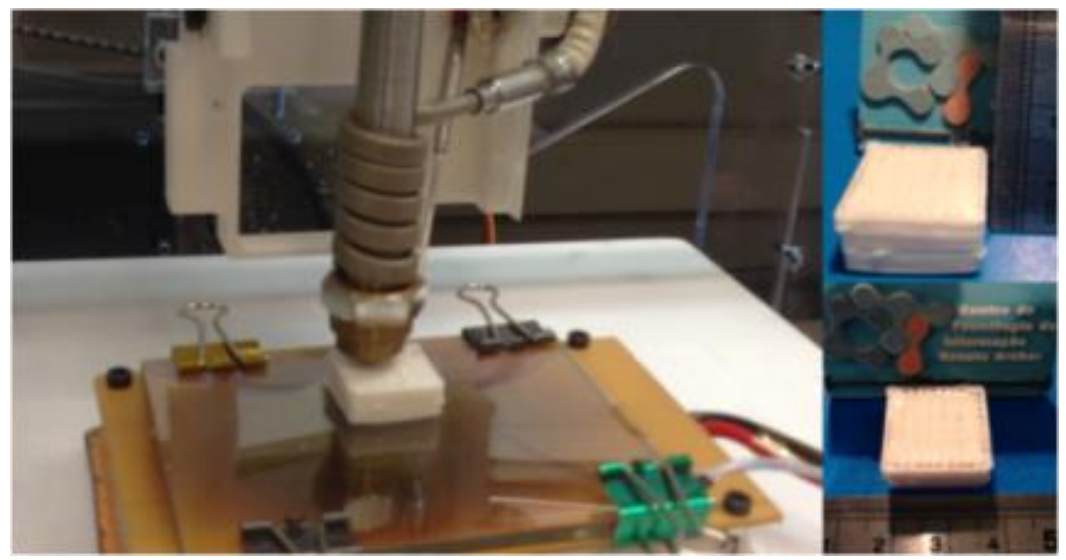

Figura 7.5 - Cabeçote de extrusão em estudo prototipando um modelo 3D, em Nylon (B) 12 
As características morfológicas dos filamentos foram analisadas por MEV (Microscopia Eletrônica de Varredura). As micrografias foram obtidas no Centro de Análises Químicas de São Carlos (CAQI/IQSC/USP) em uma máquina ZEISS LEO 440 (Cambridge, Inglaterra) com detector Oxford (modelo 7060), operando com um feixe de elétrons de 15kV. As amostras foram cobertas com $10 \mathrm{~nm}$ de ouro no equipamento Coating System BAL-TEC MED 020 (BAL-TEC, Liechtenstein) e foram mantidas no dissecador até o momento da análise. É possível observar na figura 7.6 a micrografia de filamento de Nylon extrudado, cilíndrico e contínuo. O material apresenta uma superfície sólida sem poros e descontinuidades.

a)

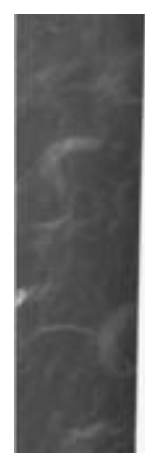

b)

Figura 7.6 - Foto de micrografias obtidas dos filamentos de Nylon 12 PA

Com o objetivo de testar a condição de extrusão do polímero $\mathrm{PCL}$, o esquema da figura 7.7, mostra onde o material foi coletado, seção de alimentação e compressão, juntamente com as micrografias dos materiais. 


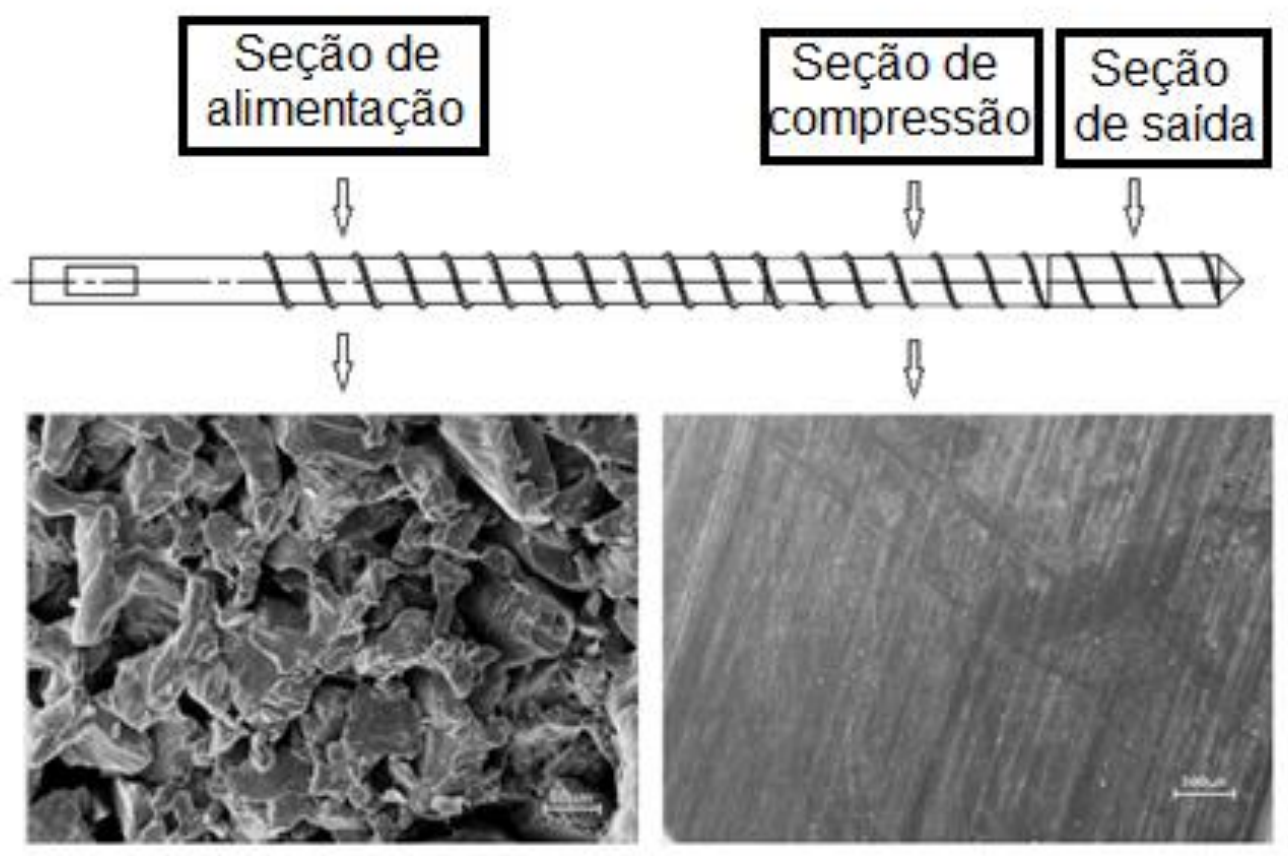

Figura 7.7 - Fotomicrografias de material PCL (policaprolactona)

A micrografia obtida do material na seção de alimentação revela grãos desconectados e ocorrência de vazios nas zonas escuras, em contrapartida a micrografia do material retirado na zona de compressão mostra um material completamente contínuo e sólido, expondo a condição da união total dos grãos devido ao aquecimento. Esse resultado representa a capacidade de a extrusora realizar dois estágios do processo de extrusão para o PCL.

Finalmente para este material é realizada a deposição controlada para produção de scaffolds sobre plataforma aquecida, figura 7.8. 


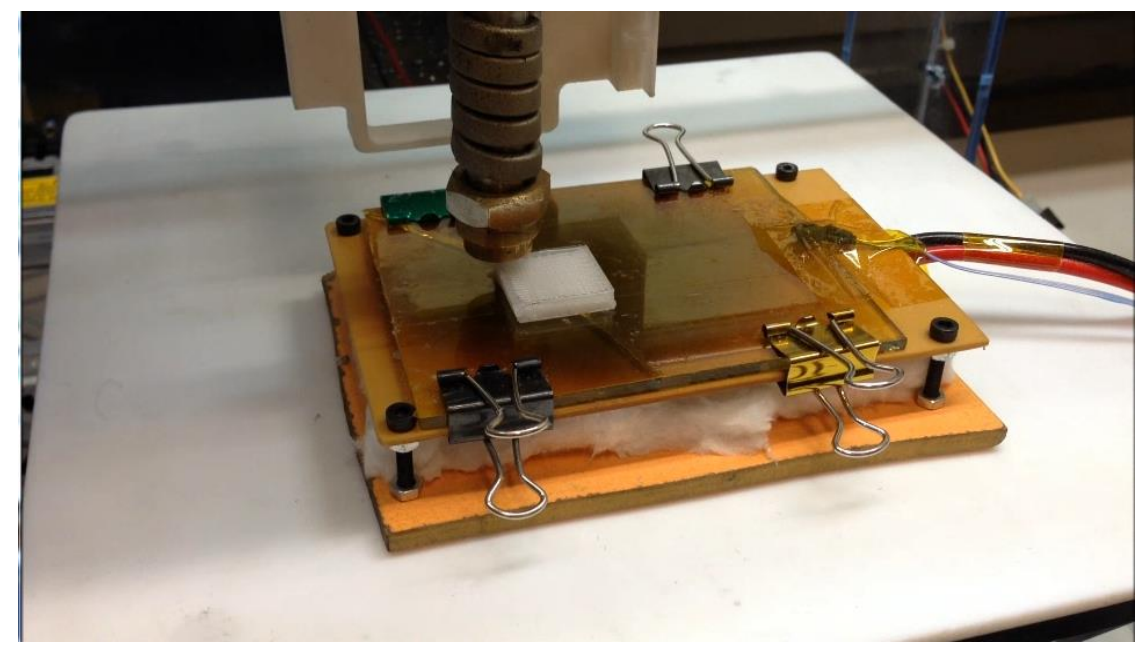

Figura 7.8: Cabeçote de extrusão por rosca realizando a deposição de um scaffold de PCL

Uns dos maiores problemas visualizados com este cabeçote é o elevado peso de 2,470 kg, e apesar de o cabeçote ter sido bem sucedido nos testes para provar o conceito de deposição e formação de peças e scaffolds com dois materiais diferentes, esse fator mostrou ser indesejável do ponto de vista da precisão de deposição. A inércia gerada pelo elevado peso gera vibrações visíveis em escala macroscópicas, na extremidade do bico de extrusão e essa vibração gera imprecisões visíveis nos modelos.

\subsection{Análise de degradação dos polímeros}

Esta seção do trabalho foi realizada com o apoio de José D'ávila cuja linha de pesquisa é centrada na fabricação de scaffolds com material PCL.

O polímero utilizado nesta pesquisa foi o PCL CAPA® 6505, fornecida pela Rhodia, que é um poliéster de alta massa molecular $\left(\mathrm{M}_{\mathrm{w}}=50000 \mathrm{~g} / \mathrm{mol}\right)$ derivado do monômero de caprolactona. Este polímero é fornecido em pó, sendo que o 97,5\% das partículas têm um tamanho menor que $500 \mu \mathrm{m}$. Na Tabela 8.1 são apresentadas as principais características deste material. 
Tabela 8.1. Especificações da PCL CAPA® 6505.

\begin{tabular}{|l|l|}
\hline Massa molecular média $\left(\mathrm{M}_{\mathrm{w}}\right)$ & $50000 \mathrm{~g} / \mathrm{mol}$ \\
\hline Temperatura de fusão $\left(\mathrm{T}_{\mathrm{m}}\right)$ & $58-60^{\circ} \mathrm{C}$ \\
\hline Teor de água & $<1 \%$ \\
\hline & $15 \% \leq 106 \mu \mathrm{m}$ \\
Distribuição de tamanho de & $106 \mu \mathrm{m}<82.5 \% \leq 500$ \\
partícula & $\mu \mathrm{m}$ \\
& $2.5 \%>500 \mu \mathrm{m}$ \\
\hline Toxicidade & Biologicamente inerte \\
\hline
\end{tabular}

Na Tabela 8.2 são apresentados os valores dos picos característicos da PCL e os picos obtidos na análise FTIR. Nesta tabela, os picos característicos estão baseados nos resultados obtidos por (Elzein et al, 2004). Cabe mencionar que os testes foram feitos com 32 varreduras para cada amostra. No gráfico é possível observar que foram obtidos espectros muito semelhantes para os três casos, o que significa que não houve degradação, principalmente devido a que a banda localizada a $1727 \mathrm{~cm}^{-1}$ está associada ao grupo carbonila $-\mathrm{C}=\mathrm{O}$ e apareceu depois do processamento. Do mesmo jeito, é possível observar dois picos bem definidos a $2979 \mathrm{~cm}^{-1}$ e $2865 \mathrm{~cm}^{-1}$, estes estão associados à vibração em tensão dos enlaces $-\mathrm{C}-\mathrm{H}$. A Tabela 8.2 mostra o espectro obtido para o PCL puro e os scaffolds S9 e S18. 
Tabela 8.2. Bandas características da PCL e bandas obtidas para o material puro e os scaffolds S9 e S18.

\begin{tabular}{|c|c|c|c|c|c|}
\hline \multicolumn{4}{|c|}{ Número de onda $\left(\mathrm{cm}^{-1}\right)$} & \multirow[b]{2}{*}{ Vibração } & \multirow[b]{2}{*}{ Abreviatura } \\
\hline $\begin{array}{l}\text { Pó de } \\
\text { PCL }\end{array}$ & S9 & S18 & $\begin{array}{c}\text { Banda } \\
\text { Característica }\end{array}$ & & \\
\hline 2947 & 2945 & 2945 & 2949 & $\begin{array}{l}\text { Alongamento }-\mathrm{CH}_{2} \\
\text { assimétrico }\end{array}$ & $\operatorname{Vas}\left(\mathrm{CH}_{2}\right)$ \\
\hline 2866 & 2867 & 2866 & 2865 & Alongamento - $\mathrm{CH}_{2}$ simétrico & $\mathrm{vs}_{\mathrm{s}}\left(\mathrm{CH}_{2}\right)$ \\
\hline 1728 & 1724 & 1724 & 1727 & Alongamento da carbonila & $\mathrm{v}(\mathrm{C}=\mathrm{O})$ \\
\hline 1293 & 1294 & 1294 & 1293 & $\begin{array}{l}\text { Alongamento C-O e C-C na } \\
\text { fase cristalina }\end{array}$ & $\mathrm{V}_{\mathrm{cr}}$ \\
\hline 1238 & 1241 & 1240 & 1240 & Alongamento COC assimétrico & $\operatorname{vas}(\mathrm{COC})$ \\
\hline 1168 & 1176 & 1172 & 1170 & Alongamento COC simétrico & $\mathrm{v}_{\mathrm{s}}(\mathrm{COC})$ \\
\hline
\end{tabular}

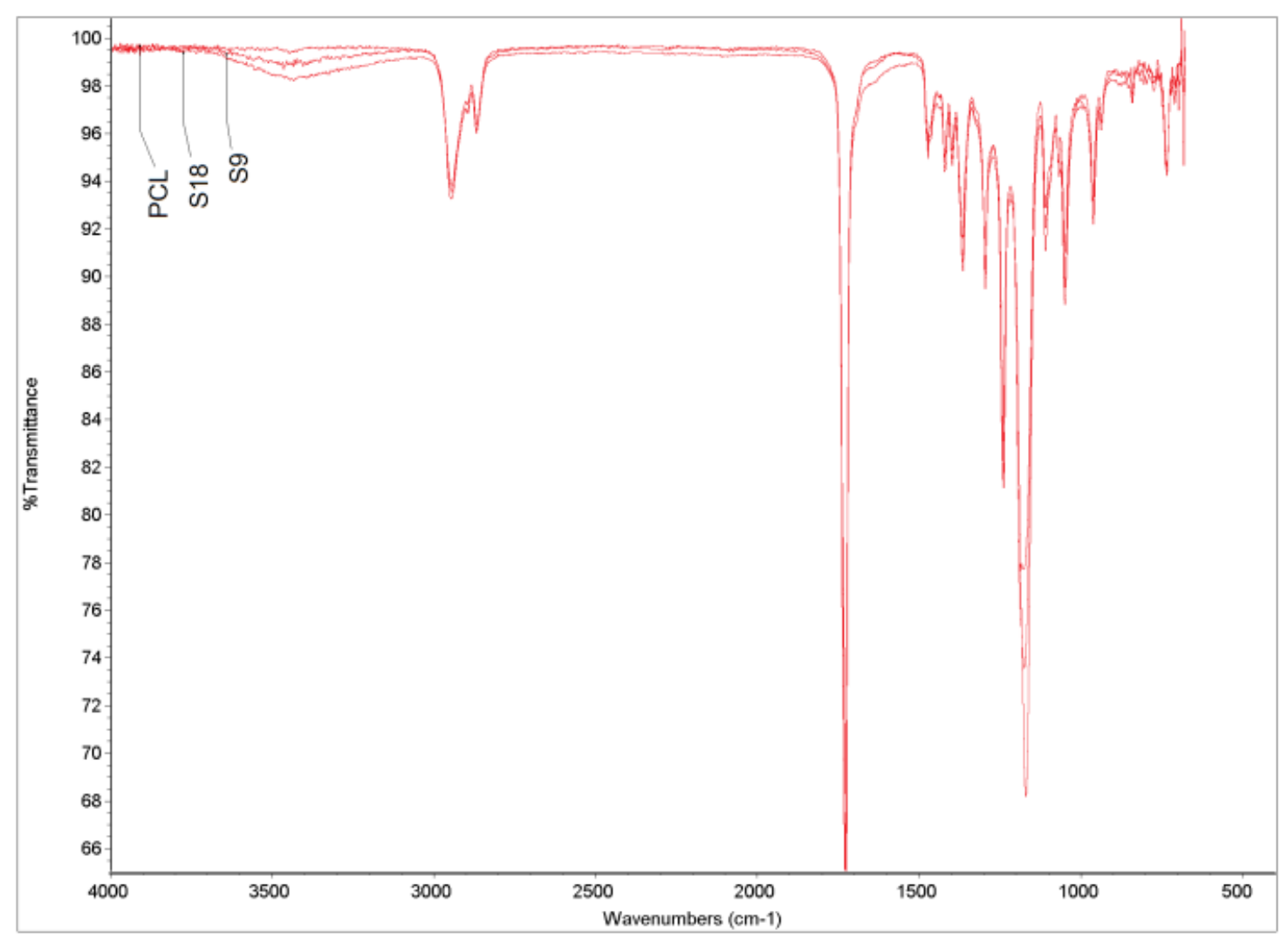

Figura 8.1 Espectro FTIR do pó de PCL CAPA® 6505 e dos scaffolds de PCL S9 e S18, fabricados com a maior temperatura e velocidades. 
Estes resultados validam o projeto de dissipação térmica do cabeçote e seu funcionamento uma vez que mostram que o material praticamente não degrada quando processado no cabeçote em estudo.

\subsection{Análise morfológica utilizando Microscopia Eletrônica de Varredura}

Em todos os scaffolds existe uma boa adesão entre camadas. Na Fig. 9.1, é apresentada a adesão e a disposição de raster em arquitetura $0^{\circ} / 90^{\circ}$.

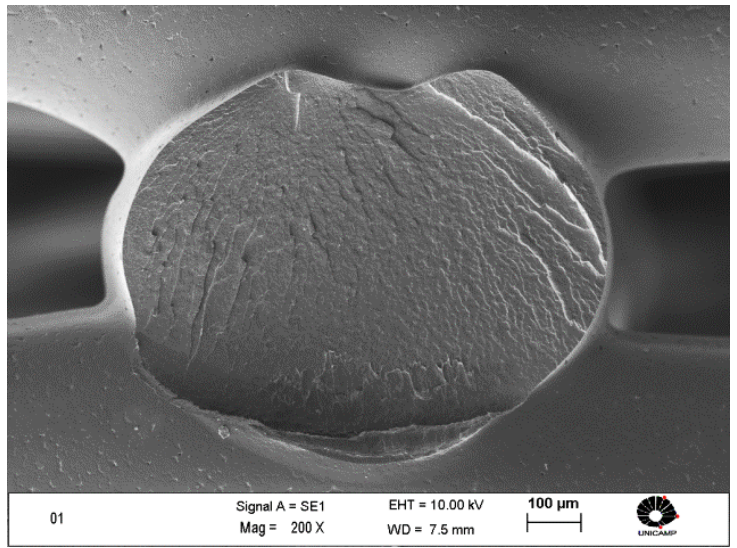

(a)

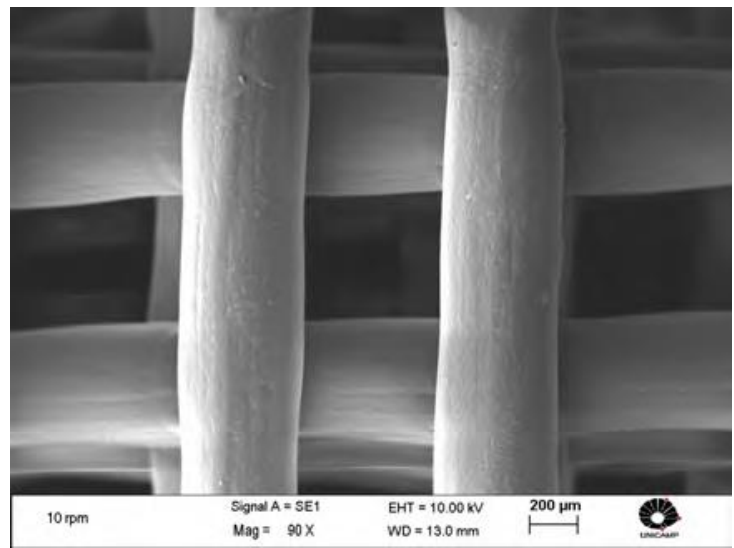

(b)

Figura 9.1 (a) Microscopia da secção transversal do scaffold 200x e (b) microscopia mostrando a arquitetura $0 \% 90^{\circ}$ para o scaffold $90 \mathrm{x}$.

Nos resultados apresentados para os diâmetros é possível observar que existe uma grande variação para todos os casos. Além do inchamento do extrudado, variáveis como a velocidade de movimentação e a velocidade de giro da rosca influenciam diretamente ao valor do diâmetro.

Segundo Bretas e D’Ávila (2005), quando um material polimérico é extrudado através de um canal estreito, ocorrem alguns fenômenos neste material. $O$ inchamento do extrudado é caracterizado pelo o aumento do diâmetro do extrudado em relação à matriz, ou capilar. Isso ocorre quando as tensões cisalhantes cessam e as macromoléculas que antes se encontravam 
estiradas no canal, tendem a voltar às conformações aleatórias de equilíbrio. Isso produz o encolhimento longitudinal e expansão lateral conforme visto na (Figura 9.2).

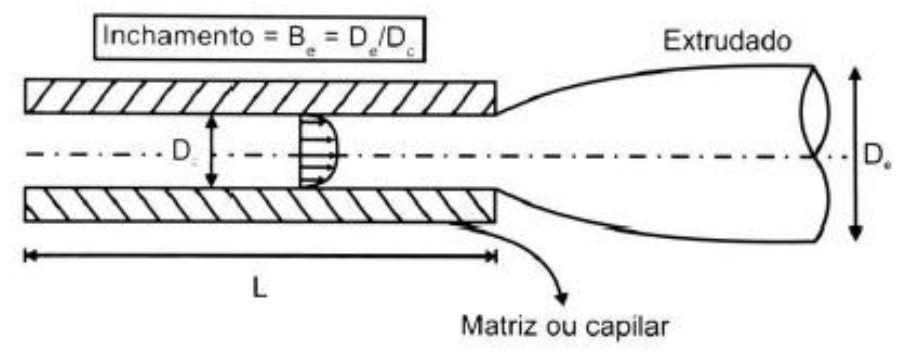

Figura 9.2 - Inchamento do Extrudado. Fonte: Bretas e D’Ávila (2005)

$\mathrm{O}$ inchamento do extrudado $\mathrm{Be}=\mathrm{De} / \mathrm{Dc}$, em que $\mathrm{De}=$ diâmetro do extrudado e Dc = diâmetro do capilar, aumenta com o aumento da taxa de cisalhamento até um limite próximo à taxa de cisalhamento crítica c, após esse limite o inchamento do extrudado diminui. Uma solução proposta para reduzir este fenômeno é aumentar o comprimento do bico de extrusão deixando-o com uma relação L/D de 1:20, uma vez que esta resolução orientaria as cadeias poliméricas reduzindo o fenômeno do inchamento de extrudado.

Com utilização de MEV foi possível observar a formação de microporos na superfície dos scaffolds. Esta microporosidade é resultado próprio do processo, e é de grande importância, porque a rugosidade da superfície vai permitir uma boa adesão das células durante a regeneração dos tecidos. A Figura 9.4 apresenta a microscopia que exibe a microporosidade obtida. 


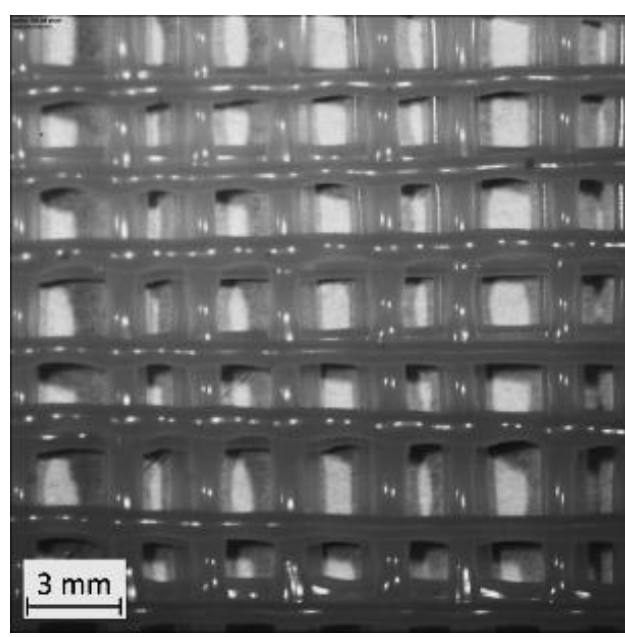

(a)

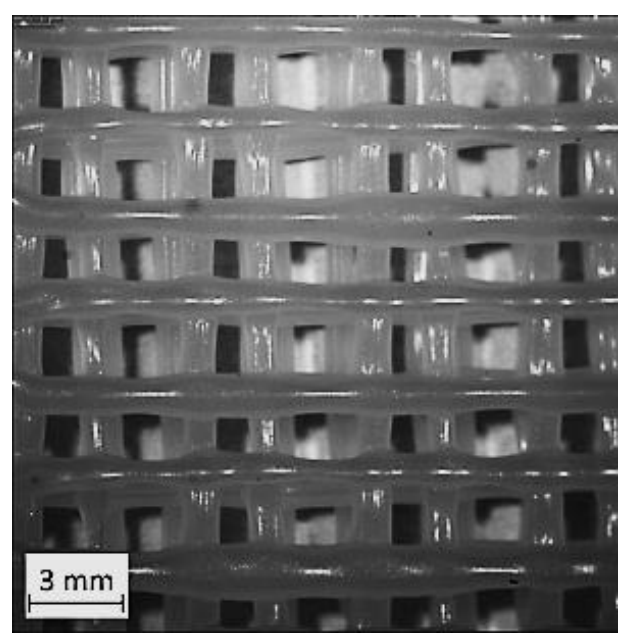

(b)

Figura 9.3 Microscopias estéreo: a) Scaffold S1 (bico $0.80 \mathrm{~mm}$ ), b) Scaffold $\mathrm{S} 18$ (bico $0.45 \mathrm{~mm}$ ).

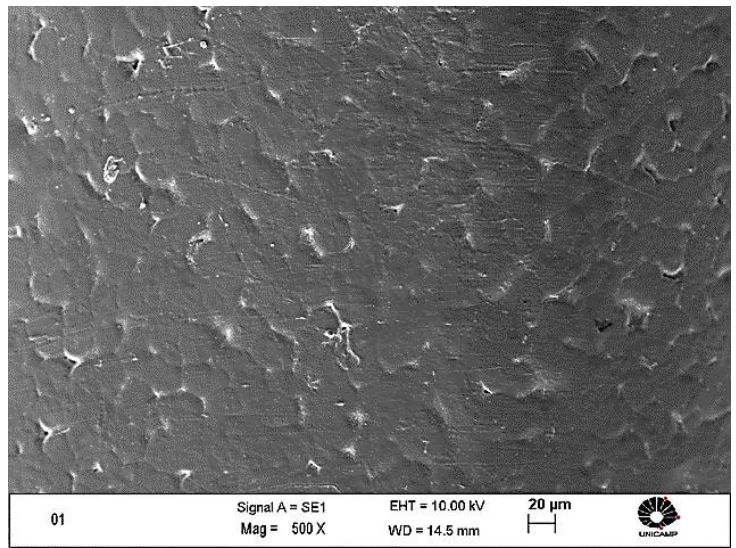

Figura 9.4. Microscopia do scaffold S1 mostrando a microporosidade da superfície.

\subsection{Planejamento de experimentos para verificação de características morfológicas PCL}

Como exposto na revisão de literatura, o DOE é uma técnica aplicada no estudo da influência de muitas variáveis em resultados de um sistema ou processo. No caso em estudo têm-se o interesse de verificar como são as características morfológicas dos scaffolds de PCL para cada combinação de parâmetros de processo. Assim pode-se caracterizar o DOE como um 
mapeamento de processo, no qual se quer visualizar como cada parâmetro interfere na resposta (diâmetro dos filamentos e forma dos scaffolds).

Utilizando o método de (Design of Experiment) ou planejamento de experimentos foram fabricados ou prototipados scaffolds de PCL variando-se os parâmetros bico de deposição (2 níveis), velocidade de rotação da rosca de extrusão (3 níveis) e temperatura da resistência microtubular (3 níveis). Foram ajustados 18 experimentos e a combinação deles é representada na tabela 13:

Tabela 10.1: Tabela de DOE para a fabricação de scaffolds de PCL.

\begin{tabular}{|c|c|c|c|c|c|c|c|c|c|c|c|c|c|c|c|c|c|c|}
\hline Bico & \multicolumn{9}{|c|}{$0,8 \mathrm{~mm}$} & \multicolumn{9}{|c|}{$0,4 \mathrm{~mm}$} \\
\hline Vel. & \multicolumn{3}{|c|}{4,5} & \multicolumn{3}{|c|}{8,5} & \multicolumn{3}{|c|}{12} & \multicolumn{3}{|c|}{4,5} & \multicolumn{3}{|c|}{8,5} & \multicolumn{3}{|c|}{12} \\
\hline $\begin{array}{l}\text { Temp. } \\
\left({ }^{\circ} \mathrm{C}\right)\end{array}$ & 115 & 120 & 125 & 115 & 120 & 125 & 115 & 120 & 125 & 115 & 120 & 125 & 115 & 120 & 125 & 115 & 120 & 125 \\
\hline $\mathrm{n}^{\circ}=\operatorname{Exp}$. & 1 & 2 & 3 & 4 & 5 & 6 & 7 & 8 & 9 & 10 & 11 & 12 & 13 & 14 & 15 & 16 & 17 & 18 \\
\hline
\end{tabular}

Para aleatorizar a sequência de experimentos foi adotada a ordem: $1 ; 8$; $5 ; 13 ; 11 ; 17 ; 10 ; 9 ; 7 ; 3 ; 2 ; 4 ; 12 ; 16 ; 18 ; 15 ; 14 ; 6$.

As medições foram feitas por José Luis Dávila, aluno de mestrado em engenharia de matérias na UNICAMP. Como resultados foram obtidas faixas de dimensão dos diâmetros dos filamentos para cada combinação de fatores, figura 10.1 .
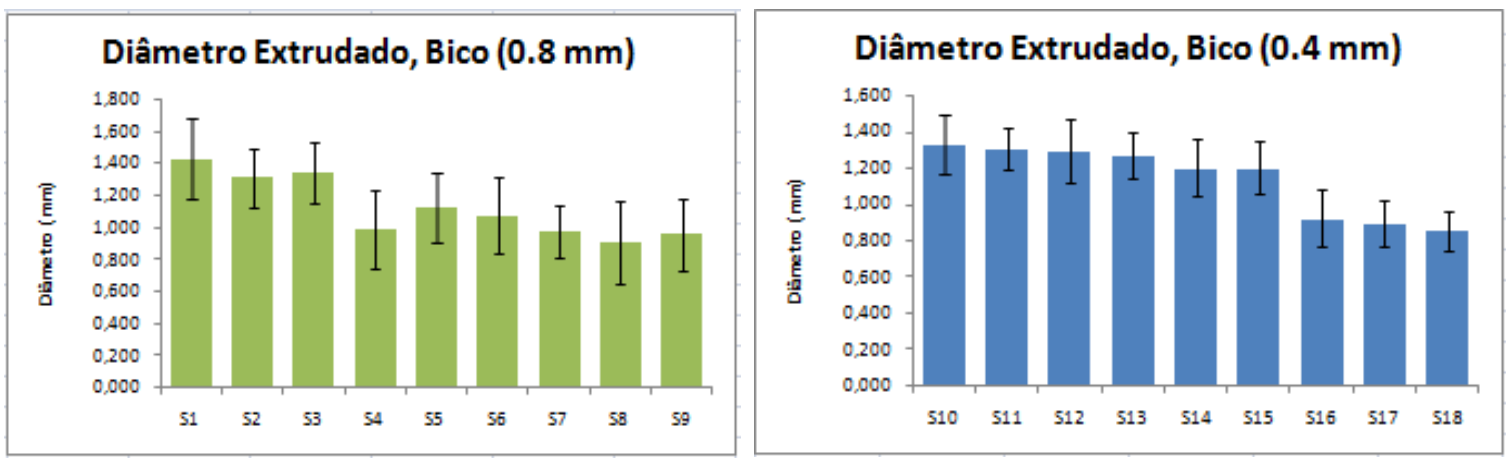

Figura 10.1 - Gráficos dos diâmetros dos filamentos extrudados obtidos no DOE 
A tabela A-1 cujos dados foram repersentados para plotagem dos gráficos pode ser vista no Apêndice $A$.

Analisando-se os dados verifica-se que o aumento da velocidade de rotação que ocorre simultaneamente com a velocidade de deposição produz em geral uma diminuição do valor médio do diâmetro do filamento, com exceção da amostra S4 e isso ocorre nos 2 bicos. O bico de $0,8 \mathrm{~mm}$ de diâmetro apresentou maior variação nos desvios padrão, sendo a média dos desvios padrão $0,2201 \mathrm{~mm}$ e a média dos desvios padrões do bico de $0,4 \mathrm{~mm}$ de diâmetro resultou em $0,1417 \mathrm{~mm}$, demonstrando que para o uso de bico de 0,4mm é possível ter valores de diâmetros de filamentos com menores variações.

A análise da sensibilidade com os dados obtidos revela uma tendência para o bico de $0,4 \mathrm{~mm}$ com o aumento da temperatura mantendo-se o diâmetro do bico e velocidade fixos e essa tendência é diminuição da média dos diâmetros dos filamentos. Com o bico de $0,8 \mathrm{~mm}$ essa tendência não se verifica já que o experimento 6- $\mathrm{s} 6$ em comparação ao experimento $\mathrm{s} 5$ apresenta maior média e o mesmo acontece com o experimento 9 em relação ao experimento 8 .

Outra característica apresentada para os dois bicos é o efeito do inchamento de extrudado. Em todas as medições o diâmetro do filamento resultou em uma dimensão maior que dos bicos e mais pronunciadamente no bico de $0,4 \mathrm{~mm}$ que apresentou dimensões de filamento de $7 \mathrm{~mm}$ à $15 \mathrm{~mm}$ aproximadamente.

Neste experimento mostrou-se que efeitos inesperados em relação aos diâmetros obtidos se apresentaram sendo assim, portanto uma análise mais profunda sobre as causas dos mesmos. Analisando os dados com o software ModeFrontier $\AA$, primeiramente analisa-se as matrizes de correlação que refletem a interação das variáveis e as respostas, sendo um número próximo de 1 representando correlação proporcional e próximo de 0 , nenhuma correlação e -1, correlação inversamente proporcional. 


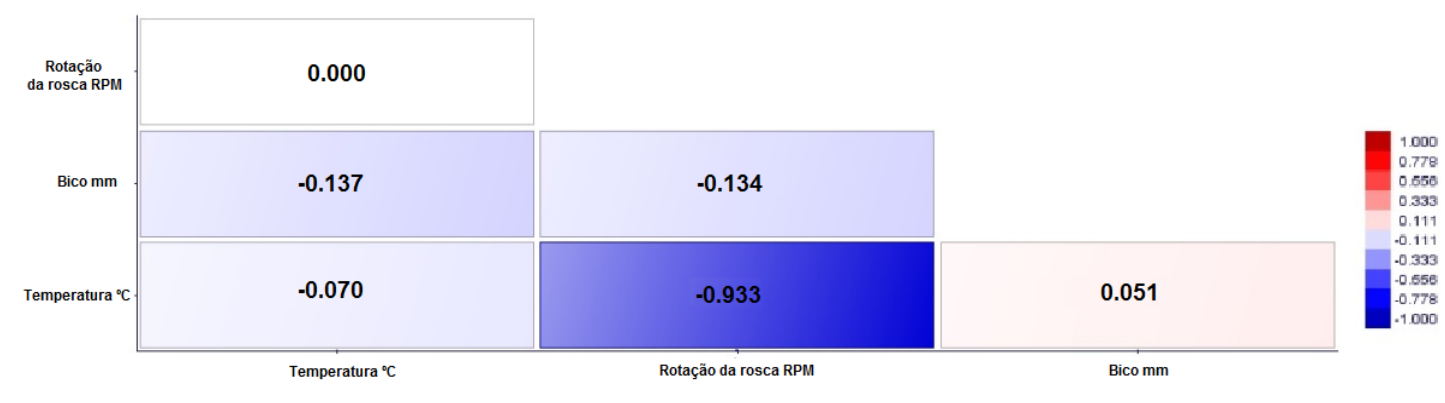

Figura 10.2: Matriz de correlação entre a resposta, média do diâmetro dos filamentos, e variáveis de entrada.

Para figura 10.2, pode-se observar uma relação de proporcionalidade negativa entre o tamanho médio do filamento e a rotação do parafuso, ou seja, quanto mais o parafuso gira e extruda material, mais fino é o filamento. Apesar de parecer incorreto ou não intuitivo, este dado faz sentido quando se sabe que para cada velocidade de rotação é definida uma velocidade de posicionamento e essa razão é determinada por um comando, "deposition rate", do software de controle da máquina. Essa razão influencia na largura do raster uma vez que se a velocidade de deposição aumenta para uma mesma velocidade de rotação o filamento afina. O resultado está relacionado com esse fenômeno, pois se quando a rotação do parafuso aumenta, o filamento afina, uma suspeita provável é que há um aumento proporcionalmente maior da velocidade de deposição gerando o afinamento.

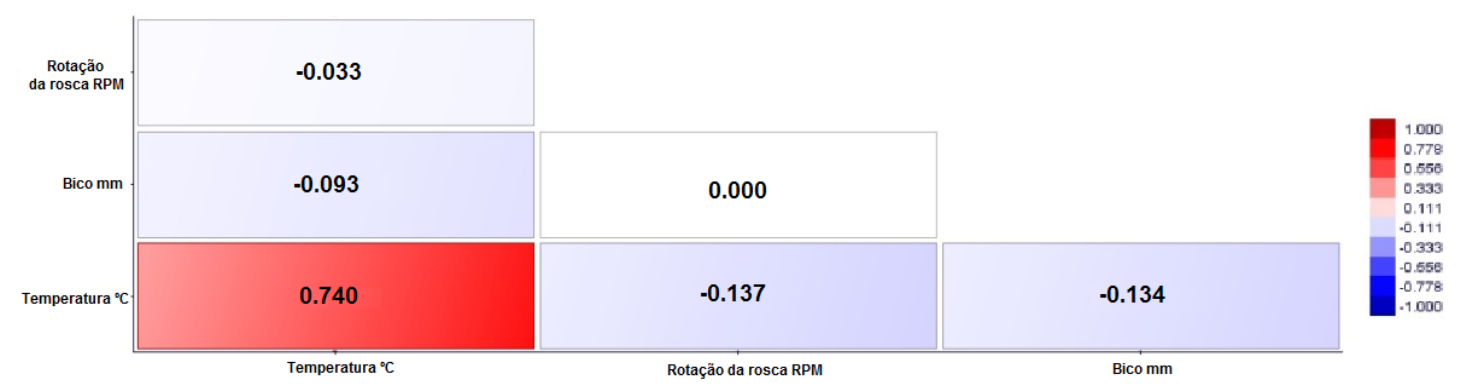

Figura 10.3: Matriz de correlação entre a resposta, desvio padrão médio, e variáveis de entrada. 
Já analisando os dados para verificar a influência das variáveis no desvio padrão verificado na resposta, figura 10.3, se observa uma influência positiva entre o desvio padrão e a temperatura, ou seja, o bico de maior diâmetro apresenta um maior desvio padrão nos dados que o bico menor. Não se tem uma explicação para essa ocorrência, tendo-se como conclusão apenas que se utilizando um bico de $0,4 \mathrm{~mm}$ se podem alcançar valores com menor variabilidade.

$\mathrm{Na}$ figura 10.4 são representadas as correlações uma a uma entre as variáveis e a resposta, diâmetro médio dos filamentos. A figura 10.4 (a) representa a relação dos bicos com a resposta. Vê-se que a alteração dos bicos isoladamente não gerou alteração nos diâmetros médios. Já na figura 10.4(b), (e), (h) vê-se que o aumento da rotação gera diminuição da largura média do raster mesmo variando-se todas as outras variáveis assim como já exposto na matriz de correlação. Para a relação entre a variação de temperatura e a resposta, tem-se que a mudança de temperatura dentro da faixa estabelecida não altera a média da resposta, figura 10.4(i). A figura 10.4(f) revela um leve decréscimo na resposta para as situações de baixa rotação, com o aumento da temperatura, e a figura 10.4(c) revela um leve decréscimo para o bico menor e um leve acréscimo para o bico maior pra mesma situação.

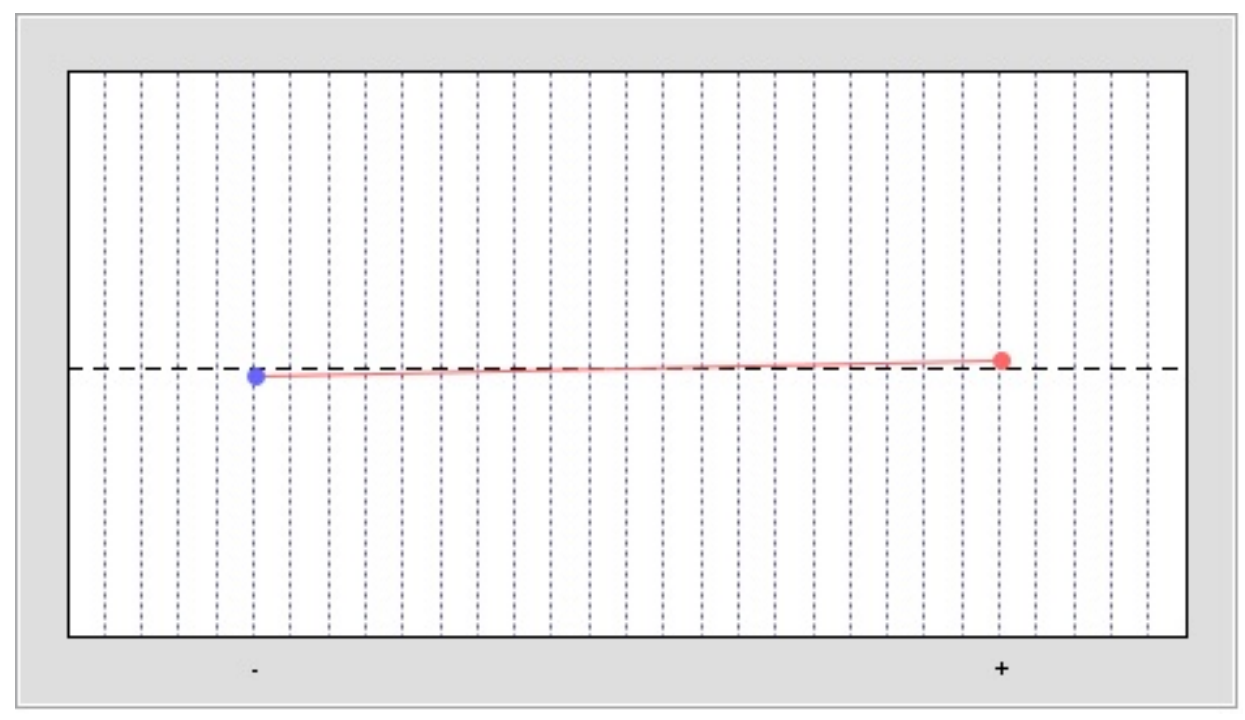

(a) 


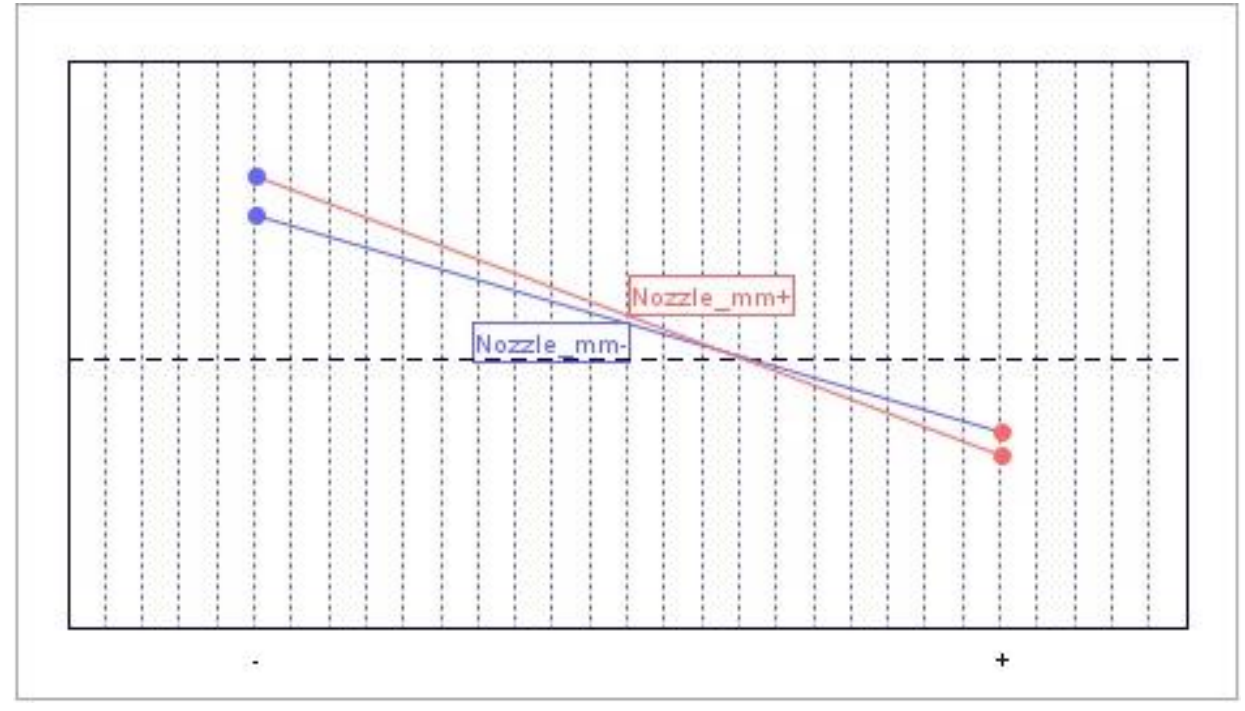

(b)

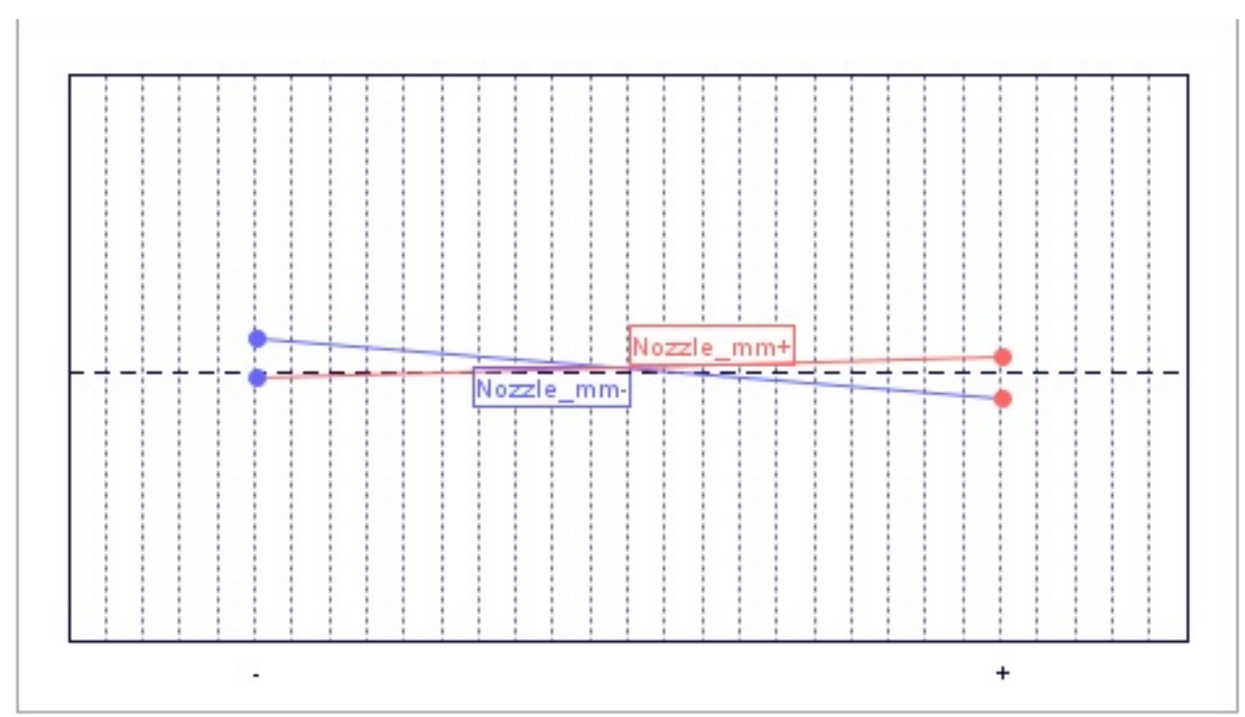

(c)

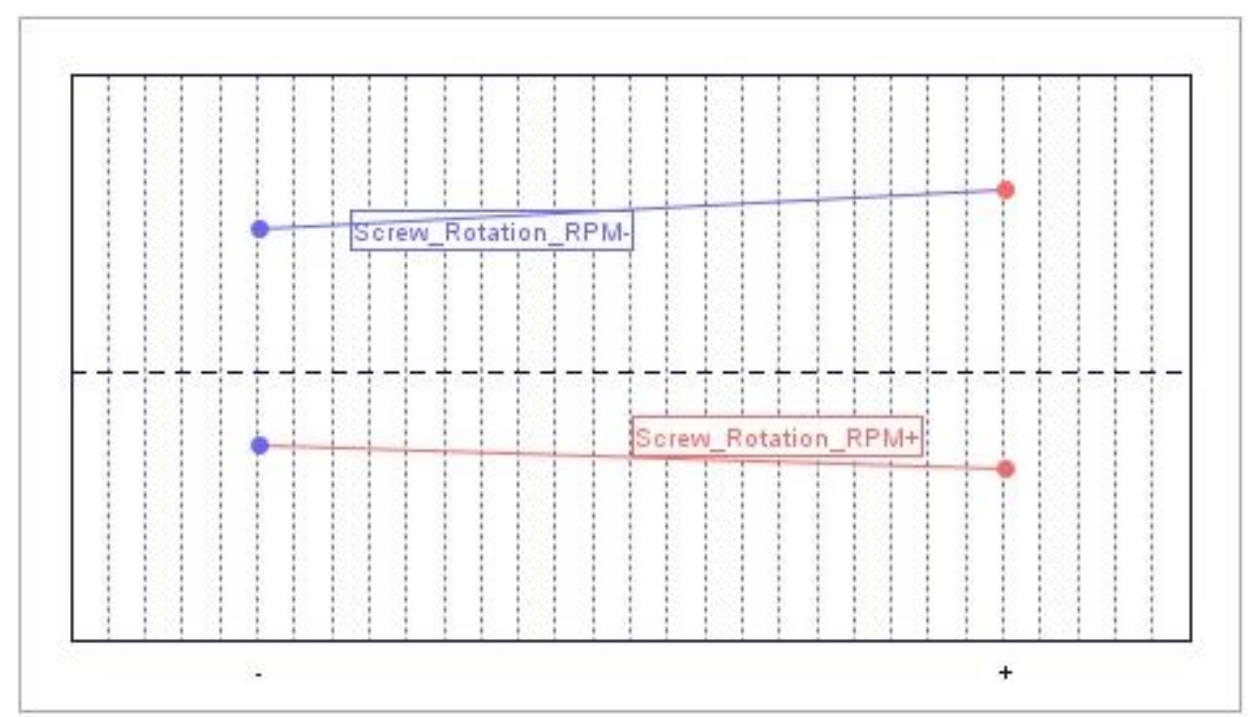


(d)

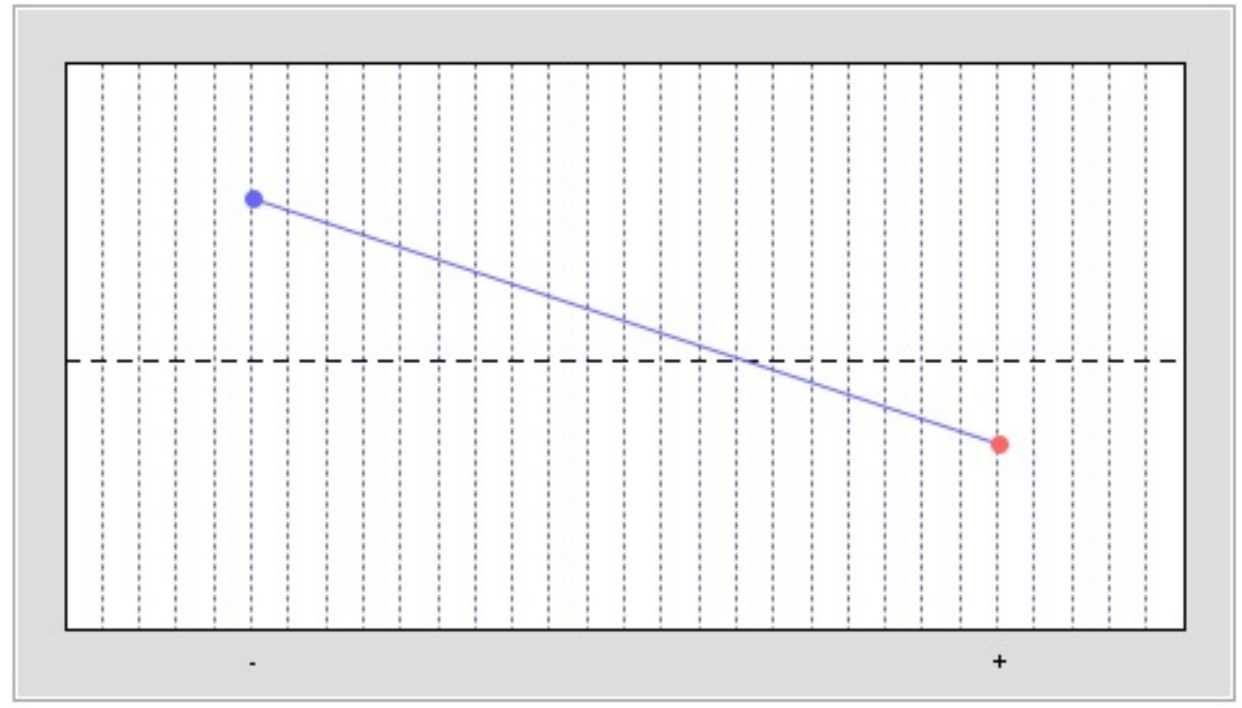

(e)

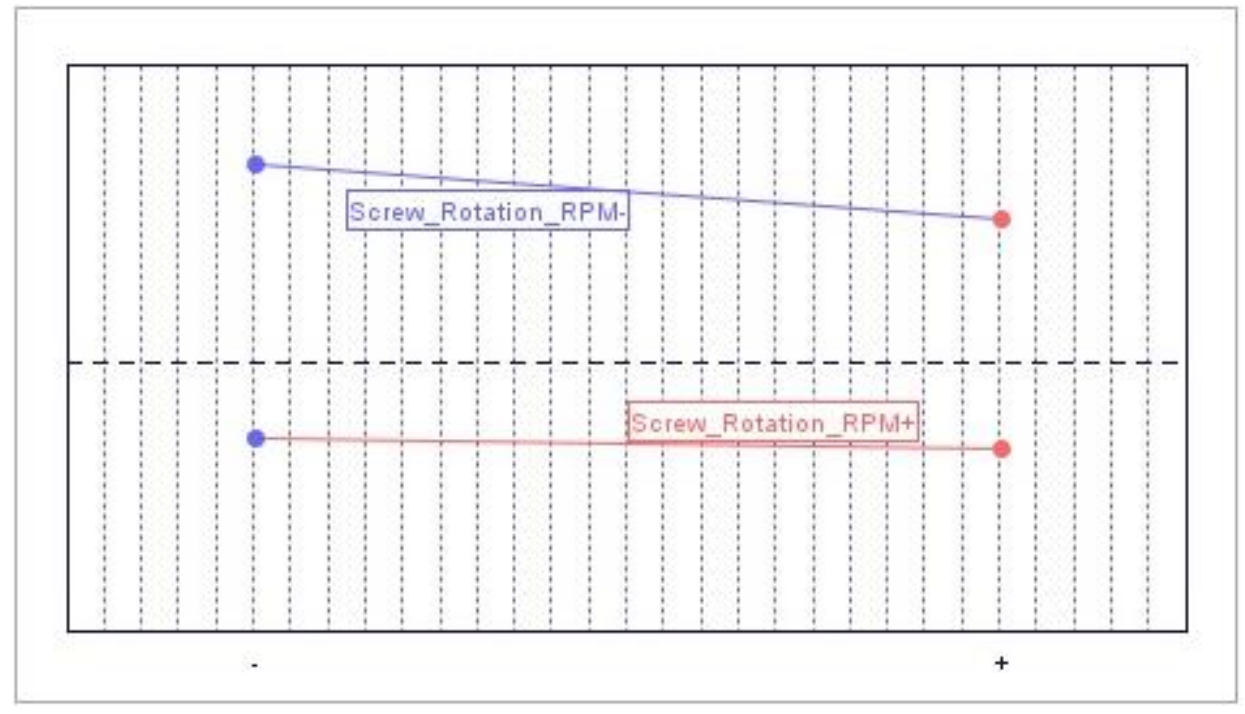

(f)

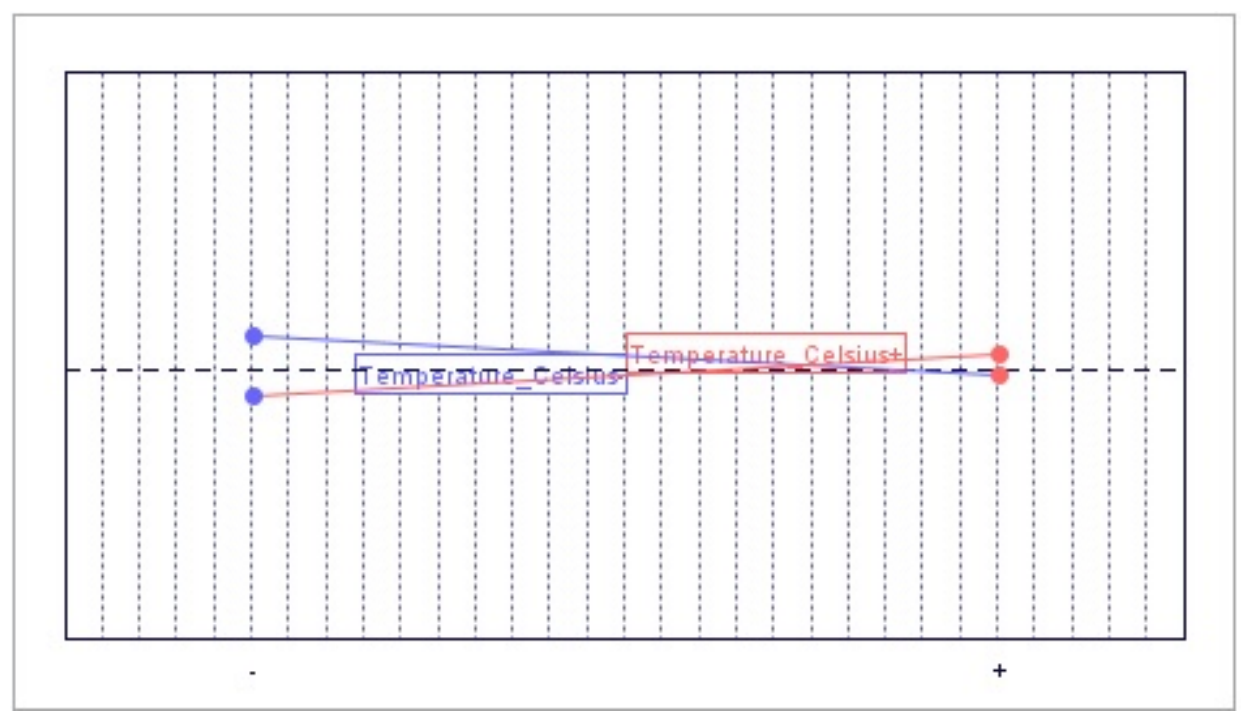


(g)

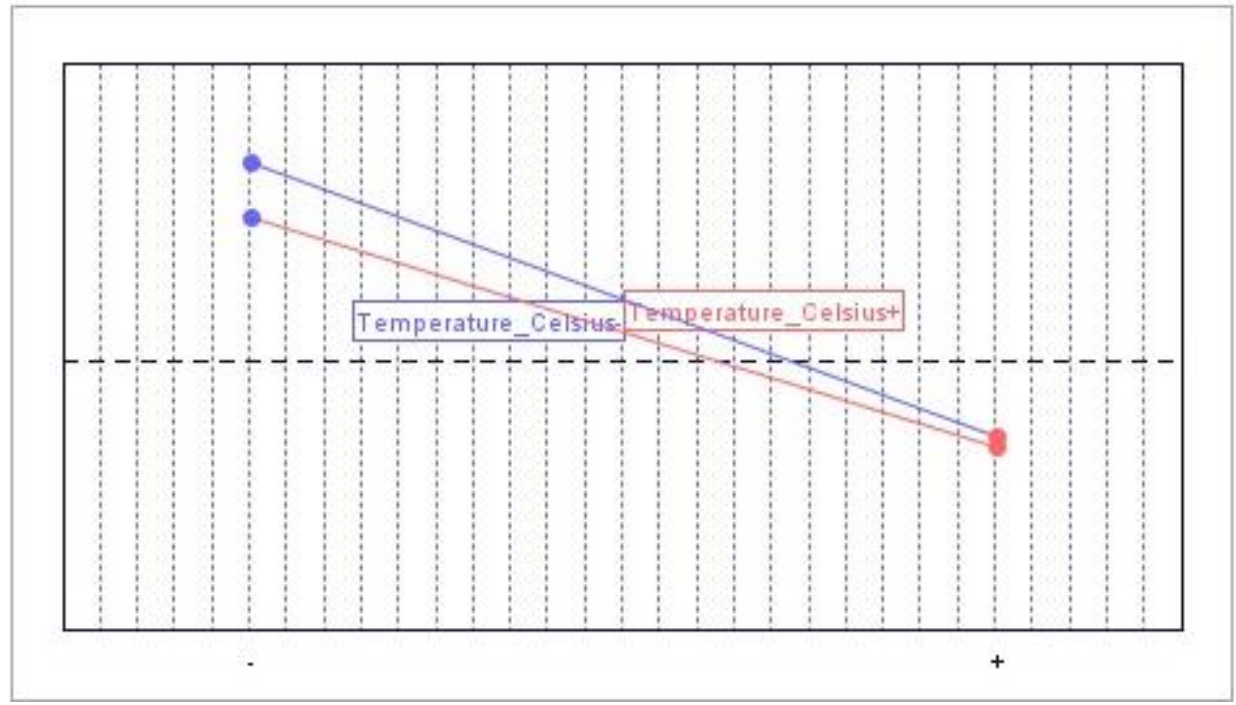

(h)

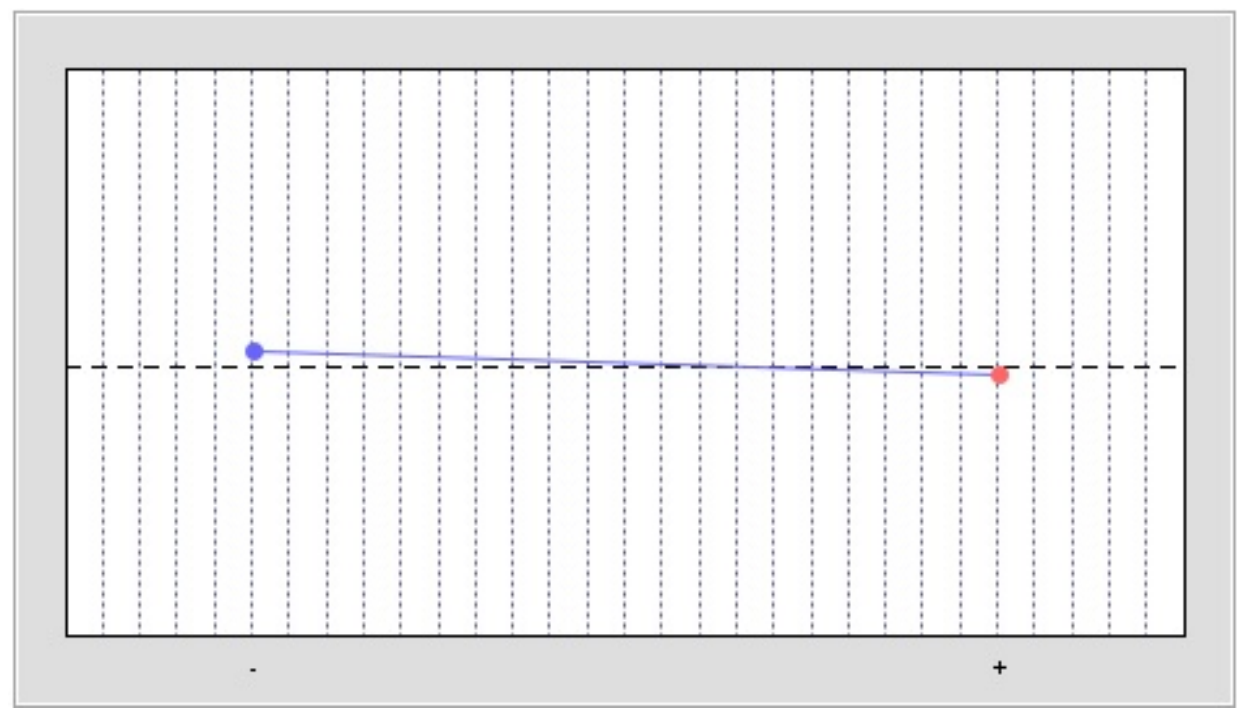

(i)

Figura 10.4: Correlação uma à uma das variáveis e diâmetro médio dos filamentos.

A figura 10.5 trata da resposta desvio padrão médio nos valores obtidos para diâmetro do filamento. É possível verificar na figura 10.5(a), (d), (e) que há um aumento do desvio padrão com o aumento do diâmetro do bico de extrusão e este aumento ocorre de maneira independente da variação da rotação e temperatura, figuras 10.5 (d) e 10.5 (g), pois mesmo alterando-se estas últimas variáveis ainda se verifica o perfil de reta crescente. Para a variação de rotação e temperatura as figuras $10.5(\mathrm{e})$ e 10.5 (i) respectivamente, mostra-se que a 
média dos desvios padrões se mantém mesmo com a variância dos parâmetros, não havendo correlação. Para baixas temperaturas, o aumento da rotação da rosca gera uma diminuição do desvio padrão. Já para baixas rotações, figura $10.5(\mathrm{~h})$ o aumento da rotação também gera uma leve diminuição na média dos desvios padrões figura 10.5(f). A alteração combinada do diâmetro de bico e temperatura não gera variância na resposta, sendo este resultado expresso pelas linhas retas na figura 10.5(c).

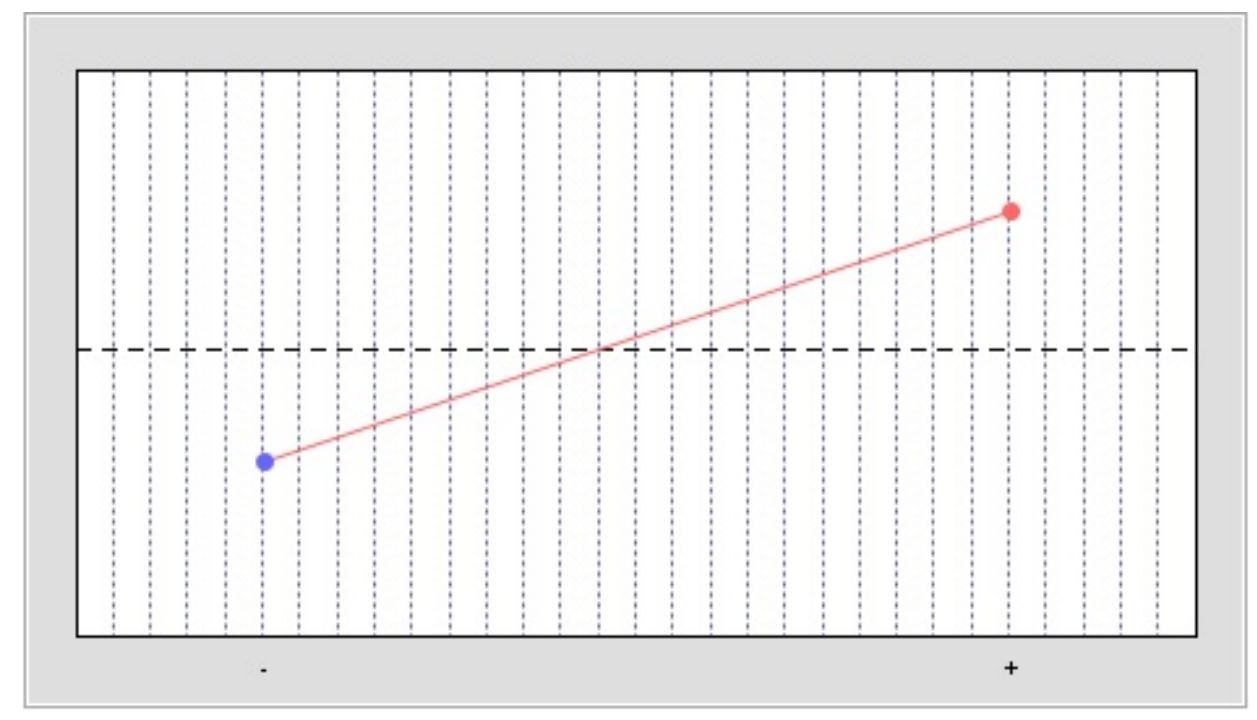

(a)

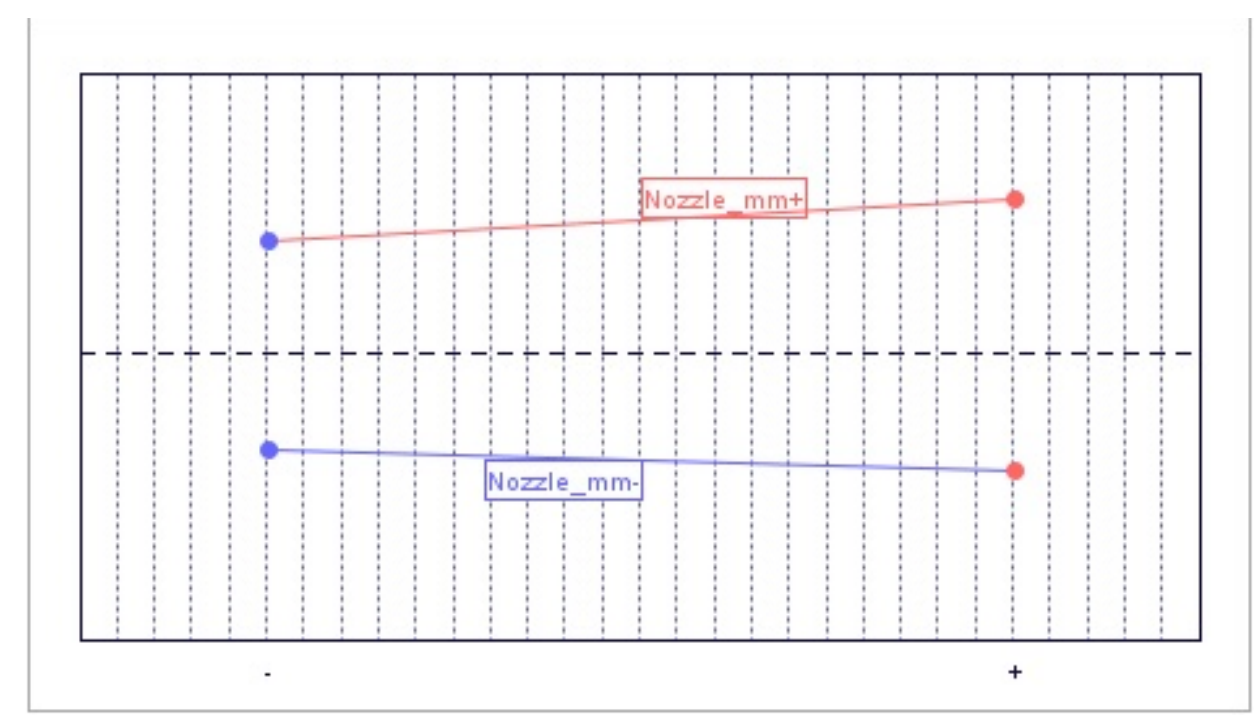

(b) 


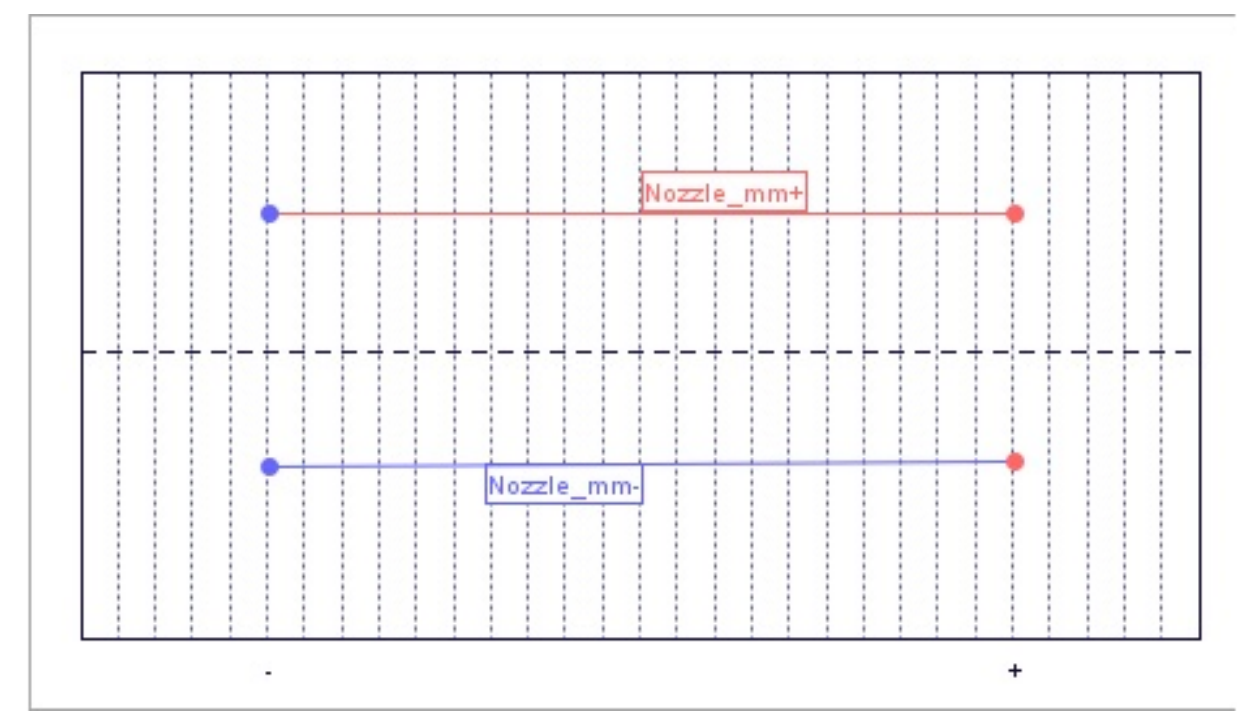

(c)

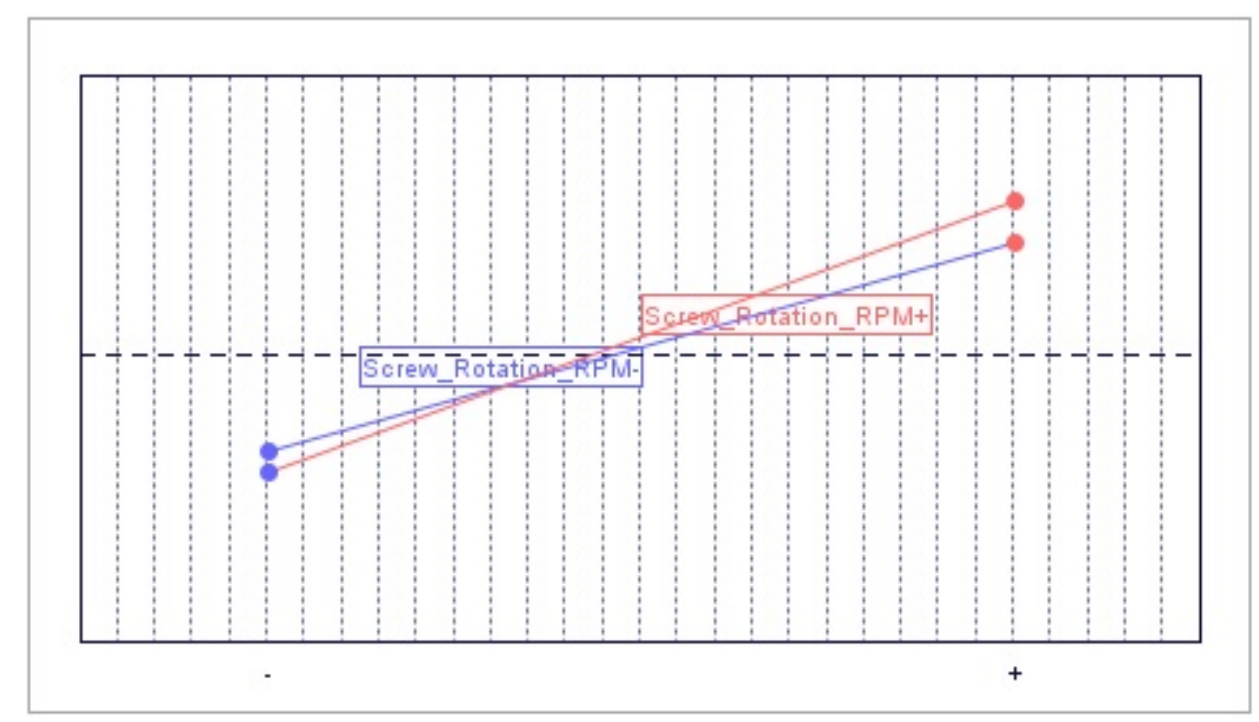

(d)

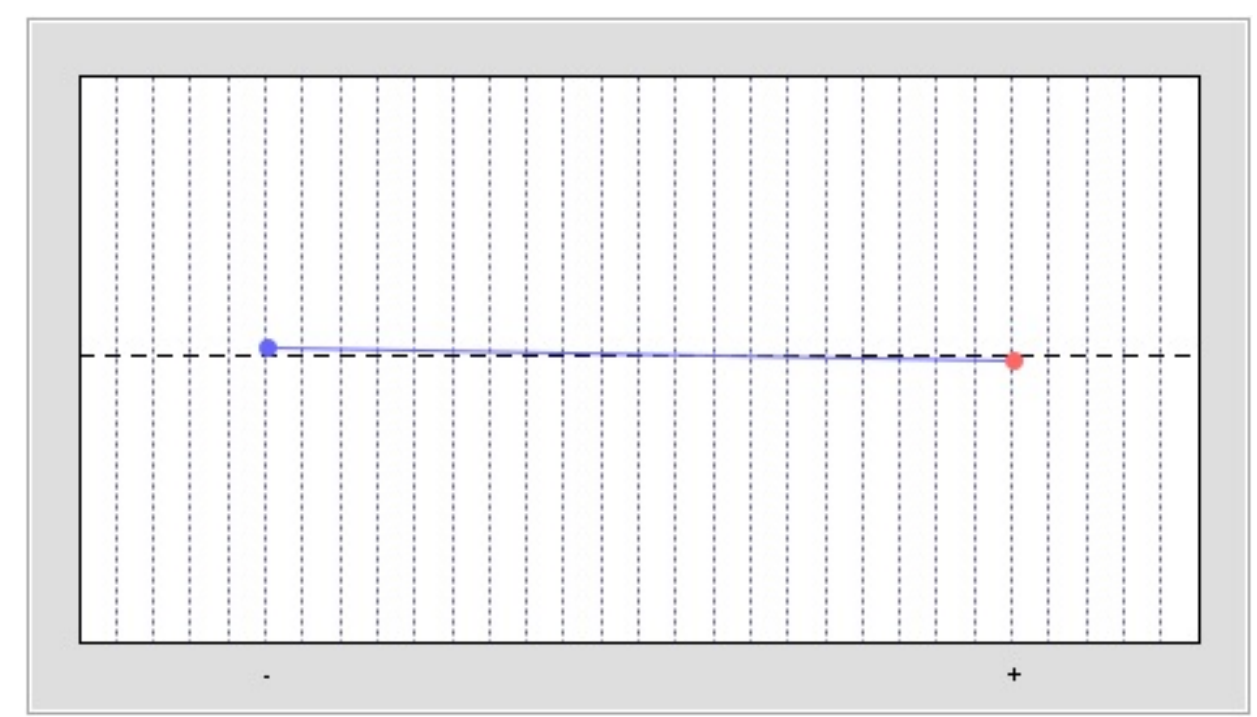

(e) 


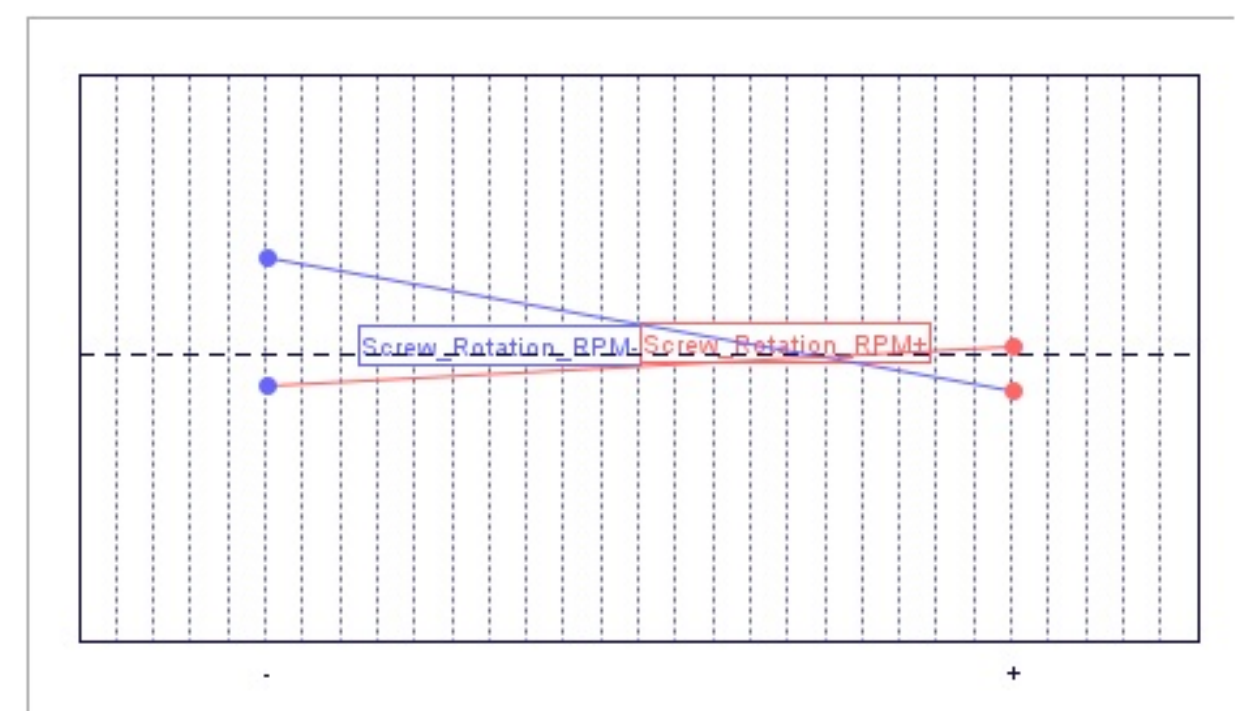

(f)

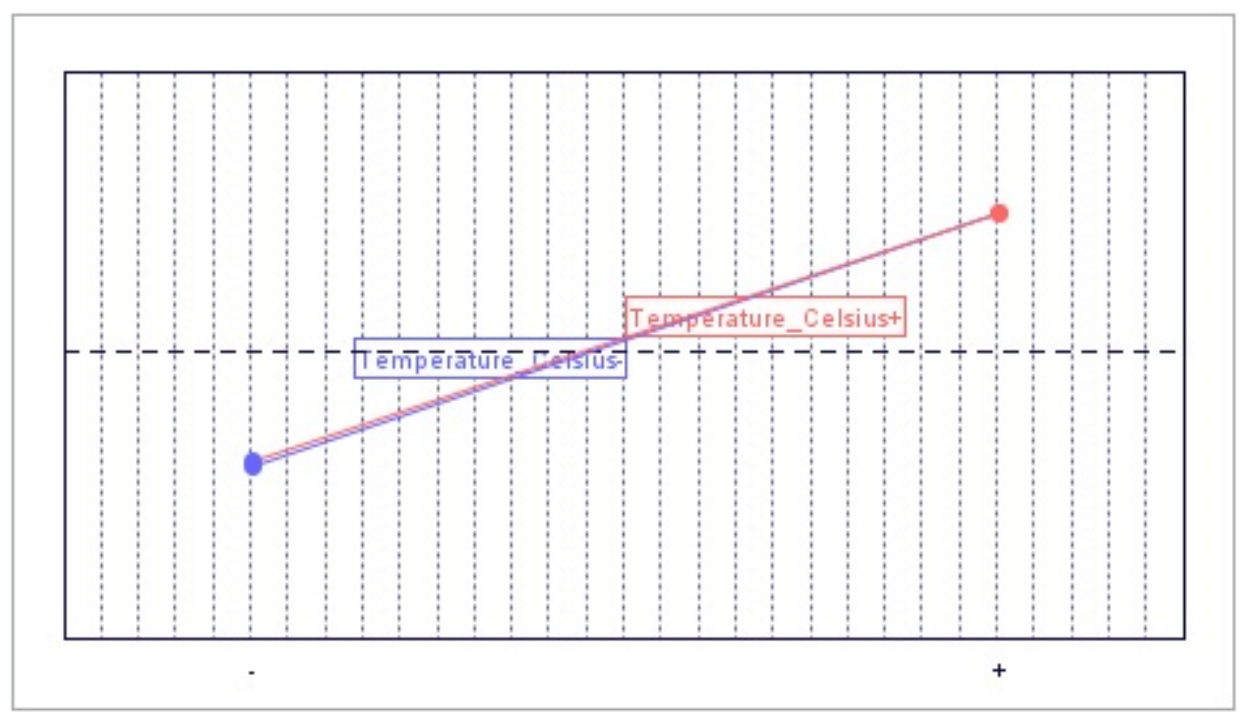

(g)

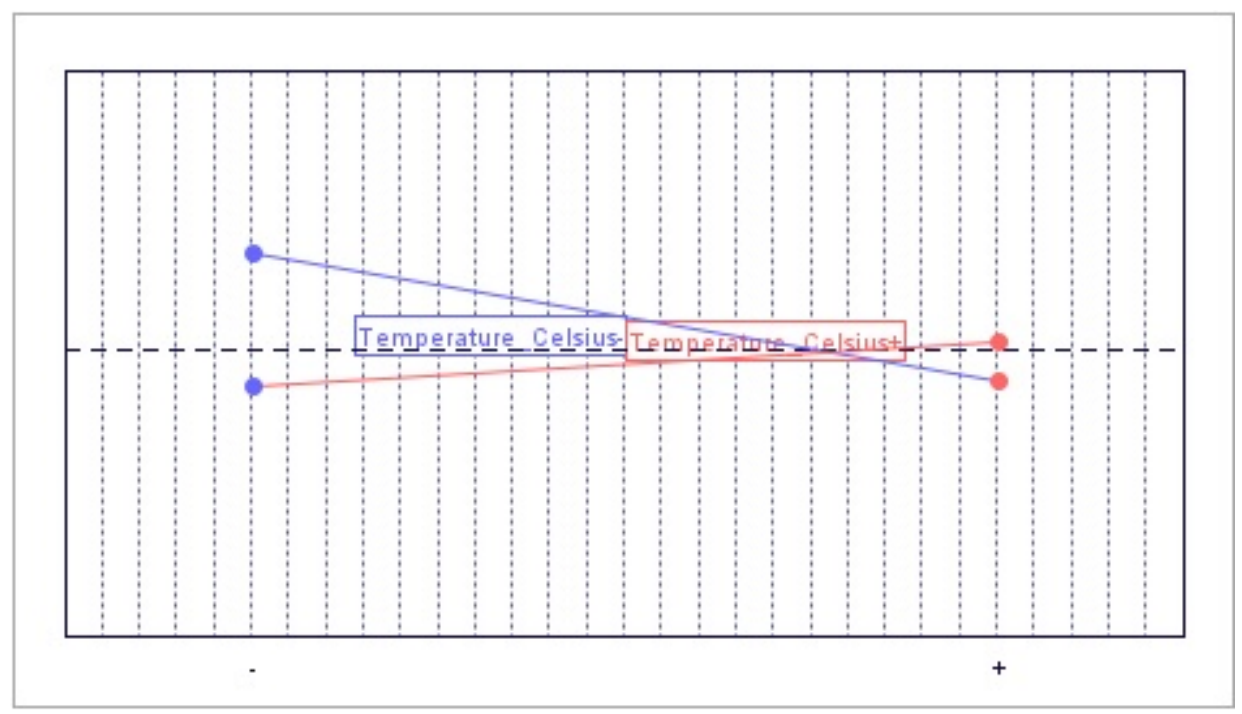

(h) 


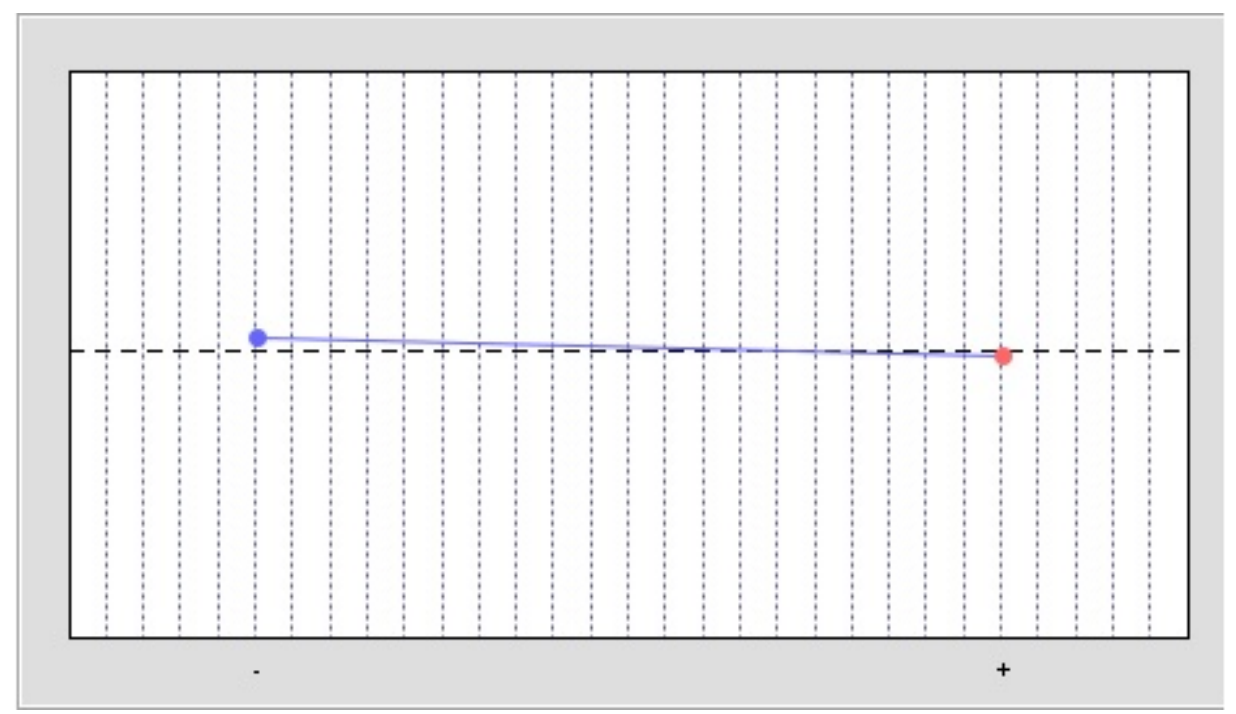

(i)

Figura 10.5: Correlação uma à uma das variáveis e desvio padrão médio dos filamentos.

Outra ferramenta visual importante é a análise gráfica 3D dos resultados obtidos. Essa análise é baseada na plotagem da resposta, no caso, o diâmetro médio dos filamentos, confrontado com duas das três variáveis de entrada em cada gráfico. Na figura 10.6, é possível visualizar valores de diâmetros médios de filamentos distribuídos, ou seja, há vários diâmetros para várias temperaturas com os dois bicos.
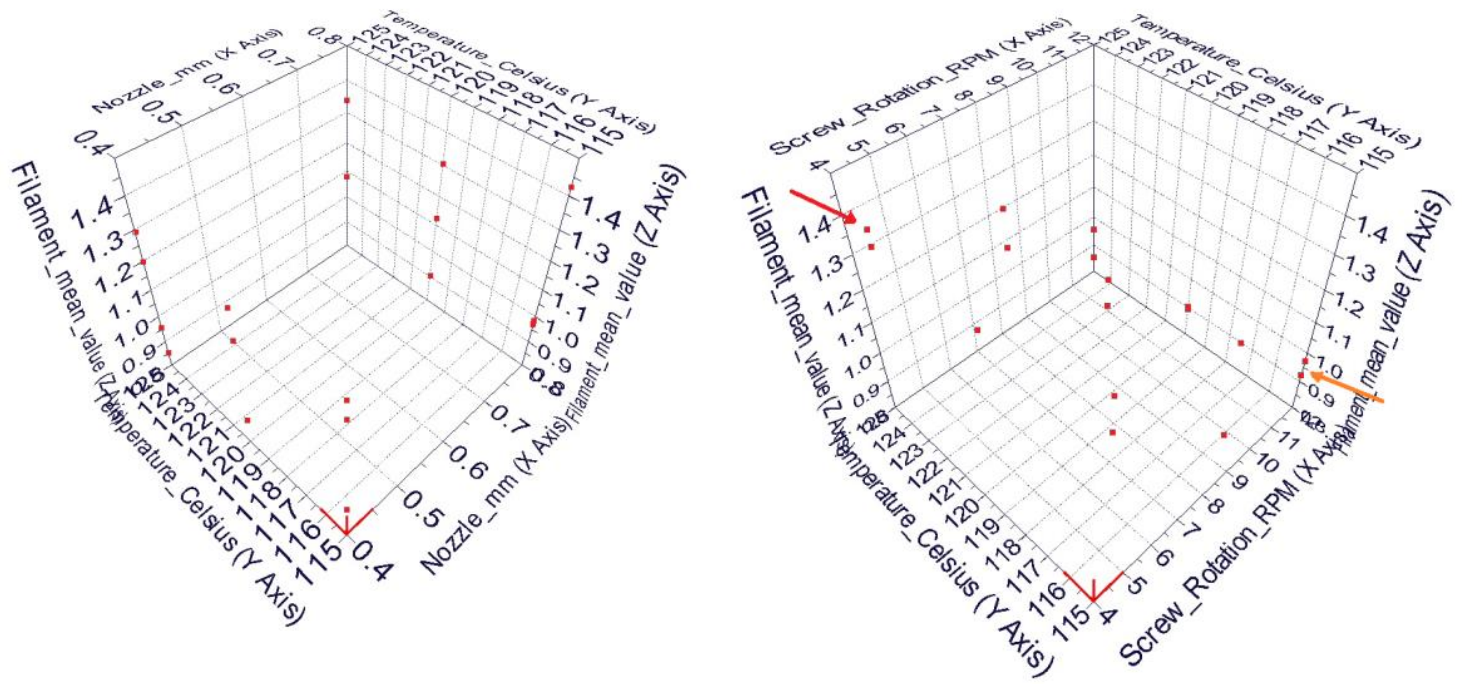

Figura 10.6: Diâmetro dos bicos x Figura 10.7: Rotação da rosca $x$ Temperatura $x$ Diâmetro médio dos Temperatura $x$ Diâmetro médio dos 
filamentos.

filamentos.

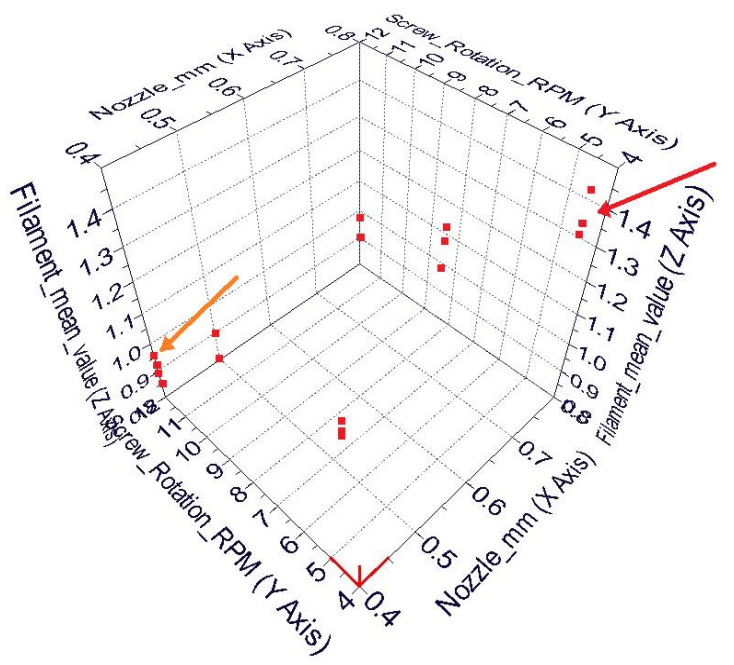

Figura 10.8: Diâmetro dos bicos $x$ Rotação da rosca $x$ Diâmetro médio dos filamentos.

A figura 10.7, já se verifica uma tendência de filamentos maiores para a combinação rotações baixas e temperaturas altas, seta vermelha indica 0 extremo desse fenômeno, e o inverso também ocorre, seta laranja, com filamentos menores para temperaturas menores e rotações altas. Na figura 10.8 observa-se a relação entre valores de diâmetros de filamentos mais altos para baixas rotações e bico maior, seta vermelha. $O$ oposto também ocorre com valores baixos da resposta para o bico menor e menores rotações.

\subsection{Testes preliminares com materiais compósitos}

Uma importante aplicação do cabeçote em estudo é a aplicação com materiais compósitos. A mistura de materiais na forma de pó para posterior extrusão é o método utilizado e três validações foram possíveis.

1 - Mistura de PCL e TCP-Beta que é o trifosfato de cálcio nas proporções de 10\%, 20\% e 30\% de TCP-Beta. Esta validação foi feita devido 
ao apoio ao trabalho de mestrado em engenharia de materiais de José Dávila, Unicamp.

2. Mistura de PCL e oxiapatita contendo lantânio $(20 \% \mathrm{~m} / \mathrm{m}$; PCL/La200AP), com intuito de se fazer um compósito com característica de radio- opacidade. Este trabalho foi realizado devido ao apoio ao trabalho de pós-doutorado de Sybele Saska, Unesp-Araraquara.

3 - Mistura de Nylon e Alumina nas proporções de 10 e $20 \%$ de alumina na mistura para fabricação de corpos porosos.

\subsubsection{Validação com PCL/ TCP-Beta (Parâmetros)}

Após a mistura manual dos pós de PCL e TCP-Beta, o material foi introduzido no cabeçote e foi extrudado e depositado com sucesso. Foi feita a deposição de scaffolds com esse material.
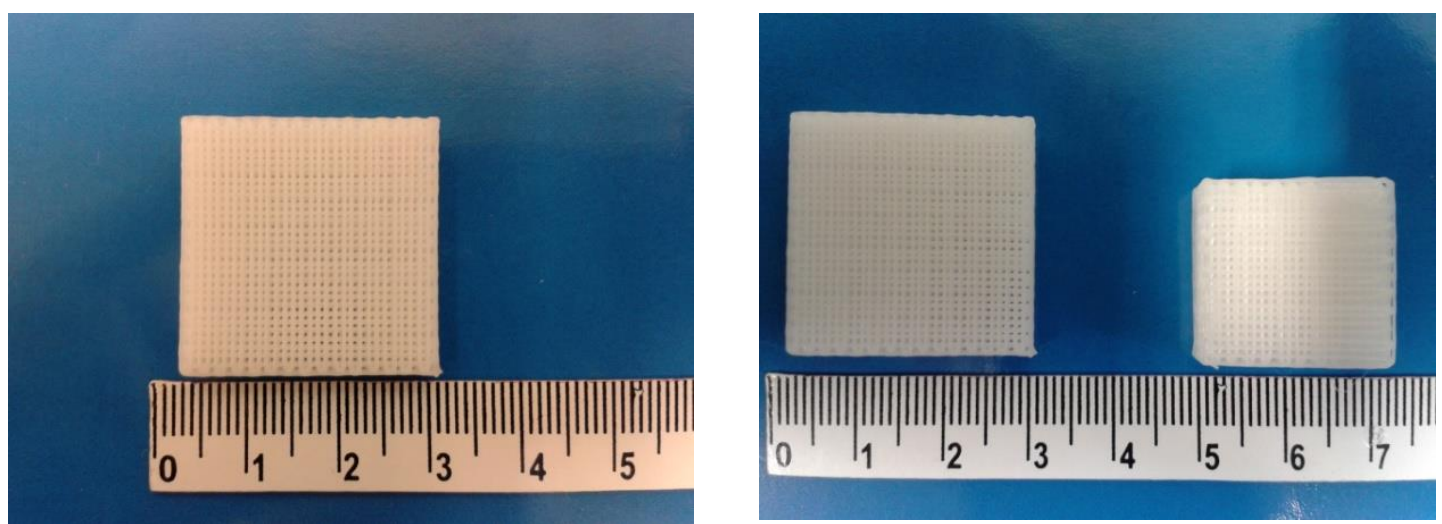

Figura 11.1 - Scaffolds feitos em PCL/TCP-Beta

As micrografias, figura 11.2, são dos filamentos dos scaffolds fabricados com 10, 20 e $30 \%$ de TCP-Beta.

A micrografia 11.2 a) mostra o filamento do PCL com $20 \%$ de beta-TCP e este se mostra continuo e o mesmo ocorre para a amostra com $10 \%$ de beta- 
TCP. As figuras 11.2 b) e d) mostram os filamento fraturados transversalmente. O filamento do material com $20 \%$ de cerâmica apresenta microposidade interna, o que não aparece no filamento com 10\% de cerâmica. As figuras 11.2 e), f), g) mostram seções transversais dos filamentos com $10 \%$ de beta-TCP e pode-se verificar a adesão de camadas sobrepostas. A figura 11.2h) mostra uma vista dos poros de um scaffold feito com 30\% de beta-TCP. Essa validação não foi somente capaz de evidenciar a possibilidade de extrusão de material biocompatível com material cerâmico, mas também a estruturação de scaffolds com adesão de camadas.

a)

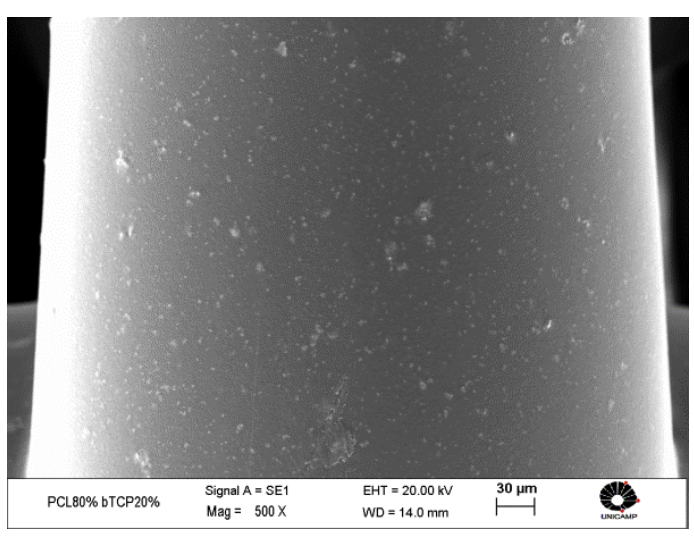

c)

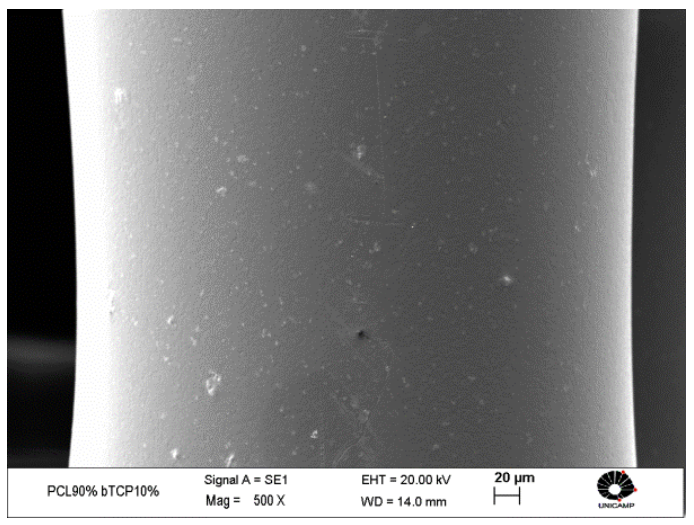

e) b)

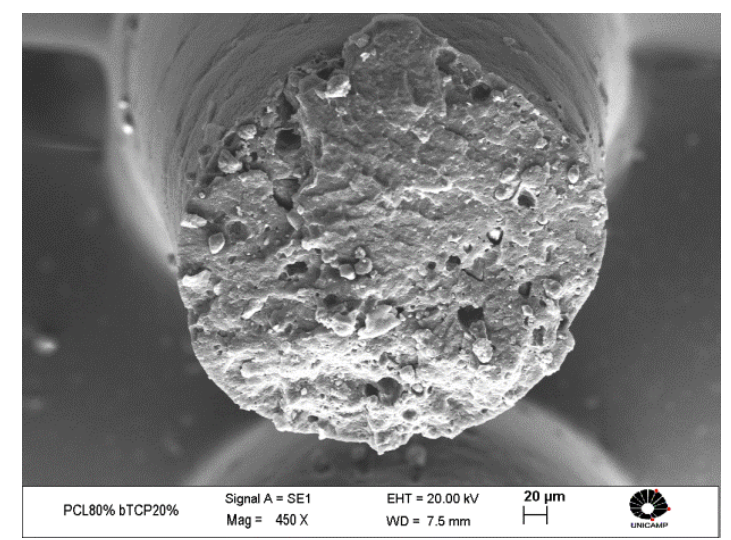

d)

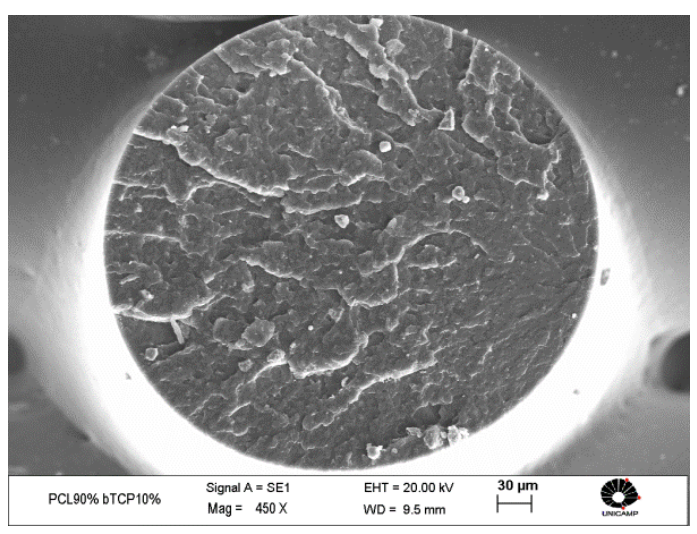

f) 

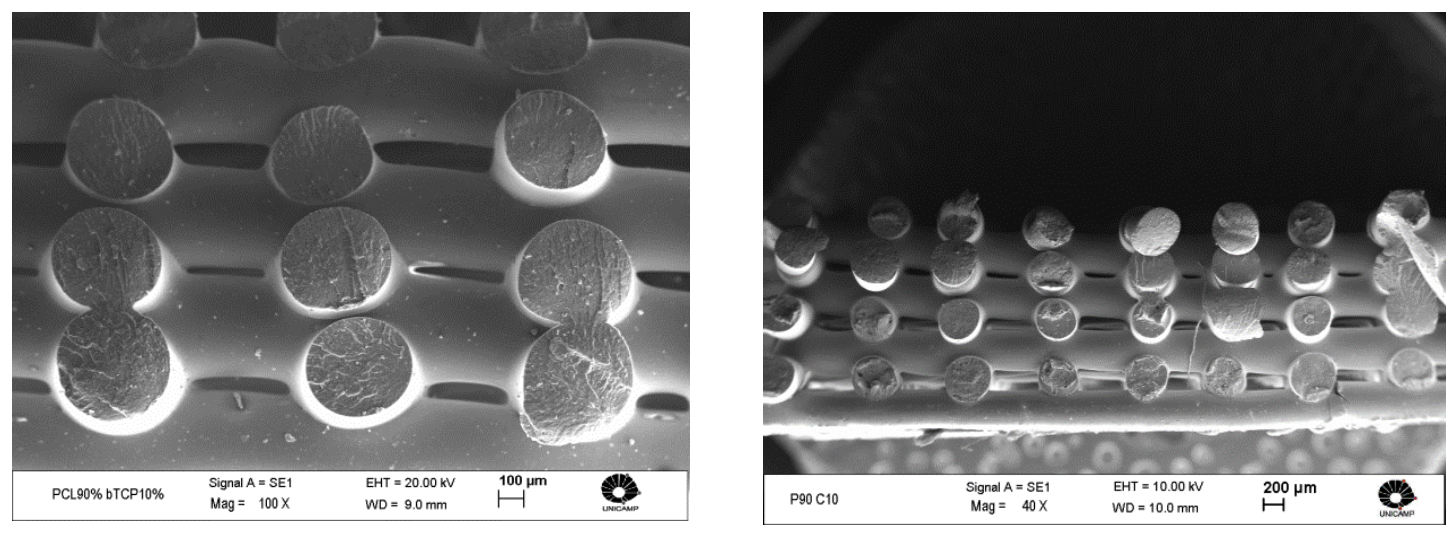

g)

h)
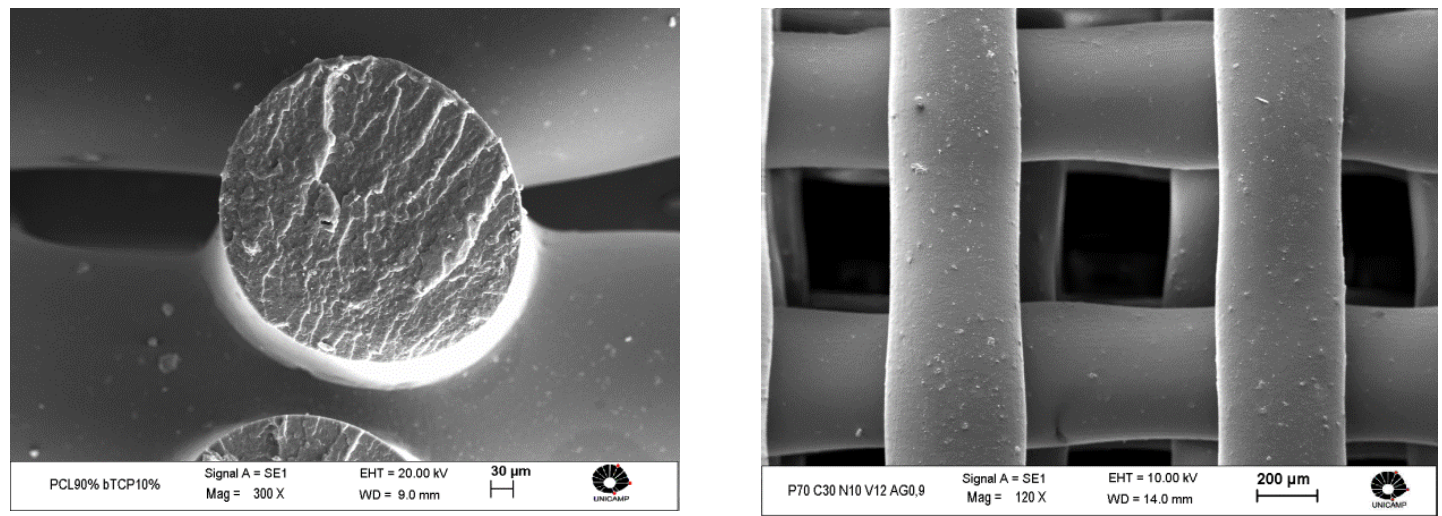

Figura 11.2: Micrografias de scaffolds de PCL/TCP-beta

\subsubsection{Validação com PCL/La20OAP(Parâmetros)}

Neste caso o PCL em pó da Polyscience®, peso molecular: 50000 $\mathrm{g} / \mathrm{mol}$, foi misturado com a oxiapatita radio-opaca em uma proporção de $20 \%$ $\mathrm{m} / \mathrm{m}$ de oxiapatita e esta mistura tem $\mathrm{o}$ intuito de possibilitar a posterior observação em teste in vivo, no qual a absorção do material em subtrato biológico poderá ser verificada por monitoramento por raio-x. Este estudo não faz parte do trabalho aqui apresentado, sendo a extrusão, deposição e consequente fabricação de scaffolds o foco para demonstração da capacidade do cabeçote em estudo, validando seu projeto mecânico e térmico. 

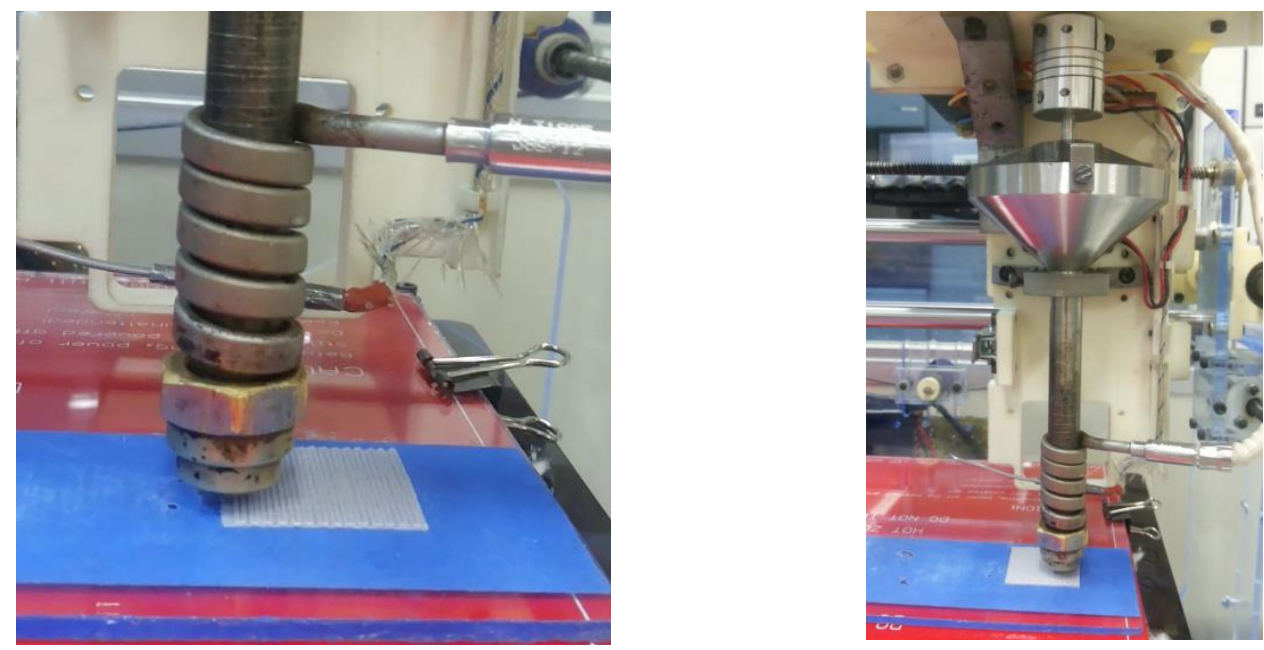

Figura 11.3 - Deposição de scaffolds com oxiapatita.

O cabeçote conseguiu realizar a fabricação de scaffolds para esta mistura com sucesso. O próximo passo para esta linha de pesquisa seria realizar os testes in vivo para verificar se há o crescimento celular em scaffolds.

\subsubsection{Validação Nylon® e Alumina (Parâmetros)}

Outra possibilidade é a mistura de material reciclado de processo SLS, Nylon 12 PA®, 58um de tamanho de grão, e alumina calcinada, 70 $\mu \mathrm{m}$ de tamanho de grão compósito (polimérico/cerâmico).

Duas amostras foram prototipadas com 0,5mm de airgap com proporção de mistura de 10 e $20 \%$ de alumina. Como mostra a figura 11.4 , peças com 20 camadas foram construídas demonstrando a capacidade do sistema na extrusão de material compósito utilizando material reciclado de processo de MA, SLS, como matriz. A plataforma na qual o material foi depositado foi aquecida a uma temperatura de $100^{\circ} \mathrm{C}$. Foi utilizado airgap de $0,5 \mathrm{~mm}$ com arquitetura de deposição, ou variação de ângulo de raster 0/90․ Apesar da estruturação em camadas ter sido validada, ainda seria necessária uma melhor análise das peças para verificação de adesão de camadas, variação de diâmetro de filamentos e testes mecânicos para se verificar a influência da introdução de material cerâmico na mistura. 

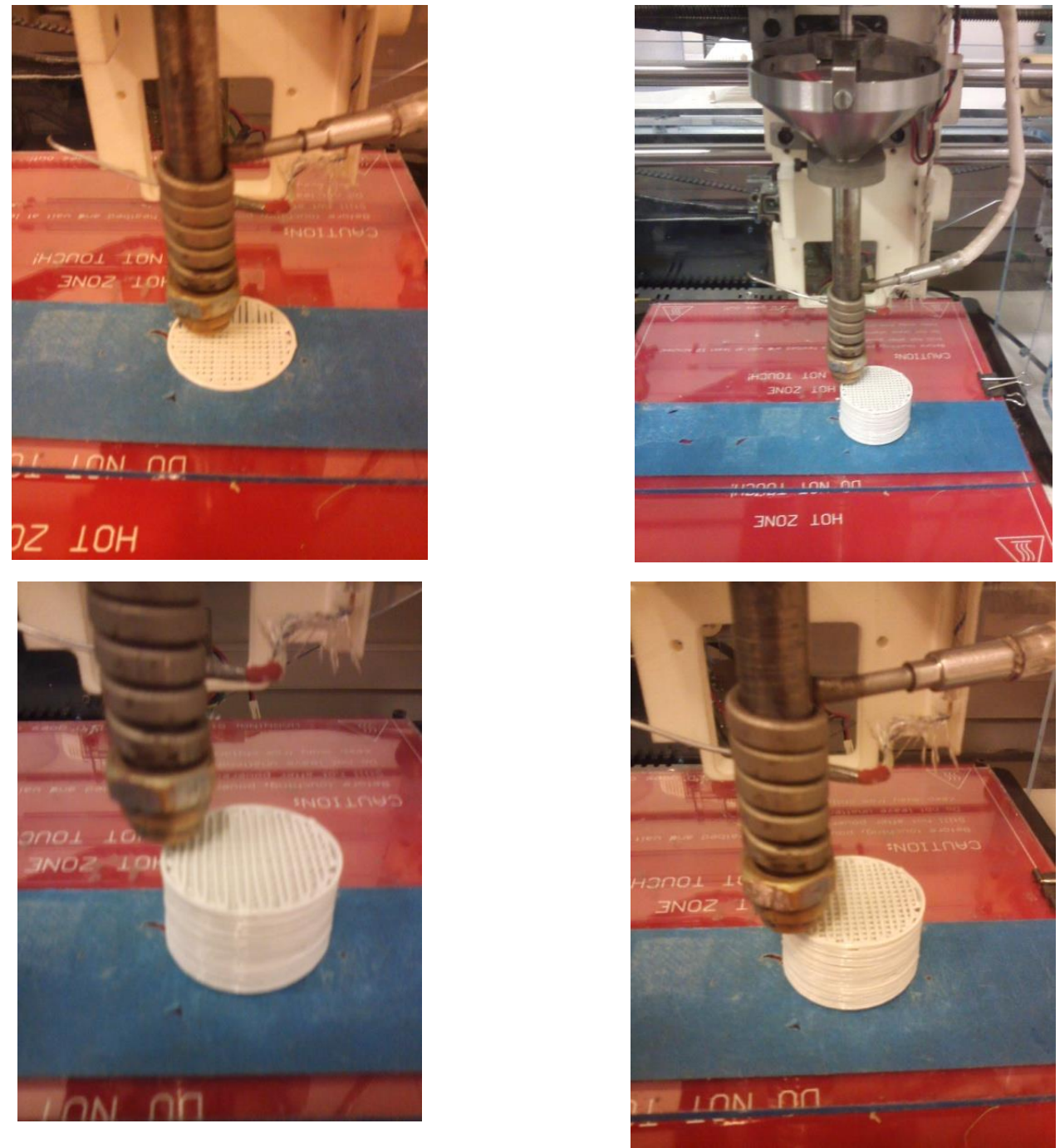

Figura 11.4 - Deposição de corpo poroso com Nylon $12 \mathrm{PA} \Theta$ e alumina. 


\section{PROPOSTAS DE MELHORIAS DO CABEÇOTE DE EXTRUSÃO: REDUÇÃO DE MASSA}

Normalmente, para dispositivos de automação de dimensões reduzidas, utiliza-se a solução de redutores de engrenagens planetárias. Há soluções especialmente estabelecidas para motores de passo NEMA 23. Porém os requisitos técnicos calculados para o projeto e necessários nestes redutores vetam a utilização dos mesmos, esses requisitos são listados na tabela 4:

\begin{tabular}{|l|l|l|}
\hline Requisitos do cabeçote & Valor & Unidade \\
\hline Torque & 20 & N.m \\
\hline Potência & 125 & W \\
\hline Peso & Menor que $2,4 \mathrm{~kg}$ & \\
\hline
\end{tabular}

Tabela 12.1 - Requisitos técnicos do redutor

Todos os redutores de engrenagens planetários que tinham capacidade técnica de realizar uma redução 20:1 com potência suficiente extrapolavam a faixa de peso aceitável para o projeto, como exemplo, expõe-se o catálogo de redutores, (ANEXO 1 e 2: catálogo do redutor)

Verifica-se que mesmo o redutor em linha, com menor peso, apresenta $1,3 \mathrm{~kg}$ o que é incompatível com o projeto, pois representa mais da metade do peso do cabeçote. A próxima opção de redutor capaz de ser utilizado neste dispositivo é o redutor harmônico. Este tipo de redutor é caracterizado pela capacidade de altas taxas de redução em um único estágio, reduzindo as dimensões do redutor e consequentemente seu peso. Além disso, este tipo de redutor apresenta folga zero de operação, melhorando seu desempenho para aplicações de precisão.

Seu princípio de funcionamento é simples e se traduz em um eixo central acoplado a um elemento ovalado chamado gerador de onda, este último ao girar com o eixo deforma uma engrenagem flexível, que em geral tem 2 
dentes a menos e diâmetro menor que a engrenagem circular externa. Conforme o giro do eixo, a zona de contato entre a engrenagem flexível e a engrenagem circular muda para a região de maior diâmetro da elipse, forma da engrenagem flexível. Para cada 180 graus de giro do eixo, a engrenagem flexível se move no sentido anti-horário com um dente de diferença em relação à engrenagem circular, figura 12.1 .

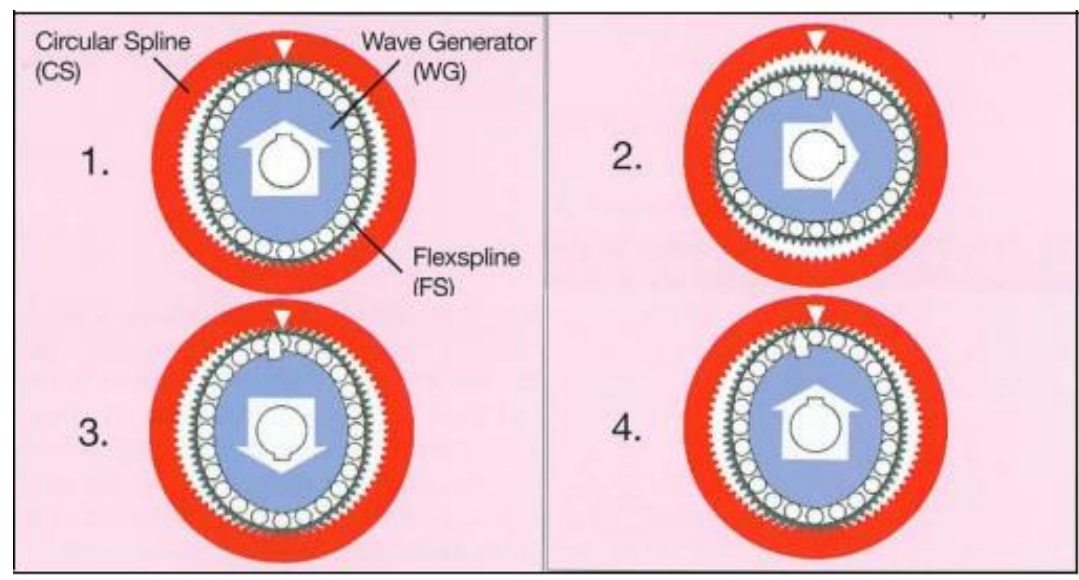

Figura 12.1: Funcionamento de redutor harmônico. Harmonic Drive (2013).

A montagem do sistema pode ser visualizada na figura 12.2.

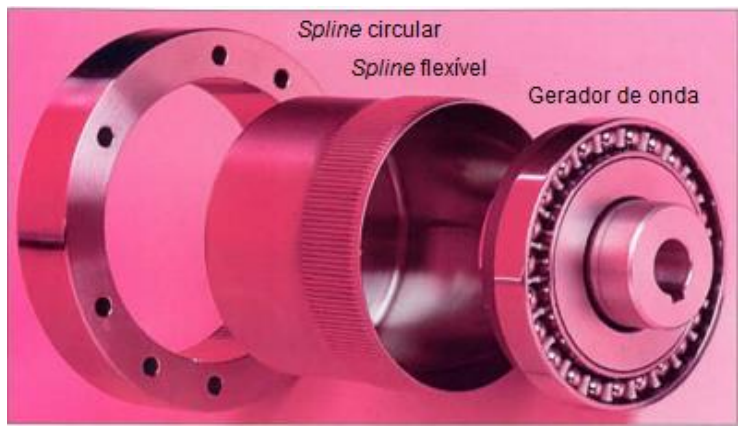

Figura 12.2: Funcionamento de redutor harmônico. Harmonic Drive (2013)

As especificações técnicas deste redutor podem ser visualizadas na figura 12.3. 


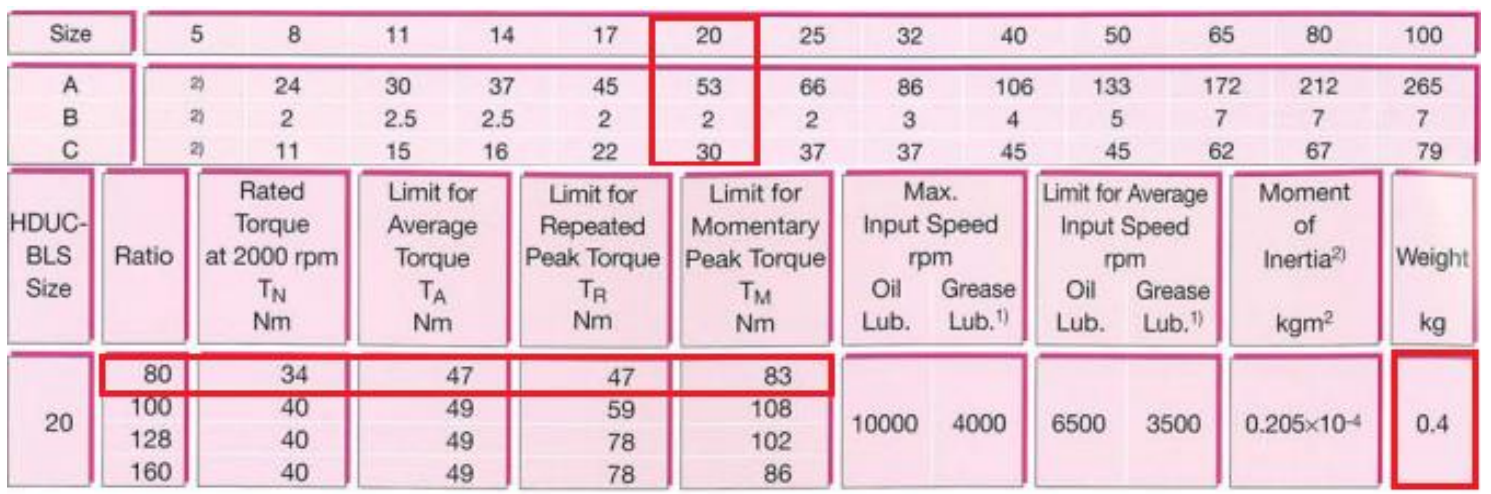

Figura 12.3: Especificações de redutor harmônico. Harmonic Drive (2013)

Realizando uma verificação de especificações do redutor, vê-se que este atende às especificações técnicas desejadas, pois tem alta redução (maior que 20:1), alto torque nominal $34 \mathrm{~N} . \mathrm{m}$, e baixo peso $0,4 \mathrm{~kg}$ e dimensões compatíveis com a do dispositivo.

Foi feita uma pesquisa de fabricantes e fornecedores de sistemas de redução e verificou-se uma dificuldade de aquisição de redutores harmônicos pois o preço dos mesmo é em média 5800 reais.

Portanto, como solução alternativa para o problema em questão, ou seja, o alto peso do redutor, propõe-se uma alternativa, o redutor cicloidal.

O redutor cicloidal apresenta um funcionamento bastante inovador e apresenta características como altas taxas de redução em um estágio, dimensões e peso reduzidos e montagem em linha como acionamento. Ao se procurar este tipo de redutor para venda no Brasil, vê-se que este apresenta soluções comerciais apenas para cargas e potências muito maiores que as requisitadas e as faixas de dimensões e peso desses redutores são inadequadas com o projeto. Portanto, propõe-se realizar o projeto do redutor cicloidal e um protótipo em Nylon 12 PA para substituir o projeto atual baseado em coroa-parafuso sem fim. A Figura 12.4 apresenta os mock-up's do redutor cicloidal. 


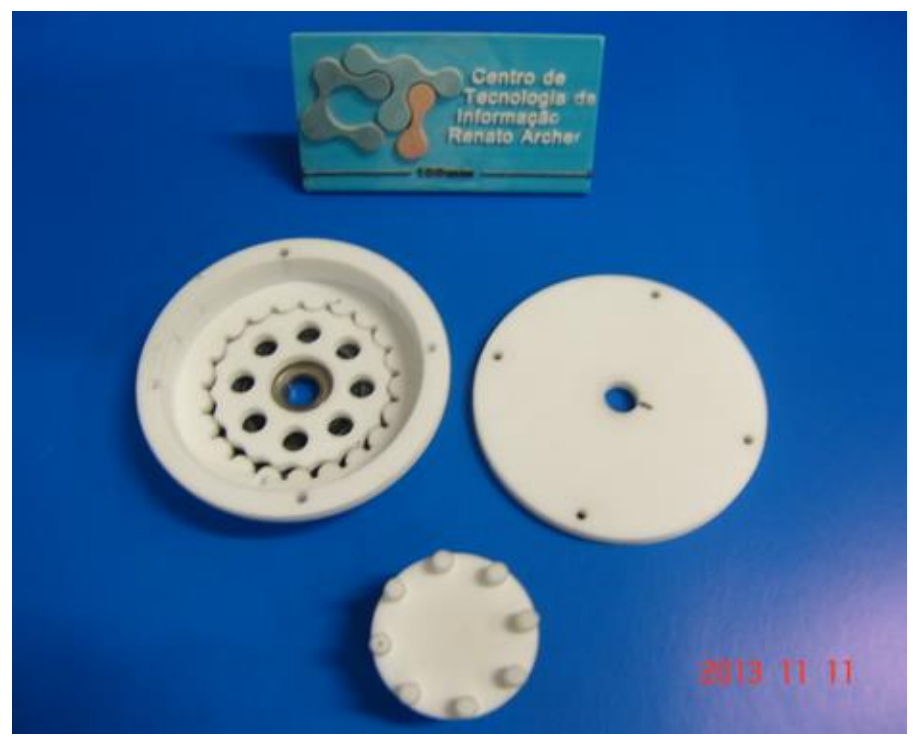

Figura 12.4: Esquema de montagem de um redutor cicloidal

\subsection{Proposta de redução de peso cabeçote de extrusão por} rosca

Propõe-se a redução de peso da coroa que inicialmente apresenta a geometria abaixo, figura 13.1(a) e foi remodelado para a geometria, figura $13.1(\mathrm{~b})$
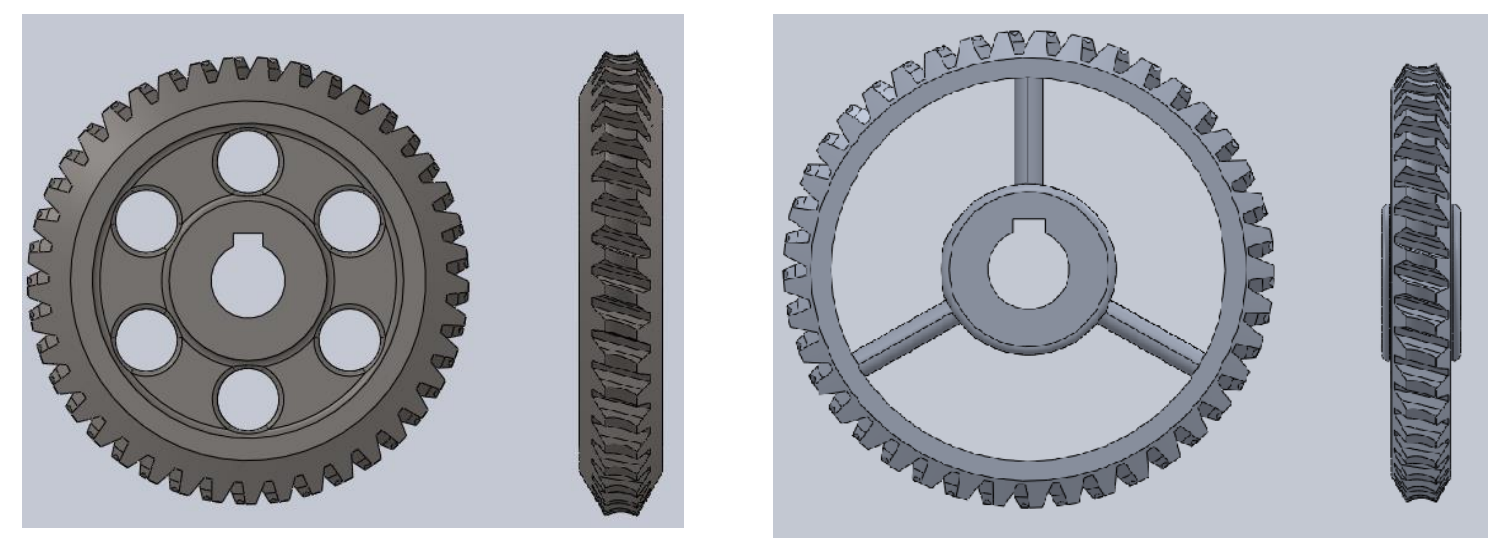

Figura 13.1(a): Coroa de Liga de Ti6Al4V (b) Coroa de Liga de alumínio EOS AISi10Mg

A nova coroa tem a geometria melhor adaptada para redução e gera uma redução de peso de $200 \mathrm{~g}$ aproximadamente. 
Também foi simulada a mudança de material do parafuso sem fim, que gera uma redução de $17,5 \mathrm{~g}$.

Outra solução foi a redução de peso das placas do redutor. Todas as placas tiveram suas espessuras reduzidas pela metade e também a introdução de cortes, com exceção da placa frontal.
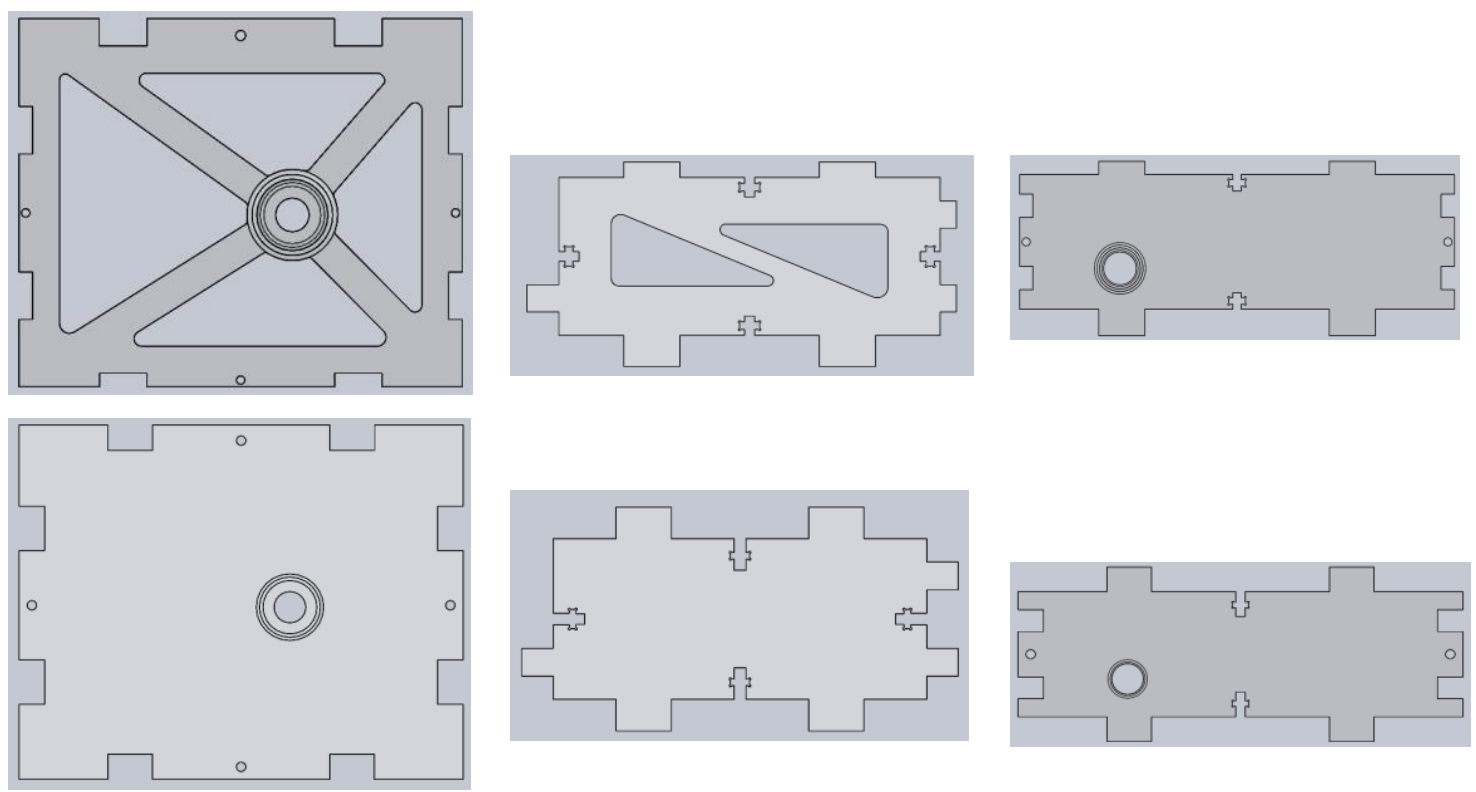

Figura 13.2: Redução do peso das placas laterais, superiores e frontal do redutor.

Essas mudanças geraram uma redução de $184 \mathrm{~g}$. 

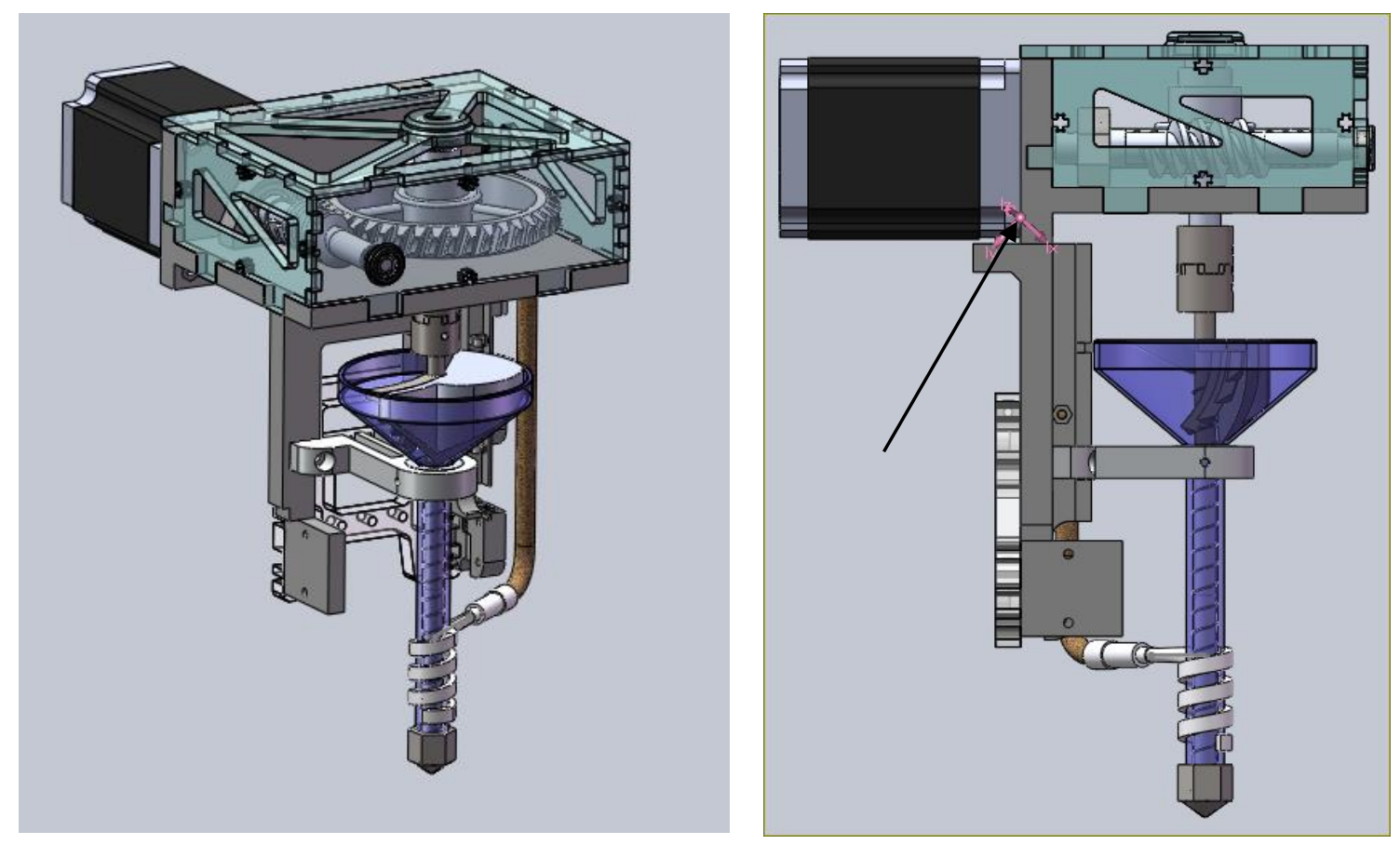

Figura 13.3: Cabeçote com peso reduzido
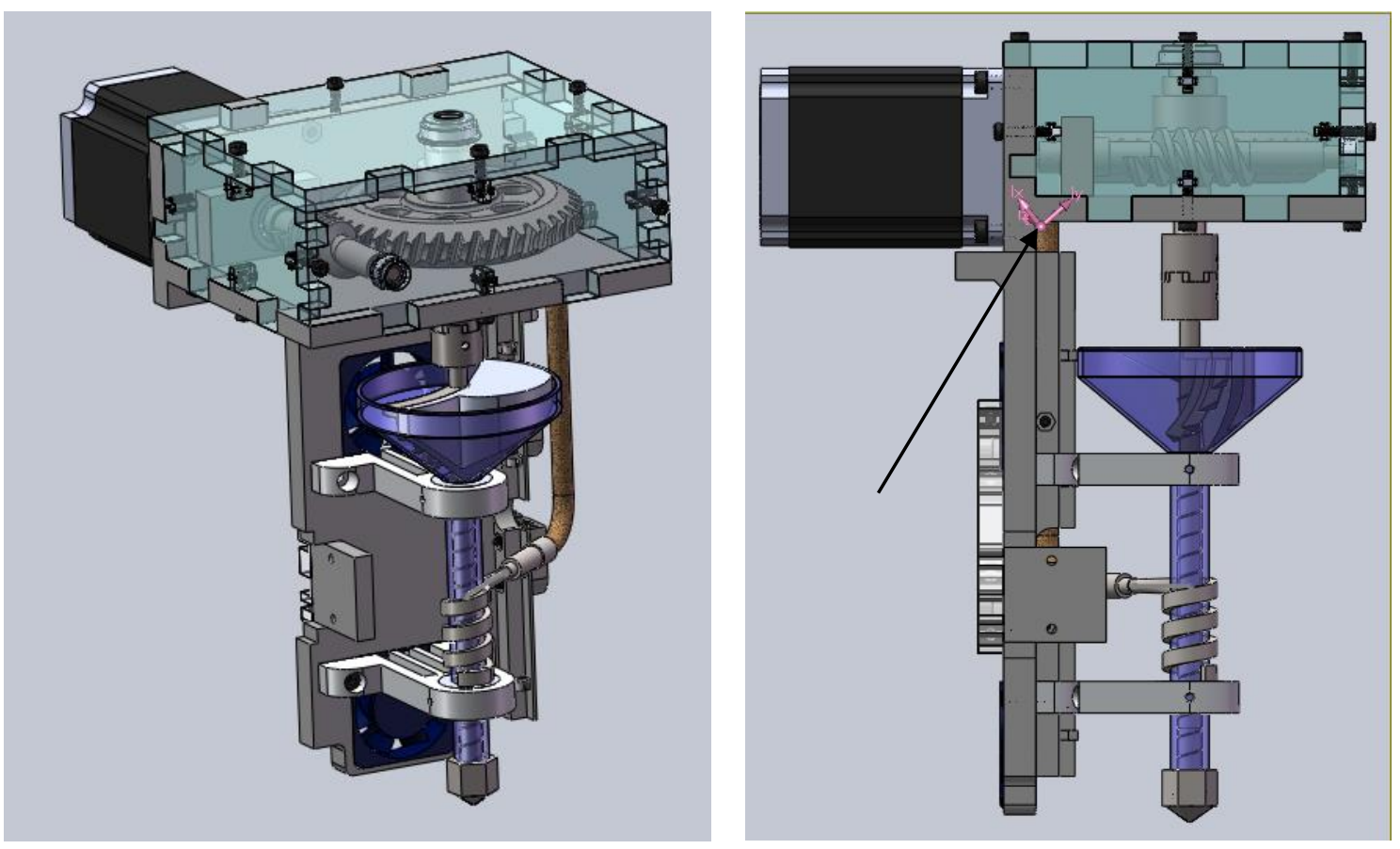

Figura 13.4: Cabeçote original.

A diminuição da placa traseira representou um decréscimo de $78 \mathrm{~g}$. Com todas as alterações o cabeçote apresentou uma redução de peso de $580 \mathrm{~g}$ e 0 cabeçote final apresentou o peso de $1,842 \mathrm{~kg}$. Apenas o conjunto da extrusora, sem redução e motor pesa $260 \mathrm{~g}$. 
O motor pesa $1 \mathrm{~kg}$, portanto o peso da redução é de $842-260=582 \mathrm{~g}$ ou seja, apenas $180 \mathrm{~g}$ mais pesado que a redução HARMONIC DRIVE. Sabendose que o redutor harmônico pesa $400 \mathrm{~g}$ e ainda sim será necessário fazer um subsistema para mudar a direção do torque, talvez não compense a compra do último. Outro problema é a redução do redutor harmônico que é de 50:1 no mínimo. Isso mais que dobraria a faixa de rotação do motor de passo NEMA 23, que hoje trabalha em redução 20:1, o que poderia causar perda de passo no mesmo, sem contar na perda de torque do motor e aumento de gasto em potência, uma vez que em rotações maiores o torque nominal é menor e a potência gasta maior.

Outra conclusão é que com a redução de peso, o centro de massa se deslocou para a parte traseira da máquina, figura 13.3 e 13.4 (indicado com seta), se aproximando dos apoios das barras, o que se espera que reduza a torção do cabeçote para a frente. 


\section{CONCLUSÕES E TRABALHOS FUTUROS}

O cabeçote concebido e pré-dimensionado em Freitas (2001) e Inforçatti (2013) foi validado experimentalmente, por meio da extrusão e deposição de filamentos obtidos de matéria-prima sob o estado de pó. Os testes iniciais foram feitos com Nylon 12 PA® e PCL. Foi usado Nylon 12 PA® para geração de filamentos, com material descartado da máquina industrial de manufatura aditiva baseada na tecnologia SLS localizada no CTI. Em seguida, foram gerados scaffolds com PCL, que apresentou boa precisão dimensional para aplicações em engenharia tecidual.

Foram conduzidos testes com material do tipo polimérico/cerâmico com as seguintes composições: PCL/TCP-beta com proporções de 10, 20 e $30 \%$ $\mathrm{m} / \mathrm{m}$ de TCP-beta, PCL/La20OAP $20 \% \mathrm{~m} / \mathrm{m}$ de oxiapatita radio-opaca, Nylon/Alumina com 10, $20 \% \mathrm{~m} / \mathrm{m}$. Além da extrusão também foi possível a fabricação de scaffolds e corpos porosos com as 3 misturas.

Análises de degradação do material (FTIR) foram realizadas em conjunto com o prof. Marcos Akira D'avila, Departamento de Engenharia de Manufatura e Materiais, da UNICAMP e indicaram que não ocorre degradação do PCL durante o processo de extrusão validando a análise térmica.

Como melhoria do sistema foi feito um estudo de redução de massa do cabeçote, principalmente com relação ao sistema de transmissão e estrutura do suporte. Foram pesquisados dois sistemas de redução: redutor harmônico comercial e o desenvolvimento do projeto de redutor cicloidal. O redutor harmônico foi excluído inicialmente, devido ao fato de ser importado e ter um custo muito elevado (em torno de 6000 reais).

A análise térmica realizada com a coleta de dados experimentais, assegurou a dissipação da elevada taca de calor $\left(220^{\circ} \mathrm{C}\right)$ gerado no processo de extrusão próximo à zona de homogeneização, mesmo tendo-se pouco espaço para essa dissipação, uma vez que se obteve uma temperatura média de $27^{\circ} \mathrm{C}$ na parte traseira do dissipador de 6 aletas, sem anel isolador, 
construído em material EOS TiAl4Va em peça prototipada por tecnologia DMLS.

No estudo de planejamento de experimentos para avaliar os filamentos extrudados em PCL, verificou-se menor variabilidade para o bico de $0,4 \mathrm{~mm}$. Uma característica interessante é a do inchamento do extrudado, fenômeno que ocorreu com o uso dos dois bicos, mais acentuadamente com o bico de $0,4 \mathrm{~mm}$. Talvez seja necessário rever o projeto para avaliar as discrepâncias entre a deposição com cabeçote FDM e o cabeçote em estudo.

Os planejamentos de experimentos obtidos com análise morfológica dos filamentos indicam que os bicos devem ser projetados de forma sistemática, considerando a relação comprimento/diâmetro do bico mais adequada para se evitar o inchamento do extrudado.

É importante ressaltar que para a validação de materiais com o cabeçote em estudo são necessários apenas $10 \mathrm{~g}$ de material para a extrusão e deposição camada à camada e isso representa uma facilidade, quanto ao interesse de se validar um novo material polimérico, blenda ou polímero/cerâmico para aplicação em manufatura aditiva.

Em um trabalho futuro pode-se modelar o processamento de diferentes polímeros, com um programa dedicado à reologia de materiais. Também seria possível comparar os resultados de simulações térmicas com leituras coletadas com câmera termográfica. 


\section{REFERÊNCIAS}

ASTM F2792-10 (2010) Standard terminology for additive manufacturing technologies, copyright ASTM International - 2010, 100 Barr Harbor Drive, West Conshohocken, PA 19428.

AZEVEDO, Á. F. M.. Método dos Elementos Finitos. 2003. Disponível em: <http://civil.fe.up.pt/pub/apoio/ano5/aae/livro_mef_aa.htm>. Acesso em: 20 nov. 2014.

BÁRTOLO, P. et al.(2008) Processo e Equipamento de fabrico rápido por bioextrusão. Patente Portuguesa No. 104247, 2008.

BARZELAY, M.E; TONG, K.N.; HOLLOWAY, G.F.(1955) Effect of Pressure on Thermal Conductance of Contact Joints. NACA Nota técnica 3295

BATCHELDER, J. S. Syringe tip assembly and layered deposition systems utilizing the same. INT PI 8287959, 16 out. 2012. Disponível em: < http://www.uspto.gov/>Acesso em: 20 dez. 2012.

BÉREAUX, Y.; CHARMEAU, J.; MOGUEDET, M,A. (2009) Simple model of throughput and pressure development for single screw. Journal of Materials Processing Technology Num. 209, pp. 611-618.

BLOOM, M.F.(1964) Thermal Contact Conductance in Vacuum Enviroment, Missile and Space Systems Division, Douglas Aircraft Company INC. SM47700. Nota técnica.

BRETAS, R.; D’ÁVILA, M.A.(2005) Reologia de Polímeros Fundidos. São Carlos: EdUFSCar, 2005, p. 19-23.

BUR, A.J.; ROTH, S.(2004) Temperature Gradients in the Channels of a SingleScrew Extruder, Polymer Engineering and Science, NOVEMBER 2004, Vol. 44 , No. 11

BUTTON, S.T. (2001) Apostila de Metodologia para planejamento experimental e análise de resultados. FEM-UNICAMP.

CALLISTER, W.D. (2002) Ciência e Engenharia de materiais: uma introdução. Editora: John Wyley and Sons 589p.

CAMPBELL, I.; BOURELL, D.; GIBSON, I. (2012) Additive manufacturing: rapid prototyping comes of age. Rapid Prototyping Journal. V. 18, Num.4, p. 255258.

CAPONE, C.; DI LANDRO, L.; INZOLI, F.; PENCO, M.; SARTORE, L.(2007) Thermal and Mechanical Degradation During Polymer Extrusion Processing, POLYM. ENG. SCI., 47:1813-1819, Society of Plastics Engineers 
CHENG, L.C.; MELO FILHO, L.D.R.(2010) QFD - Desdobramento da função qualidade na gestão de desenvolvimento de produtos. Editora Blucher. $2^{a}$. Edição revisada.

CHUNG, C.I. (2000) Extrusion of polymers: theory and practice. Hanser: Cincinnati. 369p.

COMB, J. W.; PRIEDEMAN, W. R.; LEAVITT, P. J.; SKUBIC, R. L.; BATCHELDER, S. High-Precision modeling Filament. PI INT US 6,866,807, 16 mar. 2005. Disponível em: < http://www.uspto.gov/>. Acesso em: 20 out. 2012. Vert M. (2009) Bioabsorbable polymers in medicine: an overview. Eurolntervention. V. 5, Suppl. F. ISSN 1774-024X.

CRUMP, S.S. (1994) Modeling apparatus for three-dimensional objects. United States Patent. Site: www.inpi.gov.br

DENG, J.; LI, K.; HARKIN-JONES,K.; PRICE,M.; KARNACHI,N.; KELLY,A.; VERA-SORROCHI,J.; COATES, J.; BROWN, E.; FEI, M.(2014) Energy monitoring and quality control of a single screw extruder, Applied Energy 113, 1775-1785

DROBNY, J.G.(2007) Handbook of Thermoplastic Elastomers. William Andrew Inc. ISBN: 978-0-8155-1549-4

ELZEIN, T.; NASSER-EDDINE, M.; DELAITE, C.; BISTAC, S.; DUMAS, P. (2004). FTIR study of polycaprolactone chain organization at interfaces. Journal of Colloid and Interface Science, 381-387.

FREITAS, M.S. de (2011) Projeto conceitual e preliminar de uma rosca de extrusão para uma impressora 3-D de pequeno porte. Trabalho de Conclusão de Curso, Departamento de Engenharia Mecânica, EESC, USP. $117 p$.

GIBSON, I., ROSEN, D.W, STUCKER, B. (2010) Additive Manufacturing Technologies: Rapid Prototyping to direct digital manufacturing. Springer.

GILES, H.F.; WAGNER, J.R., MOUNT III, E.M. (2008) Extrusion: The Definitive Processing Guide and Handbook. Elsevier. 143p.

HUEBNER, K.H.; DEWWHIST, D.L.; SMITH, D.E.; BYROM, T.G. (2001) The Finite Element Method for Engineers, 4th edition, John Wiley and Sons, Inc.

IKEGAMI, R.A.(2007) Desenvolvimento de corpos cerâmicos compostos bioativos com estrutura de gradiente funcional. Tese de doutorado, Escola de Engenharia de São Carlos, Universidade de São Paulo. 110p

INCROPERA, F.P; DEWITT, D.P(2007) Fundamentals of Heat and Mass Transfer. 6a. Edição, John Wiley \& Sons" pag. 2. 
INFORÇATTI NETO, P. (2007) Máquina básica de prototipagem rápida de projeto aberto de hardware e software, para uso de pesquisas em bioengenharia, desenvolvimento, inovação e aplicações de prototipagem rápida. Trabalho de Conclusão de Curso. Faculdade Independente do Nordeste, BA - Brasil.

INFORCATTI NETO, P.; LIXANDRÃO FILHO, A.L.; PEREIRA, F.D.A.S; SILVA, J.V.L.; SILVEIRA, Z. C.; BÁRTOLO, P.(2012) Thermoplastic filament extruder head for desktop additive manufacturing machines. In: Innovative developments in Virtual and Physical Prototyping. London: Taylor \& Francis Group, p. 635-638, ISBN 978-0-415-68418-7.

KELLY, A.L., BROWN, E.C.; COATES, P.D. (2006) The Effect of Screw Geometry on Melt Temperature Profile in Single Screw Extrusion, POLYMER ENGINEERING AND SCIENCE, Publicado online, Wiley Interscience

KRISHNAMOORTHY, C.S.(2001) Finite Element Analysis, Theory and Practice, 2nd edition, Tata McGraw-Hill Publishing Company Limited. 1994.

LIU, B.; XIE, Y.; WU, M.,(2009) Research on the Micro-Extrusion Characteristic of Mini-Screw in the Screw Extruding Spray Head, Polymer Bulletin, Abril 2010, Volume 64, Assunto 7, pp 727-738

LUO, R.C.; TZOU, J-H; HSIEH, C-Y.; CHOU, H-H. (2002) The development of a thermal extrusion based rapid prototyping mechatronics system. 28th Annual Conference of the IEEE Industrial Electronics Society. V.1, Num.5-8. p. 2237-2242.

MALONE, E.; LIPSON, H.: Fab@Home: the personal desktop fabricator kit. Rapid Prototyping Journal, Vol.13. nº 4, 245-255, 2007.

MANRICH, S.; SANTOS, A. S. F.(2005) An Overview of Recent Advances and Trends in Plastic Recycling. Conservation and Recycling of Resources: New Research, cap.1, Christian V. Loeffe (ed.), Nova Science Publishers, Hauppauge, NY

MONTGOMERY, D.C.(1991) Design and Analysis of Experiments, 3ª edição, John Wiley and Sons.

MONTGOMERY,D.C (2005) Design and Analysis of Engineering Experiments 6 a. edição, John Wiley \& Sons,

OLIVEIRA, M. F.(2008) Aplicações da prototipagem rápida em projetos de pesquisa. Tese de mestrado - Unicamp -Campinas, SP: [s.n.], 2008.

PALLAROLLAS, E. A. F. F.(2013) Revisão técnica de processos de manufatura aditiva estudo de configurações geométricas, para estruturas de impressoras tridimensionais. Monografia (Graduação em Engenharia Mecânica) - Departamento de Engenharia Mecânica, Escola de Engenharia de São Carlos, Universidade de São Paulo, 2013. 
POWERS, M. T.; LAVERNIA, E. J.; GROZA, J. R.; SHACKELFORD, J. F. (2007) Materials Processing Handbook. Cap. 26. ISBN 978-0-8493-3216-6.

RAUWENDAAL, C. (2001) Polymer extrusion. Editora: Hanser-Verlag Gardner Publications. p. 1-20; p.119-153; p. 425-434.

RAQUEZ, J-M; NARAYAN, R.; DUBOIS, P.(2008) Recent Advances in Reactive Extrusion Processing of Biodegradable. Polymer-Based Compositions, Macromol. Mater. Eng. 2008, 293, 447-470

RIBEIRO, G. S.; SILVEIRA, Z. C.; SILVA, J.V.L.(2013) STRUCTURAL AND MODAL ANALYSIS OF A DESKTOP 3-D PRINTER CONSIDERING AN INTERCHANGEABLE MINI SCREW EXTRUSION HEAD, High Value Manufacturing: Advanced Research in Virtual and Rapid Prototyping, Taylor \& Francis.

SENEDESE, A.; LIXANDRÃO FILHO, A., SILVA, J.V.L., INFORÇATTI NETO, P.; PEREIRA, F.D.A.S.; MACIEL FILHO, R. (2011). Additive manufacturing to build polycaprolactone scaffolds. $6^{\text {th }}$ Brazilian Conference on Manufacturing Engineering.

SILVEIRA, Z.C. (2003) Análise estatística e otimização de parâmetros de projeto em componentes de sistemas mecânicos. Tese de doutorado. FEMUNICAMP.

STEINER, S.H; MACKAY, R.J. (2009) Designed Experiments with Fixed and Varying Factors-A Cautionary Tale, Quality Engineering, 21:4, 384-391

VLACHOPOULOS, J.; STRUTT, D. (2003) The role of rheology in polymer extrusion, New Technology for Extrusion Conference, Milão, Itália. p. 21-22.

WOHLERS, T. T. (2012) Wohlers Report 2012. Editora Wohlers Associates, Inc., Fort Collins CO, U.S.A.

WHITE, J.L.; POTENTE, H. (2002) Screw Extrusion Science and Technology, Carl Hanser Verlag GmbH \& Co. KG, ISBN: 978-3-446-43418-9, Print ISBN: 978-3-446-19624-7 


\section{Referências digitais}

CIMJECT - Laboratório de Projeto e Manufatura de Componentes de Plástico Injetados

http://www.cimject.ufsc.br/knowledge (Acesso: 21/10/2013)

RepRap Org.

http://www.reprap.org (Acesso: 21/09/2013)

Base de dados - Derwent

http://www.derwent.com (Acesso em: 23/10/2013).

Base de patentes - INPI - Instituto Nacional de Propriedade Intelectual http://www.inpi.gov.br (Acesso em: 24/10/2013)

Harmonic Drive Shain Wave Gears. Harmonic Drive.

http://harmonicdrive.de/en/technology/harmonic-driver-strain-wave-gears/ (Acesso: 21/09/2013)

Parker, Planetary Gearheads Catalog 8000-4

http://www.parker.com/portal/site/PARKER/menuitem.de7b26ee6a659c147cf26 710237ad1ca/?vgnextoid=fcc9b5bbec622110VgnVCM10000032a71dacRCRD \&vgnextfmt=EN\&vgnextcatid=2578663\&vgnextcat=PLANETARY + GEARHEAD S (Acesso: 21/09/2013) 
Apêndice A 
Tabela A.1

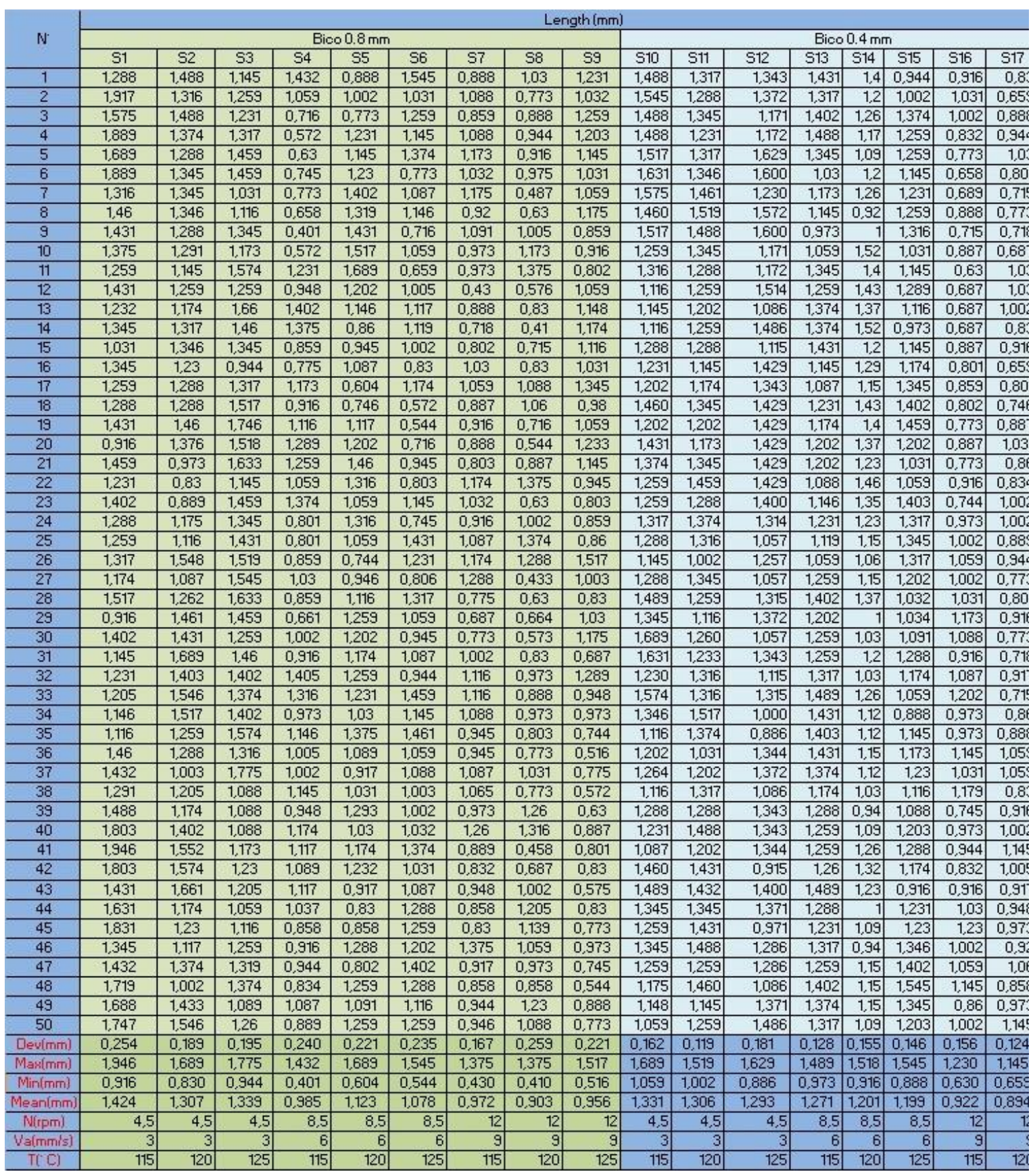

Tabela 1 - Dados do DOE com medições de diâmetro de filamentos. 


\section{ANEXO 1: Redutor planetário com mudança de direção. Parker 2008}
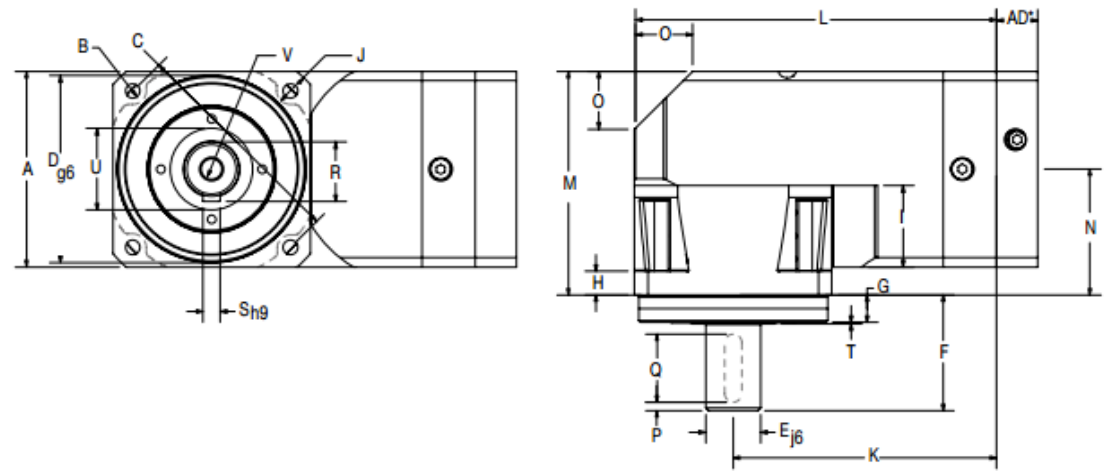

\begin{tabular}{|c|c|c|c|c|c|c|c|c|}
\hline \multirow{5}{*}{$\begin{array}{l}\text { Parameter } \\
\text { Nominal Output Torque }{ }^{1)} \\
\text { T }_{\text {nom r }}\end{array}$} & \multirow{5}{*}{$\begin{array}{l}\text { Units } \\
\text { Nm (inlbs) }\end{array}$} & \multirow{2}{*}{$\begin{array}{c}\text { Ratio } \\
5\end{array}$} & \multicolumn{2}{|c|}{ RX60 Gen II } & \multicolumn{2}{|c|}{ RX90 Gen II } & \multicolumn{2}{|c|}{ RX115 Gen II } \\
\hline & & & 10 & (89) & 44 & (390) & 68 & $(602)$ \\
\hline & & 10 & 19 & (168) & 64 & (566) & 128 & (566) \\
\hline & & $15,20,25,50$ & 24 & (212) & 66 & (585) & 136 & $(584)$ \\
\hline & & $30,40,100$ & 20 & (177) & 60 & (530) & 128 & (531) \\
\hline \multirow{4}{*}{$\begin{array}{l}\text { Maximum Acceleration Output } \\
\text { Torque }{ }^{2} \\
\mathbf{T}_{\text {acc }} \mathbf{r}\end{array}$} & \multirow{4}{*}{$\mathrm{Nm}$ (inlbs) } & 5 & 15 & (133) & 66 & (584) & 102 & (903) \\
\hline & & 10 & 28 & (248) & 96 & (850) & 192 & $(1,700)$ \\
\hline & & $15,20,25,50$ & 36 & (319) & 100 & (885) & 204 & $(1,805)$ \\
\hline & & $30,40,100$ & 30 & (266) & 90 & (797) & 192 & $(1,700)$ \\
\hline \multirow{4}{*}{$\begin{array}{l}\text { Emergency Stop Output Torque }{ }^{\text {a }} \\
T_{\text {em r }}\end{array}$} & \multirow{4}{*}{$\mathrm{Nm}$ (inlbs) } & 5 & 32 & (283) & 120 & $(1,062)$ & 216 & $(1,912)$ \\
\hline & & 10 & 58 & (513) & 192 & $(1,700)$ & 384 & $(3,398)$ \\
\hline & & $15,20,25,50$ & 64 & (566) & 200 & $(1,770)$ & 408 & $(3,611)$ \\
\hline & & $30,40,100$ & 48 & (425) & 160 & $(1,416)$ & 345 & $(3,053)$ \\
\hline \multirow{3}{*}{ Nominal Input Speed $\mathbf{N}_{\text {nom r }}$} & \multirow{3}{*}{ RPM } & 5,10 & \multicolumn{2}{|c|}{3200} & \multicolumn{2}{|c|}{2800} & \multicolumn{2}{|c|}{2400} \\
\hline & & $15,20,25,30,40$ & \multicolumn{2}{|c|}{3700} & \multicolumn{2}{|c|}{3300} & \multicolumn{2}{|c|}{2900} \\
\hline & & 50,100 & \multicolumn{2}{|c|}{4200} & \multicolumn{2}{|c|}{3800} & \multicolumn{2}{|c|}{3400} \\
\hline Maximum Input Speed $N_{\max } \mathbf{r}^{4)}$ & RPM & $5-100$ & \multicolumn{2}{|c|}{6000} & \multicolumn{2}{|c|}{5300} & \multicolumn{2}{|c|}{4500} \\
\hline Maximum Radial Load $\mathrm{Pr}_{\max }{ }^{5,7)}$ & $\mathrm{N}$ (lbs) & & 1550 & (348) & 2800 & $(1,079)$ & 5500 & $(1,236)$ \\
\hline Maximum Axial Load $\mathrm{Pa}_{\max }$ ต) & $\mathrm{N}$ (lbs) & & 2100 & $(475)$ & 3600 & $(810)$ & 6800 & $(1,530)$ \\
\hline Service Life & h & & \multicolumn{6}{|c|}{20,000} \\
\hline \multirow{2}{*}{ Standard Backlash ${ }^{\text {g) }}$} & \multirow{2}{*}{ arc min } & 5 to 10 & \multicolumn{2}{|c|}{$<20$} & \multicolumn{2}{|c|}{$<18$} & & 16 \\
\hline & & 15 to 100 & & & & 8 & & 16 \\
\hline Lum Packlagh \& & man & 5 to 10 & & & & 6 & & 14 \\
\hline Low Dackiasn & arcmin & 15 to 100 & & & & & & 12 \\
\hline Efficiency at Nominal Torque & $\%$ & 5 to 10 & & & & & & 4 \\
\hline Noise Level at 3000 RPM $₫$ & $\mathrm{db}$ & $5-100$ & & & & 88 & & 68 \\
\hline Torsional Stiffness & $\begin{array}{l}\mathrm{Nm} / \mathrm{arcmin} \\
\text { (inlb/arcmin) }\end{array}$ & $5-100$ & 2.5 & (22) & 10 & $(90)$ & 22 & (195) \\
\hline $\begin{array}{l}\text { Maximum Allowable Case } \\
\text { Temperature }\end{array}$ & ${ }^{\circ} \mathrm{C}$ & $5-100$ & & & -20 & ० 90 & & \\
\hline Lubrication & & $5-100$ & & & laintena & nce Sche & ule & \\
\hline Mounting Position & & $5-100$ & & & & yy & & \\
\hline Degree of Protection & & & & & & 65 & & \\
\hline Maximum Weight & kg (lbs) & 5 to 10 & 2.0 & $(4.4)$ & 6.0 & $(13.2)$ & 11.0 & (24.2) \\
\hline
\end{tabular}




\section{ANEXO 2: Redutor planetário com montagem em linha. Catálogo Parker, 2008}

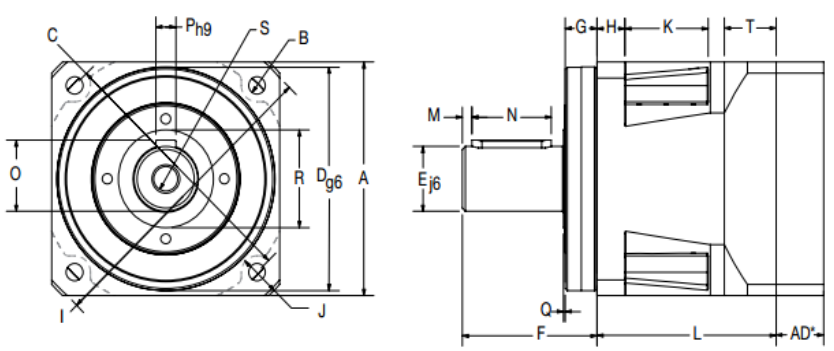

\begin{tabular}{|c|c|c|c|c|c|c|c|c|}
\hline \multirow{4}{*}{$\begin{array}{l}\text { Parameter } \\
\text { Nominal Output Torque }{ }^{1)} \\
T_{\text {nom }} \mathbf{r}\end{array}$} & \multirow{4}{*}{$\begin{array}{c}\text { Units } \\
\mathrm{Nm} \text { (inlbs) }\end{array}$} & \multirow{2}{*}{$\begin{array}{l}\text { Ratio } \\
3,15,30\end{array}$} & \multicolumn{2}{|c|}{ PS60 Gen II } & \multicolumn{2}{|c|}{ PS90 Gen II } & \multicolumn{2}{|c|}{ PS115 Gen II } \\
\hline & & & 27 & (239) & 76 & (673) & 172 & $(1,522)$ \\
\hline & & $4,5,7,20,25,40,50,70$ & 37 & (327) & 110 & (974) & 230 & $(2,036)$ \\
\hline & & 10,100 & 32 & (283) & 93 & (823) & 205 & $(1,814)$ \\
\hline \multirow{3}{*}{$\begin{array}{l}\text { Maximum Acceleration Output } \\
\text { Torque }{ }^{2} \\
\mathrm{~T}_{\text {acc }} \mathrm{r}\end{array}$} & \multirow{3}{*}{$\mathrm{Nm}$ (inlbs) } & $3,15,30$ & 34 & $(300)$ & 105 & (930) & 225 & $(1,990)$ \\
\hline & & $4,5,7,20,25,40,50,70$ & 48 & (425) & 123 & $(1,090)$ & 285 & $(2,525)$ \\
\hline & & 10,100 & 37 & (325) & 112 & (990) & 240 & $(2,125)$ \\
\hline \multirow{3}{*}{$\begin{array}{l}\text { Emergency Stop Output Torque } \\
T_{\text {em }} \text { r }\end{array}$} & \multirow{3}{*}{$\mathrm{Nm}$ (inlbs) } & $3,15,30$ & 80 & (710) & 260 & $(2,300)$ & 600 & $(5,310)$ \\
\hline & & $4,5,7,20,25,40,50,70$ & 70 & (620) & 230 & $(2,035)$ & 500 & $(4,425)$ \\
\hline & & 10,100 & 60 & $(530)$ & 200 & $(1,770)$ & 430 & $(3,805)$ \\
\hline \multirow{6}{*}{ Nominal Input Speed $\mathbf{N}_{\text {nom }} \mathbf{r}$} & \multirow{6}{*}{ RPM } & 3 & \multicolumn{2}{|c|}{3000} & \multicolumn{2}{|c|}{2500} & \multicolumn{2}{|c|}{2000} \\
\hline & & 4,5 & \multicolumn{2}{|c|}{3500} & \multicolumn{2}{|c|}{3000} & \multicolumn{2}{|c|}{2500} \\
\hline & & $7,10,15$ & \multicolumn{2}{|c|}{4000} & \multicolumn{2}{|c|}{3500} & \multicolumn{2}{|c|}{3000} \\
\hline & & $20,25,30$ & \multicolumn{2}{|c|}{4500} & \multicolumn{2}{|c|}{4000} & \multicolumn{2}{|c|}{3500} \\
\hline & & 40,50 & \multicolumn{2}{|c|}{4800} & \multicolumn{2}{|c|}{4400} & \multicolumn{2}{|c|}{3800} \\
\hline & & 70,100 & \multicolumn{2}{|c|}{5200} & & 300 & & 00 \\
\hline Maximum Input Speed $\mathbf{N}_{\max } \mathbf{r}^{4)}$ & RPM & $3-100$ & & & & 00 & & 00 \\
\hline Maximum Radial Load $\left.\mathrm{Pr}_{\max } 5,7\right)$ & $\mathrm{N}$ (lbs) & & 1650 & $(370)$ & 4800 & $(1,080)$ & 7500 & $(1,685)$ \\
\hline Maximum Axial Load $\mathrm{Pa}_{\max }$ & $\mathrm{N}$ (lbs) & & 2100 & (475) & 3600 & $(810)$ & 6800 & $(1,530)$ \\
\hline Service Life & h & & & & & 000 & & \\
\hline & & 3 to 10 & & & & 6 & & \\
\hline Standard Backlash \& & $\operatorname{arc} \min$ & 15 to 100 & & & & 8 & & \\
\hline & & 3 to 10 & & & & 4 & & \\
\hline Low Backiasn us & $\operatorname{arcmin}$ & 15 to 100 & & & & 6 & & 5 \\
\hline Efficiancy at Nominal Torou & $\alpha$ & 3 to 10 & & & & 7 & & \\
\hline Concericy at ivominal torque & $\%$ & 15 to 100 & & & & 4 & & 4 \\
\hline Noise Level at 3000 RPM $\%$ & $\mathrm{db}$ & $3-100$ & & & & 62 & & 55 \\
\hline Torsional Stiffness & $\begin{array}{l}\mathrm{Nm} / \text { arcmin } \\
\text { (inlb/arcmin) }\end{array}$ & $3-100$ & 3 & (27) & 12 & (105) & 27 & $(240)$ \\
\hline $\begin{array}{l}\text { Maximum Allowable Case } \\
\text { Temperature }\end{array}$ & ${ }^{\circ} \mathrm{C}$ & $3-100$ & & & -20 & to 90 & & \\
\hline Lubrication & & $3-100$ & & Per & Mainten & ance Sche & dule & \\
\hline Mounting Position & & $3-100$ & & & & ny & & \\
\hline Direction of Rotation & & $3-100$ & & & Same & as Input & & \\
\hline Degree of Protection & & & & & & 65 & & \\
\hline Maximum Weight & $\mathrm{kg}(\mathrm{lbs})$ & 3 to 10 & 1.3 & (2.9) & 3.0 & (6.6) & 7.0 & (15.4) \\
\hline
\end{tabular}

